\title{
THE FEASIBILITY OF 'BUILDING PERFORMANCE SKETCHING' WITHIN THE BUILDING DESIGN PROCESS
}

\author{
By \\ Elzine Braasch
}

A thesis submitted to the Victoria University of Wellington in fulfilment of the requirements for the degree of Master of Building Science

Victoria University of Wellington 


\section{Preface}

This thesis was submitted in fulfilment of the requirements of the degree for Master of Building Science to the School of Architecture, Victoria University of Wellington.

\section{Author}

Elzine Braasch

School of Architecture

Victoria University of Wellington

Email: elzinebraasch@gmail.com

\section{Supervisor}

Dr. Michael Donn

Associate Professor

School of Architecture

Victoria University of Wellington

Email: michael.donn@vuw.ac.nz 


\section{Abstract}

This study investigated the question of whether or not the distributed model method (DMM) could be perceived by the New Zealand building industry's architects and engineers as overcoming barriers which prevent them from implementing building performance sketching within their design processes.

Current literature on the barriers to building performance simulation (BPS) have suggested a number of recommendations for tool developers to address, with little documented success to their impact on overcoming these perceived barriers. The recommendations suggested mainly improving tool interoperability for effective design team collaboration, and means to demonstrate model quality assurance. The DMM presented itself within literature as a new means to overcome the difficulties of interoperability faced by the central modelling method, commonly used in building information modelling (BIM), to meet requirements for design team collaboration. With the ability to provide high interoperability and parametric capabilities with detailed simulation programs, the DMM was hypothesised to address all recommendations from literature to overcome the barriers to implementing BPS within the design process. Furthermore, the study proposed the use of building performance sketching as an approach to assess the architectural sketch as a means to ensure quality assurance.

The study concluded that DMM cannot currently address all wants and wishes of users established in literature, but has potential. Future research efforts are required to focus upon: creating industry specific templates for building types; developing these templates to be adaptable for the different modelling operators of the proposed workflow demonstrated to the participants within this study; and developing quality assurance standards for modelling and guidelines for model validation. Finally, the study concluded with future work required beyond tool development: improving education of architects; and introducing legislation. 


\section{Confidentiality Statement}

Due to the potential political and human ethical considerations within this study, the author and participants of the study have agreed that all identifiable information is kept confidential.

To maintain confidentiality, pseudonyms are used throughout this paper to replace all identifiable information, such as 'participant', 'company', or 'project'. For the purposes of this study, however, the participants have agreed to be identified by profession i.e. architect, engineer.

See Section 3.3.3. for additional information regarding confidentiality and ethical considerations. 


\section{Acknowledgements}

Firstly, a huge thank you to my supervisor, Dr. Michael Donn, for his continuous support and review of this research project. Mike, thank you for providing your time, especially while being away on sabbatical. Thank you for getting up early in the morning to advise me. I would also like to thank Jamie Sullivan as my 'unofficial supervisor' who put up with all my arguments, stupid comments and pestering for edits (to which I received back several pages nearly covered in red ink)!

I would like to give a warm thank you to Stewart Milne for helping me in setting up my workshops and dealing with all the IT problems which arose from them. Thank you to Kevin Cook for helping me edit and format my audio files for transcription. Also thank you to Selena Shaw for all her administration help in organising the workshop bookings and lunch meals for the participants.

A warm thank you to Ethan Duff in his help as my assistant moderator, recording all the responses of the participants and being there to bounce off ideas and theories.

A special thank you to my friends and family for their support! I would like to take this moment to give a grateful thank you to one close friend and partner, Locky Reid, for keeping me sane throughout this endeavour. I would not have gotten where I have without your warm support and constant positive attitude!

Finally, a huge thank you to all my participants for providing me their time and expertise - without them I would not have been able to complete this thesis. 


\section{List of Acronyms and Abbreviations}

The following are the acronyms and abbreviations used throughout this thesis.

\section{General}

$\begin{array}{ll}\text { BPS } & \text { Building Performance Simulation } \\ \text { PoE } & \text { Post-Occupancy Evaluation } \\ \text { IDP } & \text { Integrated Design Process } \\ \text { DMM } & \text { Distributed Model Method } \\ \text { VPL } & \text { Visual Programming Language } \\ \text { BIM } & \text { Building Information Modelling }\end{array}$

Data Analysis

GTM Grounded Theory Method

$\mathrm{C}_{\mathrm{L}} \mathrm{CA}$ Classical Content Analysis

DCA Directed Content Analysis

MIA Micro-Interlocutor Analysis

FA Framework Analysis 



\section{Table of Contents}

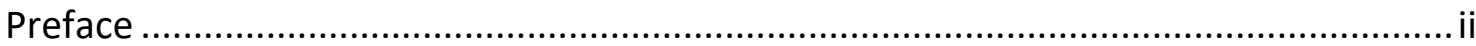

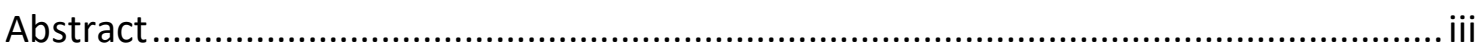

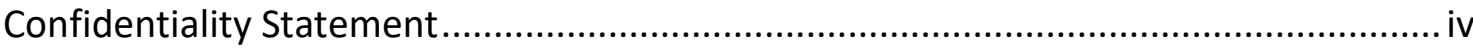

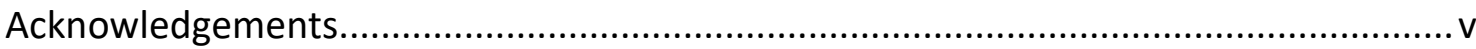

List of Acronyms and Abbreviations .................................................................... vi

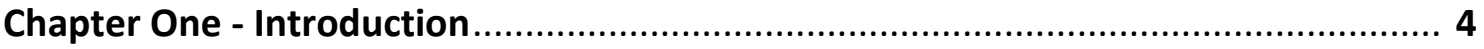

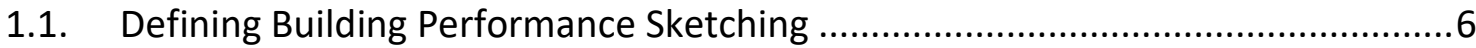

1.2. Research Aim, Question and Objectives....................................................

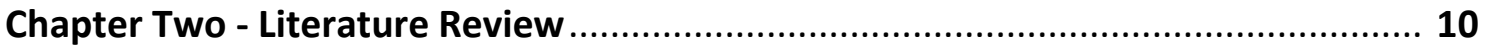

2.1. Building Performance Simulation within the Building Design Process................11

2.1.1. Quality Assurance: known issues in Building Performance Simulation .......12

2.1.1.1. Validation and Transparency of the Tool ...........................................14

2.1.1.2. The Quality of Inputs for Building Performance Simulation .................15

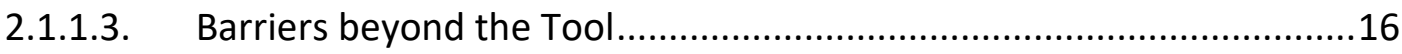

2.1.2. The Wish List for Future Tool Development ...........................................18

2.2. Addressing the Wish List: A Proposal for Future Development ........................20

2.2.1. Addressing Quality Assurance through Building Performance Sketching....21

2.2.2. Modelling Methods and their Use in Industry ........................................23

2.2.2.1. Combined Model Method ..............................................................23

2.2.2.2. Central Model Method.........................................................................24

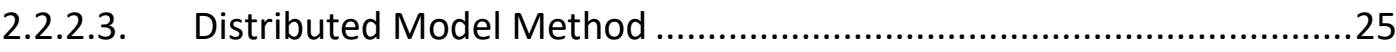

2.2.3. Can the distributed model method (DMM) address all the wishes for future

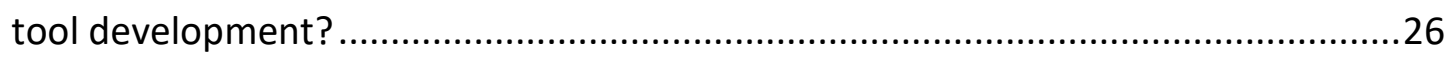

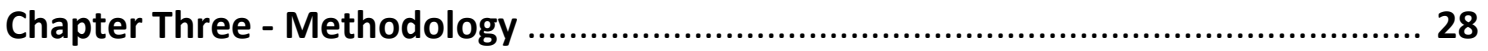

3.1. The Interview Guide: Providing Context.........................................................

3.1.1. Thermal and Daylight Assessment as an example of Building Performance

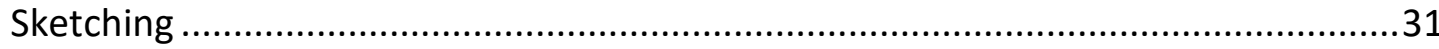

3.1.2. Coupling Tool Selection for demonstrating the 'Building Performance

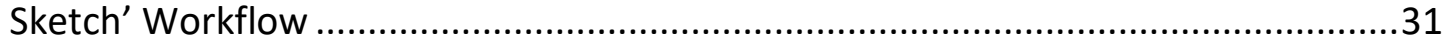

3.1.2.1. Rhinoceros/Grasshopper vs Revit/Dynamo ........................................32 
3.1.2.2. Honeybee and Ladybug: Meeting the Recommendations from Literature 35

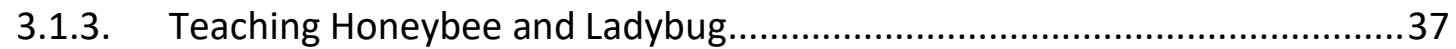

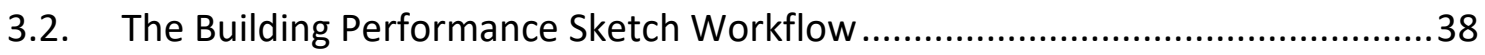

3.2.1. Transferring the Geometry from Rhino to Honeybee ...............................42

3.2.2. Creating the Building Performance Sketch using New Zealand specific Data 44

3.2.3. Simulating the Model using EnergyPlus and DAYSIM ..............................46

3.2.4. Processing Results for Thermal and Daylight Analysis ...............................47

3.2.5. Visualising the Comparison of Results from a Parametric Simulation

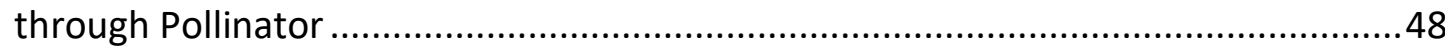

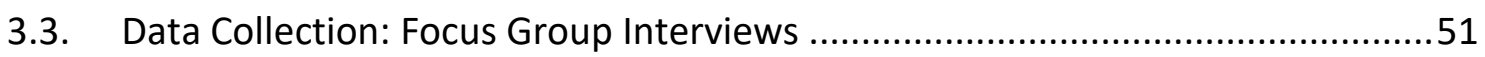

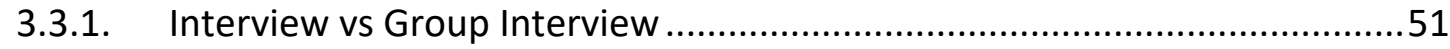

3.3.1.1. Advantages and Disadvantages of Focus Group Interviews .................52

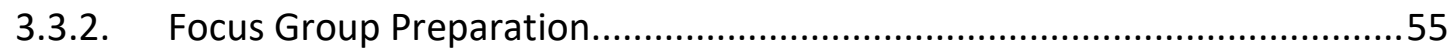

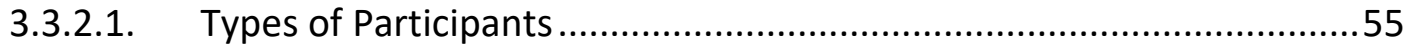

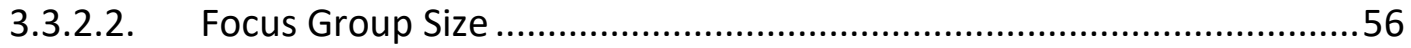

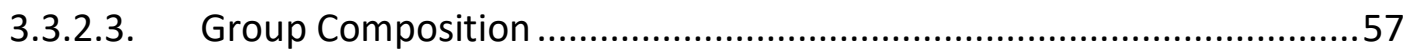

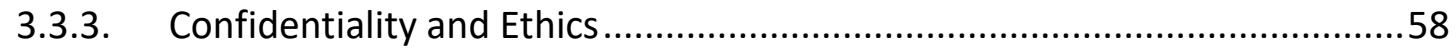

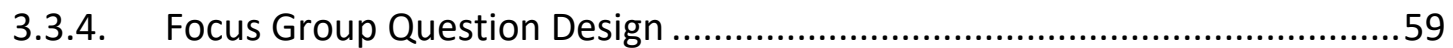

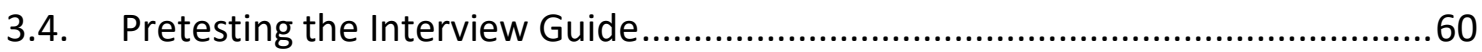

3.4.1. Lessons Learnt from Student Trial.........................................................61

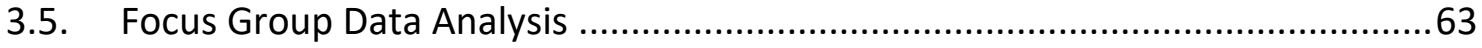

3.5.1. Types of Qualitative Analysis Methods .....................................................63

3.5.2. Directed Content Analysis (DCA) ........................................................... 72

3.5.2.1. Key Limitations of the Analysis ........................................................ 72

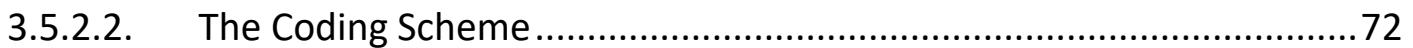

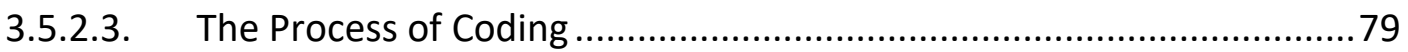

3.5.2.4. Group Observation Recording ….................................................... 84

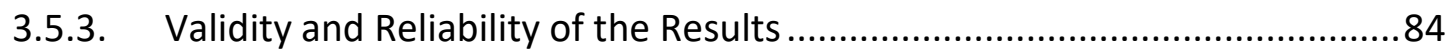

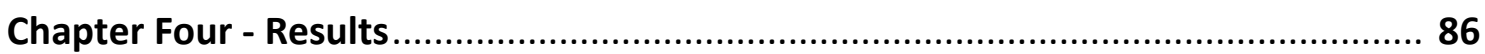

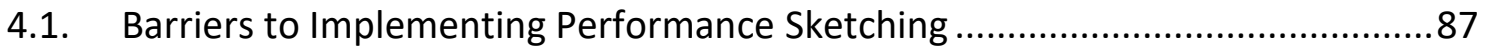




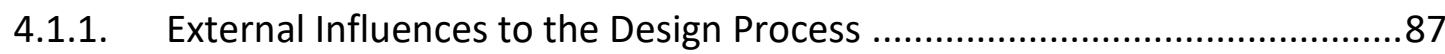

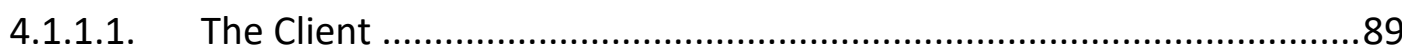

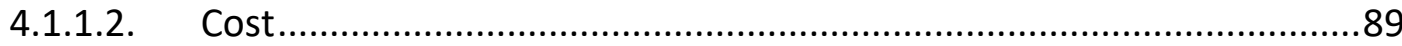

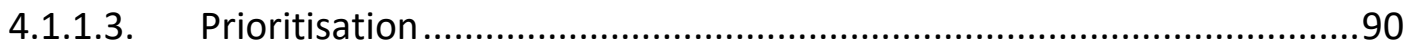

4.1.1.4. Designer Perception on Workload ...................................................91

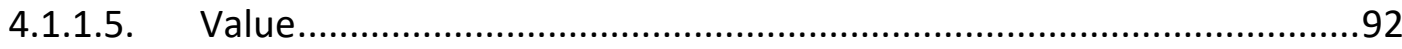

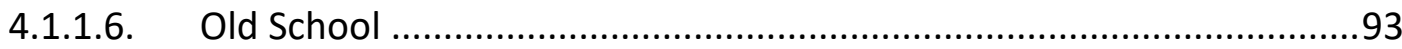

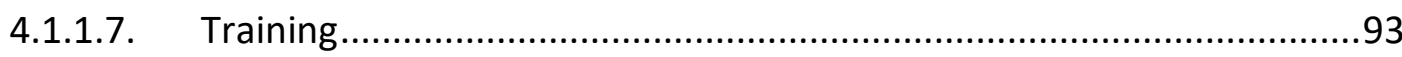

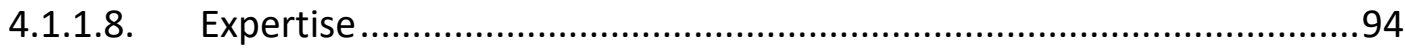

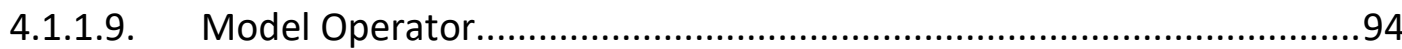

4.1.2. Integrated Building Design Process (IBDP) …..........................................95

4.2. Barriers overcome by the Distributed Model Method .......................................96

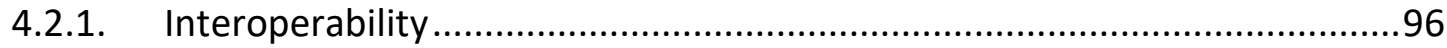

4.2.2. Graphical Representation of output Results ...........................................97

4.2.3. Transparency of Assumptions and Calculations.........................................98

4.3. Recommended Improvements for Future Development ................................98

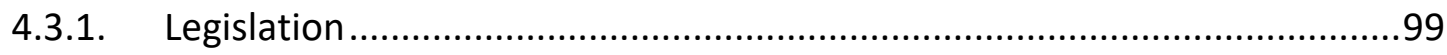

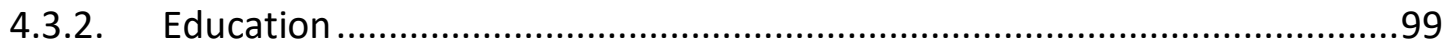

4.3.3. Quality Assurance of Results ..............................................................100

4.3.4. $\quad$ Adaptable Graphical User Interfaces for Different Users .........................101

4.4. Is the use of the Distributed Model Method for Building Performance Sketching

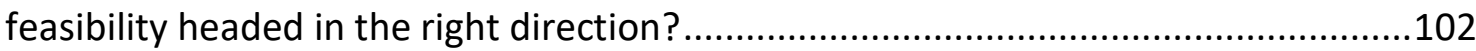

4.5. Summary of Results: Mapping the Categories and their Relationships ............103

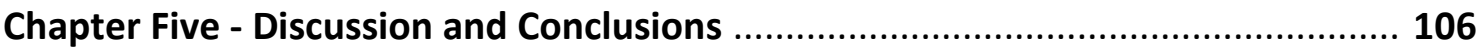

5.1. Discussion: The Distributed Model Method as focus for Future Tool

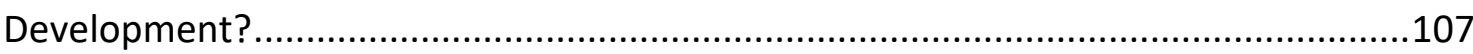

5.1.1. Usability and Information Management (UIM) of interface .....................109

5.1.2. Integration of Intelligent design Knowledge-Base (IIKB) .........................112

5.1.3. Accuracy of tools and Ability to simulate Detailed and Complex building

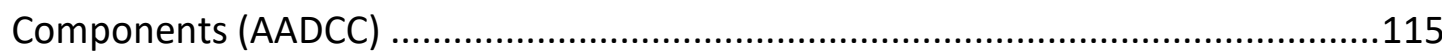

5.1.4. Interoperability of Building Modelling (IBM) …....................................117

5.1.5. Integration with Building Design Process (IBDP) ...................................119 
5.1.6. External Influences on the Design Process

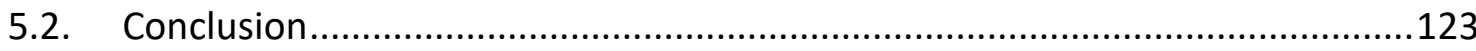

5.2.1. Can the use of the distributed model method address the wants and wishes of users for tool development?

5.2.2. What must be improved in order to make the integration of building performance sketching feasible within the design process? 124

5.2.2.1. Education .125

5.2.2.2. Legislation and Standards .127

5.3. Future Work 127

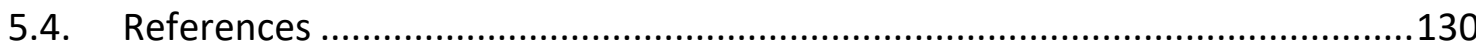

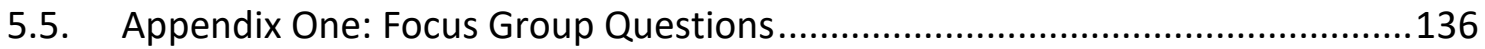

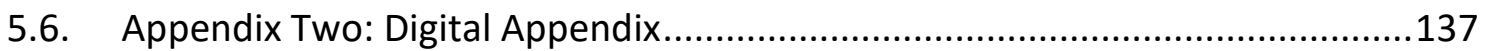




\section{CHAPTER ONE - INTRODUCTION}

Imagine the following scenario: an architect is approached by a client to design a commercial office building. The client asks for a 'sustainable' building, with high energy efficiency and excellent indoor environmental quality. How can the architect as a designer ensure that the building will perform as intended?

Recommendations from literature suggested that the first step should be to ensure the 'architectural sketch', or design concept, will lead to good building performance (Goulding, 1993; Granadeiro, Duarte, Correia, \& Leal, 2013; Hygh, DeCarolis, Hill, \& Ranji Ranjithan, 2012; Jacobs \& Henderson, 2002; Carlos Ernesto Ochoa \& Capeluto, 2008; Pollock, Roderick, McEwan, \& Wheatley, 2009). A building's performance is largely influenced by the design decisions made at the early stages of design. The passive performance of a window size, type and/or orientation for example can have a large impact on the overall heat gains, acoustics and quality of light of the indoor environment. Thereby, the thermal, acoustic, daylight and energy performance of the building in operation can be affected by the design of the windows, or any changes made to them in subsequent design stages. 
In the early stages of design, the architect is faced with three options to inform design decisions: a) copy features of high performance building precedents; b) use rules of thumb established in literature; or c) use detailed building performance simulation (BPS) tools to create a building physics model of the concept design to predict the performance of the building in operation. The first two options are prescriptive design measures, therefore cannot provide quantifiable answers to design questions. Furthermore, these options can often be misleading, unreliable or difficult to apply to complex concepts (Jacobs \& Henderson, 2002). Rules of thumb as pre-processed information inevitably represent a limited and constrained subset of the infinite variety of potential designs (Donn, Selkowitz, \& Bordass, 2012). Where the assumptions and limitations of the calculation of these rules of thumb do not align, the architect cannot use them to inform their decisions.

Option $\mathrm{C}$ is contended to be the most reliable means of informing design decisions (Goulding, 1993; Granadeiro et al., 2013; Hygh et al., 2012; Jacobs \& Henderson, 2002; Carlos Ernesto Ochoa \& Capeluto, 2008; Pollock et al., 2009). Building performance simulation (BPS) enables the comparison of a broad range of design variants to understand the usability of a design, and the interactions between design parameters and the occupant comfort. The process of BPS analysis provides the design team a better understanding of the consequences of design decisions, thereby leading to more optimal designs (Augenbroe, 2002). However, in our scenario, the use of BPS tools to ensure the design will perform as intended has a number of challenges which discourage its use.

Architects and designers have difficulty in using even the most basic BPS tools (Punjabi \& Miranda, 2005). Attia et al. (2009) suggested that this gap between the architect and the BPS tool exists when tool developers do not comprehend architects' problems in interacting with these tools. The target audience, or user, of the BPS tool is commonly the engineer. This presents a challenge to the architect because they have a different background; different knowledge processing methods and they are visually orientated (Attia et al., 2009). Furthermore, BPS tools are often seen by many architects as complex and cumbersome (Tianzhen, Jinqian, \& Yi, 1997). Previous efforts in developing tools targeted at architects included features to simplify the interface or design assessment to single parameters. These examples are presented currently in such tools as COMFEN (assessing the performance of one zone and one building façade)(Selkowitz, 2014) and DIVA (assessing the performance of one zone)(Jakubiec \& Reinhart, 2011). Such tools often simplify BPS to one parameter - typically energy use with no possible understanding of trade-offs between design parameters and the whole building's occupant comfort performance.

The concern in the simplification of BPS and building physics models for simulation during the early design stages is accuracy (Picco, Lollini, \& Marengo, 2014). Many existing BPS tools such as EnergyPlus (EnergyPlus, 2016a) and DOE-2 are quite 
effective at simulating final building designs and promise a high level of accuracy. However, these tools require detailed information about design parameters which are often sparse and uncertain during the early stages of design. Where input data is unknown, default values are used instead. The creation of detailed models with tools which provide high accuracy also takes time to be accurate. This is in contrast with the necessity to minimize the time taken to analyse the results of a concept to avoid discouraging rapid concept development (Picco et al., 2014).

Over the past three decades, tool development focused on the architect has not been successful in encouraging the use of building performance simulation (BPS) in the design process. BPS modelling software is simply too technical, complicated and cannot be considered 'architect-friendly' due to the differences in language, modelling processes and visualisation of results (Attia et al., 2009). Hence, BPS does not lend itself well to the casual user, but rather requires the input of an expert who can ensure reliable and robust performance predictions.

Thus, the proposed answer for the architect in our scenario is to look for an approach to 'sketching' the performance of their design concepts with the aid of the expert engineer in a partnership, using detailed BPS tools to provide high levels of accuracy, in a quick and easy manner.

\subsection{Defining Building Performance Sketching}

We propose this approach to be early design stage performance modelling called 'building performance sketching'. The 'Building Performance Sketch' is described by Donn et al (2012) as a building performance analogy for the architectural sketch. The architectural sketch roughly outlines key design features which distinguish the potential end product, but does not solidify any design ideas. Thus, the architect is able to choose between possible paths of development. The key principle of the performance sketch is thus mirrored in that by roughly modelling the basic design concept with minimal, but most influential, levels of detail, the likely performance of the concept can be simulated and evaluated in a quick and easy manner using detailed BPS tools.

The key idea with performance sketching is the identification of the 'most influential' levels of detail for the concept sketch. Each design is unique, in that rules of thumb or precedents cannot provide a full picture to indicate which design parameters must be modelled with detail. However, literature can tell us that the likely performance is dramatically affected by a number of common critical details that are often undetermined during the early stages of design (e.g. occupant behaviour). Too often, Post-Occupancy Evaluation (PoE) studies tell us that designs lack the consideration of the occupant, and their behaviours within the design space (Donn et al., 2012). 
Consequently, we want to avoid considering the behaviour to the point where fine tuning the building will result in a reality where only an automaton can successfully use it.

Thus, accuracy becomes a high priority in performance sketching. Unlike the architectural sketch, the performance sketch cannot leave precise details of elements such as windows or shading for later stages. In the absence of confirmed design parameters, unknown parameters in a performance sketch are defaulted to a range of low, typical or high scenarios using real-world building data. Building performance sketching uses this data in sensitivity analysis to analyse the cloud of design potential that a concept could be developed into. For example, the performance sketch of a design with blinds would include a process of varying blind usage within 'reasonable' ranges (e.g. real-world low, typical or high usage known for that building type) with the purpose of testing the robustness of the simulated outcomes under variations that might reasonably be expected in practice (Donn et al., 2012). This approach does not require the burden of creating a detailed representation of the building, but rather looks to develop ways of modelling the richness of the human experience of interaction with buildings through the use of detailed accurate performance simulation tools in conjunction with building 'sketches'.

For building performance sketching as an approach to early design stage performance assessment to be plausible, users must have access to real-world building data. Furthermore, for this process to be feasible, the same barriers against building performance simulation integration in the design process must be overcome. In literature, several studies exist which outline these barriers faced within developed countries and their building industries. These barriers are described in Chapter Two of this thesis as a response to the question: What can current literature tell us about why BPS is not common practice in early design processes? The studies outlined in literature used user feedback from surveys to determine the barriers present in industry, and established user requirements as recommendations to tool developers. Negendahl (2015) proposed the theory that the answer to the problems faced in industry, and a means to address all recommendations, is by considering the integrated design process (IDP) approach by the application of the distributed model method (DMM).

The integrated design process (IDP) approach has been well established to be essential in designing high performance buildings (Cory, 2016; Klitgaard, Kirkegaard, \& Mullins, 2006; Negendahl, 2015). However, no evidence has been given to date on whether or not the DMM can address all recommendations for tool development and overcome the barriers against BPS, thereby making building performance sketching within design feasible. 


\subsection{Research Aim, Question and Objectives}

The thesis aimed to understand how building performance sketching can become feasible within the design process by the use of the DMM, and if not, why not, and what must be improved to make it plausible. Thus the research questions of the thesis were:

- Can the use of the distributed model method (DMM) address the wants and wishes of users for tool development?

- What must be improved in order to make the integration of building performance sketching feasible within the design process?

To answer these questions, the study firstly had to determine what challenges to the implementation of building performance simulation, and by extension building performance sketching, currently exist in literature. The study then had to identify any known theories to how these barriers may be overcome. The literature concluded that the study required a methodology to gain in-depth responses from architects and engineers within the industry regarding existing barriers to building performance sketch integration using a new emerging method (DMM). To understand why the method could not overcome the barriers, and what must be done for it to do so, a range of responses as feedback for improvements to overcome the established barriers was necessary. However, gaining feedback from industry on the use of the DMM where no example exists is a near-impossible research task.

Thus, the thesis approach was to create a template building performance sketch workflow within an example tool which used the DMM. This workflow was demonstrated to groups of architects and engineers in a workshop format after they were given a three-hour tutorial on the use of the tool using the DMM. The participants were then questioned using focus group interviews to gain feedback to guide future development. 


\section{CHAPTER TWO - LITERATURE REVIEW}

In considering the scenario of the architect approached by the client to design a 'sustainable', high energy efficient commercial office building in Chapter One, we established the importance of building performance simulation (BPS) as an integral part of the design process. To ensure accuracy of such a 'complicated and cumbersome' process, we introduced the need for the expert engineer as the consultant. The chapter proposed that the answer to the question, 'How can the architect as a designer ensure the design will perform as intended', required two prerequisite research questions to be answered first. In relation to the scenario, these are rephrased here to: 'Why can the architect not currently ensure the design will perform as intended' and 'What must be improved for the architect and engineer to do so in the future?'

This chapter develops the story of the scenario further by describing in detail the problems faced by the architect and engineer as known barriers within literature against building performance simulation (BPS). Barriers particularly surrounding quality assurance of results and design team communication present themselves as the greatest known challenges. To overcome these barriers, current literature used user studies to summarise a 'wish list' of recommendations for tool developers, and 
are outlined within this chapter to later form the basis of the data analysis technique used in this thesis.

The clear underlining theme from literature, however, is the suggested partnership between the architect and engineer during the early stages of design through the integrated design process (IDP) approach. With a 'wish list' established, the chapter describes the need to consider another question: 'Who is the user?' With both the architect and engineer present, we have two 'users' who operate a model differently. The architect would produce a design in a computer aided design (CAD) tool, and the engineer would need to assess the design by creating a building performance sketch of the design in a BPS tool. This recreation of a design model within another program by the engineer, and the communication and collaboration of the team, can be very time consuming. The early stages of design already have time constraints, and the architect is often under significant pressure to produce concepts very quickly. Constantly needing to wait for the engineer to produce the model, simulate and analyse the results will deter rapid concept development.

Hence, the chapter finishes with the theory from literature that a modelling method with high interoperability would address all the known challenges posed to the architect and engineer. Where the combined model method is very limited in its application across the team and the central model method has known issues in coupling with BPS tools, the chapter concludes with the only real option of the distributed model method (DMM) at the time of writing this thesis.

\subsection{Building Performance Simulation within the Building Design Process}

From the RIBA (Royal Institute of British Architects) Design Plan of Work, Mortbitzer (2003) specified three design stages where building performance simulation (BPS) would play an important role in the design's evolution, namely: Outline Design Stage; Scheme Design Stage; and Detailed Design Stage. In other words, BPS has been found to be an integral part to the whole building design process. However, despite wide acknowledgement from the research community of the importance of BPS during early stages of design, the use of BPS during the early stages of the design process is not common within current practice. The use of BPS is mainly restricted to the end of the design process to verify the design and show building code compliance in construction documentation (Hygh et al., 2012).

So if it is done at the end of the design process, why not the beginning? To understand this, we outline here what is necessary to assess the conceptual design's performance through simulation. 
Building performance simulation (BPS) relies upon an accurate digital model abstraction of the building design, created within a BPS tool often limited to the assessment of one environmental quality (i.e. EnergyPlus can assess thermal and energy performance, with limited daylighting assessment and no acoustic assessment). Unlike the architectural sketch mentioned within Chapter One, the abstracted, 'simplified' model for early design assessment cannot leave certain design parameters to be input later. A thermal simulation for example cannot provide an accurate prediction of indoor air temperatures if the model does not have windows or wall construction thermal properties 'input' within the model. Therefore, with these design parameters often unknown during the early stages of design, the inputs have a degree of uncertainty.

The model is also 'simplified' to only include the necessary design parameter inputs, leaving every other input as default. These unknown inputs which are defaulted for simulation are often based upon assumptions made either from: previous experience; values from existing building case studies relevant to the building type; or values established by modelling guidelines such as CIBSE (CIBSE, 2013). In early design stage BPS tools, tool developers create their own default inputs which they as simulation experts believe the designers should not change. Thus, a simplified model is assumed to be quick and easy to create and simulate as there are very few parameters of the model which need changing to test different designs.

However, the danger in using simplified models and tools specifically built for early stages of design, and thus the main reason for the lack of implementation, is the accuracy and transparency of these defaulted assumptions (Cerezo, Dogan, \& Reinhart, 2014; Hygh et al., 2012). The use of inaccurate inputs for design can produce a problem in quality assuring the results of a performance prediction. Thus, a significant barrier to the implementation of BPS in the design process is a matter of quality assurance.

\subsubsection{Quality Assurance: known issues in Building Performance Simulation}

The view from the design community that BPS can produce unreliable results stemed from findings demonstrating clear discrepancies between the energy performances predicted during the design process and the actual measured performance of the operated building. Evidence had been given that suggest operational energy use in buildings due to occupancy variability were higher than expected during the design stage (Bordass, Cohen, \& Field, 2004; Bordass, Leaman, \& Ruyssevelt, 2001; Gill, Tierney, Pegg, \& Allan, 2010; Menezes, 2013; Pegg, 2007). Other reasons for the reluctance of designers was briefly discussed by Rezaee et al. (2015) and noted that the disinterest in the use of performance-based tools came from several known issues revolving BPS modelling, namely: the challenge of simplifying complex building design 
concepts; the large number of undecided parameters for simulation; and the unreliable performance prediction related to other uncertainties. These issues are the main contribution to what is often observed as 'the performance gap'.

The 'performance gap' was evaluated by the PROBE (Post-occupancy Review of Buildings and their Engineering) studies in which 23 buildings were investigated between 1997 and 2002 within the UK. The study aimed to encourage the idea of feedback to non-residential building design and expose the current shortcomings in the UK building industry, permitting professionals to realise the issues within the systems and designs used (Cohen, Bordass, Standeve, \& Leaman, 1999). The study recognised that the measured energy consumption of the evaluated buildings was typically higher than predicted in the preliminary design stage. These discrepancies between calculated and measured energy is what is defined as the 'performance gap' or 'credibility gap' (Bordass et al., 2004). Over the past 20 years a number of studies have identified and provided explanations for a significant 'performance gap' between designed and actual energy performance of buildings which all support the findings from Bordass et al (Arup, 2013; Gann, Salter, \& Whyte, 2003; Newsham, Mancini, \& Birt, 2009; Norford, Socolow, Hsieh, \& Spadaro, 1994). To understand these discrepancies, we must first understand how BPS can be unreliable.

Performance modelling is limited to the assumptions which are based upon previous experience in existing building case studies or values established by modelling guidelines such as CIBSE (CIBSE, 2013). No single program can absolutely predict the performance of a building when it is in operation due to the limitations of the modeller's knowledge to future circumstances and the variability of occupant behaviour. For example, any simulation program, EnergyPlus, IES-VE or any other energy modelling software, requires the input of occupancy scheduling ${ }^{1}$. In these schedules, the modeller is able to create scenarios based upon 'typical' working hours - when the building would be occupied and for how long. However, occupancy behaviour is impossible to predict for all the years of the building's occupation. Therefore, simulation modelling is commonly modelled based on a 'typical' year of occupation, with no consideration to how the building occupation may change during its lifetime of use.

The building design reality is thus 'simplified' and caricaturised to create a building physics model based on assumptions of the user, or predetermined assumptions within the tool. The accuracy of such a model is therefore reliant on the user using accurate assumptions, and/or understanding the limitations of the predetermined assumptions within the tool.

${ }^{1}$ Patterns of use is hereby referred to as scheduling commonly used within modelling 
This outlined two main issues surrounding quality assurance and the use of BPS tools: the validation of the BPS tool calculations and their transparency of in-built assumptions made default; and the quality of the inputs applicable for the specific design.

\subsubsection{Validation and Transparency of the Tool}

The quality assurance of simulation tools are becoming less of an issue due to stringent quality assurance procedures by standards including CIBSE TM33 and ANSI/ASHRAE 140-2007 which implement frameworks for assessing the validity of commercial software calculation tools (ASHRAE, 2007; CIBSE, 2006).

However, these standards do not outline a process of communicating the default, inbuilt assumptions of the tools used within industry. The problem for the designer as the user of such tools is that they regard the tool as a 'black box', thereby relying and trusting upon the assumptions made by the developers (Augenbroe, 2002). The danger here is that the designer may not be aware of the applicability limitations of these in-built assumptions, and may lead to an incorrect abstraction of their design. In their ignorance, the user may simulate a building concept to have an acceptable level of performance using a tool which has hidden assumptions and find that the building in operations' performance is significantly different to what was predicted. In many cases, this is from the result of using a tool specifically built for a different building industry. Example of this exists in tools such as COMFEN (Selkowitz, 2014), which uses USA climates for its simulation, and Sefaira (Sefaira, 2016), which uses constructions and occupancy patterns specific to USA.

Morbitzer (2003) described the ideal generation of BPS tools to have complete transparency surrounding in-built assumptions, they should undertake multi-variant analysis and these tools must be "easy to use and interpret" to accommodate for the architect as the user. The study found that the main restrictions to the current generation of BPS tools were issues surrounding designer knowledge to quality assurance. The study found that the simplifications of the inputs within the tool may lead a non-simulation expert to create an inaccurate model without entirely being aware of it. As such, the issue surrounding quality assurance was found to be a large concern of the designers, stating that many believed the responsibility for the accuracy of the performance predictions obtained from a simulation exercise should remain with the building services engineer as the expert. These findings were supported by Donn (2009), stating that most architects surveyed lacked the confidence to rely on inhouse use of simulation tools.

Hence, basing design decisions on the results of a tool which may be using unknown assumptions in calculating performance can be very risky for the inexperienced user. However, recent studies have highlighted that even the use of experts for BPS model creation and simulation can still lead to inaccuracies in results. These inaccuracies are 
mainly credited to the assumptions made by the users, rather than the ignorance of hidden assumptions.

\subsubsection{The Quality of Inputs for Building Performance Simulation}

The quality assurance of assumptions is difficult to control. The study undertaken by Bordass et al. (2001) found that energy modellers consistently make inaccurate assumptions regarding internal heat gains, plant and control performance, and occupant and management behaviour. This was often the result of poor understanding of how the occupants may use the space when the building was built, poor design team communication and/or the reliance on minimum inputs set as standard by modelling guidelines.

De Menezes (2013) observed that the over-simplification of inputs for simulation can result in large differences in performance, and that the reliance on standards which prescribe default inputs cannot ensure accuracy. In their study, they compared the energy result of modelling as per the standard, 'CIBSE'S TM 54: 2013 guideline to modelling' to the real building in operation. In their guideline, CIBSE (2013) state that the differences between the case study building monitored energy and the predicted energy usage from following the methods stated by the Building Regulations Approved Document L2A are twofold. Firstly, the document suggested the use of standard inputs for variables such as hours of operation. Secondly, it excluded energy uses such as small power, external lighting, lifts etc. These points are illustrated in comparing the Part $L$ model and the actual performance within Figure 1, where the lack of lifts, servers, equipment and miscellaneous items causes the large difference in annual consumption.

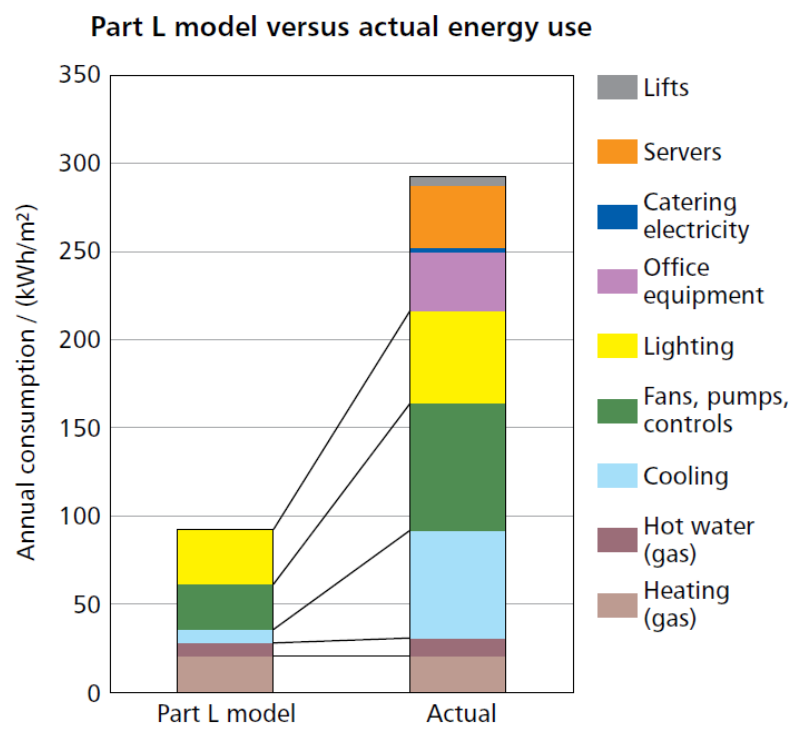

FiguRE 1 COMPARISON OF ADL2A CALCULATIONS AND OPERATIONAL PERFORMANCE FOR A CASE STUDY. SOURCE: (CIBSE, 2013) 
However, not using modelling standards, but rather previous experiences, can also result in inaccuracies in modelling input assumptions. The differences in assumptions made in modelling between users can be substantial, as evidence given by Berkeley et al (2014). In their study, 12 professional energy modellers were given identical information of the same non-residential building - an unspecified school located within San Jose, CA. Results found that participant decisions surrounding equipment power usage and HVAC energy usage made the largest differences, where a $-11 \%$ to $+104 \%$ variation in simulation results from a baseline model was observed. Berkeley et al (2014) indicated that the main reasons for the differences in internal loading resulted from: the need to alter the information in order to input within the energy modelling program, eQUEST; and their own experience on what the 'typical' and most reasonable loads would be for lighting, equipment and occupancy. Furthermore, the differences in fuel usage (electricity and gas) resulted from the participants' decision to use gas water heaters rather than electric heaters. This study emphasised the concern in regards to uncertainties within a project, as all 12 participants were professional experts in energy modelling and all used 'reasonable' values for all inputs used.

Thus the way in which the user uses such a tool of complexity can in turn affect the quality of the results of the concept. Therefore, the user of the tool must be experienced in simulation to identify if the results do not make sense given the specific building case. Users who blindly trust the program, such as the inexperienced architect, can be blind-sighted by the end product performance due to hidden assumptions. Thus, the engineer must be consulted by the architect to ensure their design will perform as intended. However, their engagement early in the design process presents itself as another barrier, which falls beyond that of the tool.

\subsubsection{Barriers beyond the Tool}

In practice, the implementation of the use of BPS tools within the design process has been strained by the process of design within an industry. It is here that we finally touch upon the problem we have for our given scenario. The architect by themselves cannot ensure their design can perform as intended, as they lack the experience and time to identify issues in quality assurance of their results, or creating accurate models. To quality assure a model, the architect as the designer would need to spend time understanding the processes, and ensuring all in-built assumptions are addressed. Pilgrim et al (2003) found that designers often face the challenge presented by the client and stated that designers believed their greatest barriers to be time and cost constraints which prevented them from spending too much time on quality assuring their models. Donn (2009) elaborated the problem by reporting that designers did not feel like they could request for more time to do BPS, as they stated the client already expected the service of them. 
Any added step to the design process was reported by Jacobs \& Henderson (2002) to be viewed by designers with scepticism and generally did not want to delay the design process to wait for performance feedback on a variety of different design iterations due to time constraints and allocated professional costs. Donn (2001) reported that architects recognised that testing design ideas took much longer than it should due to lack of experience, with anything adding to the conceptual design stage being viewed as an 'obstacle'. Tools can aid in these issues by providing speed and efficiency, but cannot remove the annoyance of extra workload.

Furthermore, in discussing the market barriers and institutional barriers in 2002 for the adoption of energy-efficient building design in their study, Jacob \& Henderson (2002) noted the barriers of performance uncertainty along with the financial concerns related to the design community perception of unreliability. These financial concerns included the added costs of gathering information on new energy-efficient products and services or hidden costs such as maintenance and operational costs of the product. Here, the community must be shown the value of BPS before they are prepared to invest in its processes.

However, provided that the client does allocate enough time and cost for consultant fees, the main barrier beyond the tool against the integration of BPS is design team coordination.

The issue which arises from working together as a team to produce a high performance building is the need for an integrated model which can accommodate a spectrum of targets and end objectives as users have different approaches in operating their models. In addressing the user's requirements, Attia et al (2012) surveyed a number of architects and engineers. The study found that architects in general were more concerned with architectural design issues such as passive design techniques for shading, orientation, natural ventilation and geometry over HVAC systems and occupant controls. Whereas the engineer ranked comfort, glazing openings, HVAC systems and insulation respectively at the top.

With these varying priorities, the users must find a means to communicate their varying approaches to modelling (Negendahl, 2015). The architect argues that the holistic expression must remain with the architect to protect the architectural values of the building. The other approach is argued by the engineer where building energy codes and demands on indoor climate command a stronger position in the earliest phase of the design. This argument is supported by the notion that the passive techniques implemented at early design are crucial factors of the building performance. Despite this argument, the architect commonly recognises the importance of including a specialist in the early design stage to achieve a valid ground of informed design - "Input quality affects accuracy while output needs careful expert interpretation" (Carlos E. Ochoa, Aries, \& Hensen, 2012). 
The best collaborative relationship to producing excellent building performance is considered to be the engineer and architect working together as a formal team within Integrated Design Process (IDP) approach (Klitgaard et al., 2006; Negendahl, 2015). The leading quality of this approach is its need for defining a framework to negotiate criteria and end goals which allow effective communication between the participants. Thus complex design problems can be addressed collaboratively and efficiently. Furthermore, the method defines a design team of composed users, where users refers to all project participants who have a relevant influence on the content and course of project design and realization (Negendahl, 2015). However, this approach requires a means for the different users to efficiently work together in modelling, thereby requiring the use of tools which have high interoperability.

To summarise: the barriers known by literature against the implementation of BPS in the design process are issues in quality assurance, external influences which effect time and cost allocation to do BPS assessment, and model integration to promote a IDP approach to design. The architect as a designer cannot ensure their design will perform as intended due to lack of experience in recognising where simplified models can be inaccurate, or which inputs for modelling must be treated with care. The engineer as a consultant can provide this level of expertise to the designer to ensure their design will perform as intended, but the challenges of design parameter uncertainties and design team collaboration during a stage of design which demands rapid concept development must be overcome.

\subsubsection{The Wish List for Future Tool Development}

The response of the research community to the growing concerns of integrated design processes and quality assurance of BPS had exploded into a number of studies which recommended tool features necessary for future tool adoption (Attia et al., 2012; Pilgrim et al., 2003; Donn et al., 2012; Augenbroe, 2002).

Studies such as (Asadi, Amiri, \& Mottahedi, 2014; Hygh et al., 2012) had attempted to address the issues in quality assurance by creating rules of thumb based on simulation in the form of regression models to inform design decisions, rather than focusing upon program creation. The greatest limitation in these studies have often been their limited application to any design concept, following the same issues of most rules of thumb. Though it can provide the designer an indication, it cannot allow the team to compare design concepts nor allow the assessment of other criteria. However, the information of such an analysis can be very valuable in addressing uncertainties. Current attempts are underway to implement such an analysis within building performance sketching to enable the creation of a regression model for each concept design, as a means of sensitivity and uncertainty analysis. 
Other studies which attempt to address problems with the tool users have focused upon user interfaces and integrating intelligent design knowledge-base such as template creation. The most recent tools which have emerged are tools such as OpenStudio (OpenStudio, 2016).

In spite of tremendous progress over the years of tool development, however, some wishes for tool development documented in current literature have remained unfulfilled. Attia et al (2012) summarised these recommendations and 'wishes' of previous studies into five categories, created by surveying the users of the tools, architects and engineers, presented as criteria for tool selection:

1. Usability and Information Management (UIM) of interface: This criterion incorporates usability of the interface features including representation of data, navigation, error diagnostics, and use of templates. The information management feature of the criteria includes input quality control, performance benchmarking, data storage, transparency of in-built assumptions and user customisation. Users specifically ask for interfaces which can accommodate for lack of experience and can include a means of checking whether or not the results from simulation can be trustworthy through comparing against industry benchmarks. Recommendations include:

a. The ability to provide transparent default options

b. The ability for users to be aware of in-built assumptions

c. Features which enable adaptive graphical user interfaces (GUIs) to provide a balance between extensive and basic data input in relation to the user type and expertise

2. Integration of Intelligent design Knowledge-Base (IIKB): Also known as design decision support and design optimisation. Integrating a Knowledge Base includes building templates, design guidelines, and procedural methods. Furthermore, intelligent BPS tools can perform parametric analysis, compare concepts and enable the ability to conduct sensitivity studies. Users specifically ask for templates and modules which they can use for concepts of certain building types. Recommendations include:

a. Features for benchmarking and results comparison

b. The ability to store and/or create and share user libraries for contextual material properties, occupant behaviour patterns and climatic design characteristics

c. The ability to inform different users at different stages of design to optimise and identify optimum building design strategies

\section{Accuracy of tools and Ability to simulate Detailed and Complex building} Components (AADCC): This criterion classifies those aspects regarding validity and quality of simulation models and their resolution. Additionally, this criterion deals with the ability to simulate building components with high model resolution. Recommendations include:

a. Features which indicate the degree of error that should be tolerated in the results to inform an uneducated user 
b. Features which enable the description of the uncertainty of the model, algorithms used and their limitations

c. The ability to conduct sensitivity and uncertainty tests and represent the data in a format all users can understand

4. Interoperability of Building Modelling (IBM): This criterion deals with the ability to manage and communicate building data and design analysis results between the design team members. It is a direct requirement hypothesised to address issues with translating information from a design tool to a BPS tool to speed up the process of concept design assessment. Recommendations include:

a. One common language to become an open standard and full IFC (BIM) compliance.

b. The ability to use the same model for all applicable programs, without the need for remodelling, or facing difficulties in lost information

5. Integration with Building Design Process (IBDP): This criterion deals with the adaptability of tools which enable the tool to be 'design process centric', to be used for various purposes, by different users and at different design stages. Recommendations include:

a. The ability of the tool to be used during the design, commissioning and occupancy phases by different users

b. The ability to create simplified and detailed models within the same program

c. The ability for different user interfaces to communicate to different users using their familiar language

The authors concluded that the next generation of BPS tools should direct their development within the five listed categories. Thus, the recommendations made above, and the findings from Attia et al (2012) were briefly summarised for quick referral. These categories were used later within this paper to formulate the coding scheme for data analysis, and their application is discussed in more detail in Section 3.4.2.2.

\subsection{Addressing the Wish List: A Proposal for Future Development}

During the early stages of design, the key issue is that inputs for simulation are often unknown and therefore simplified to defaults. Where tools do not make these default assumptions clear, the user is unaware of the restrictions to which they can apply the tool. Furthermore, relying upon 'typical' or 'reasonable' inputs alone for simulation during the early stages of design for uncertain design parameters is not enough. These can cause unreliable and inaccurate results. These findings suggest that an approach to modelling should be taken which focuses upon testing a range of scenarios of 
inputs, rather than only using one, as a means for the simulation expert to address issues in parameter uncertainties.

What this thesis tested was the proposal that the barrier of quality assurance of simplified models can be overcome by the use of building performance sketching processes described earlier in Chapter One. Rather than relying upon a value from previous experience for simulation inputs, the user must use real-world data and conduct sensitivity and uncertainty analyses to test the cloud of design potential that a concept could be developed into. Furthermore, tools should not be simplified to have hidden default inputs, but rather provide full control to the user to enable the capability of testing this potential.

This approach therefore has one significant flaw - the need for the simulation expert in the early stages of design. To address all recommendations from literature summarised in the 'wish list', a modelling approach which can complement the integrated design process (IDP) approach is necessary. The architect and engineer in a partnership require a means to communicate efficiently and transfer information quickly, in order to not obstruct rapid concept development. This calls for the need to examine modelling methods known in literature which can provide high interoperability for this approach to work, specifically: combined model method; central model method; and distributed model method (DMM).

\subsubsection{Addressing Quality Assurance through Building Performance Sketching}

As a response to the numerous studies over the years regarding issues in quality assurance, the development community indicate the need for tools to address the challenges concerning quality of models, uncertainties in design parameters, and result validation (Augenbroe, 1992; Donn, 1997, 2001, 2009). With numerous unknown design parameters present throughout the stages of the design process, designers and engineers alike were found to also acknowledge the need to have credible default values for unknown inputs in simulation (Jacobs \& Henderson, 2015). These inputs had to be applicable to the project, a feature which was often lacking in past tool libraries.

These recommendations for future development were previously stated by Augnebroe (2002), with emphasis on "rapid evaluation of alternative designers by tools that facilitate quick, accurate and complete analysis of candidate designs". An additional feature was recommended which explicitly checks embedded 'application validity' rules in order to inform the user that their application is being used outside of the validity range. When implemented into tool developed to address these issues, they have been reported to be met with a level of resistance by the architect as a user. This resistance has been explained by user studies such as (Donn, 2001) where it was 
commented that often the inclusion of such features are not well understood by the user with little understanding of quality assurance processes. Donn (2009) thus suggested the need to educate the user in the form of error reporting, benchmarking, and incorporating quality assurance processes within the user interface as a form of design assistant philosophy.

The inexperienced user of the tool poses a risk for quality assurance. Donn et al (2012) conclude the need for shared templates of basic building types which include real-use data, a form of modularity which may provide enough information to a non-expert user to create realistic modelling of design options. Furthermore, a recommendation is made to building designers stating that they must become sufficiently knowledgeable about building performance analysis in order to posit relevant performance questions and use correct performance indicators, or be able to select the required performance sketch module, to answer their modelling questions.

The building performance sketch by definition encompasses the need for all the above. It is a sketch of the design concept, in that the necessary design parameter inputs indicative of the end product are simulated along with a range of unknown design parameters to test the cloud of design potential. The approach requires the need to simulate 'what-if' scenarios to test the sensitivity of the team's design proposal to the initial simulation assumption of perfect operating conditions. These claims require the need for improved parametric simulation and the need for a library database of building inputs from real-world data taken from PoEs.

The rapid evaluation of alternative designs suggested as a necessary feature of future tools by Augenbroe (2002), and these 'what-if' scenarios from the building performance sketch approach requires the capability to easily translate the results of pre and post processing and communicate these results with other members of the design team. Hence, along with the need for high interoperability, design result visualisation must also be addressed (Pilgrim et al, 2003).

Pilgrim et al (2003) define visualisation as 'the process of presenting data to gain greater insight'. In their study, they identify three desirable forms of visualisation of results by users: Interactive; Spatial; and Real-time (where 'feedback from actions is without noticeable pause'). All three properties were found by the designers surveyed to be essential in effective result communication, with particular interest to real-time visualisation. Jacobs \& Henderson (2002) believed that the recommendation of improved graphical representation of results of lighting and daylight analysis, and the effect of lighting design changes, would promote the use of interoperable tools for the designer as it would provide immediate and understandable feedback. These studies stated that the awareness of value towards the use of BPS would require the development of graphical representation. Furthermore, Donn (2001) stated that often BPS tools which can assess the conceptual design questions do not produce the 
answers to questions which architects want answered, nor in a format which can be easily understood by the architect.

For an integrated design process (IDP) approach to work effectively, the tools used by the users must also complement their priorities and modelling style. In order to encourage designers to design with building performance sketchin in mind, the process to assess performance must be as stream-lined as possible and allow for visualisation of the 'answers' to questions posed in formats architects can understand, thereby calling the need for interoperability between design tools and BPS tools.

\subsubsection{Modelling Methods and their Use in Industry}

New ways of integrating design tools and Building Performance Simulation (BPS) tools during the design process are being developed to form the beginnings of the $5^{\text {th }}$ generation of BPS tools. These new methods of modelling provide high interoperability between design tools and BPS tools, and have been created to address recommendations from users.

These methods are able to provide performance feedback directly in the native design tool, enabling options for new design scenarios previously inaccessible for architects and engineers during the early design stage. There are three modelling methods which couple design and BPS tools for use in the early stages of design (Negendahl, 2015): Combined model method; central model method; and distributed model method.

a) Combined model method

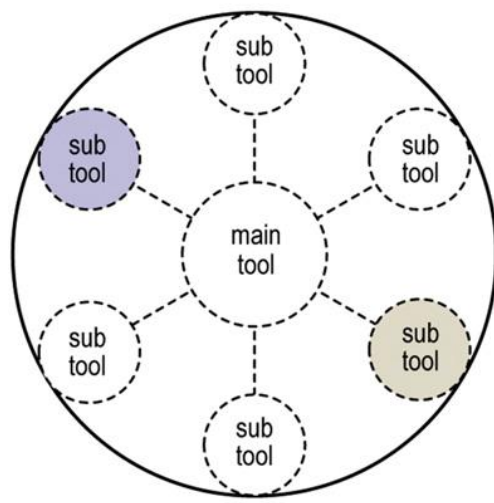

Design tool (CAD) b) Central model method

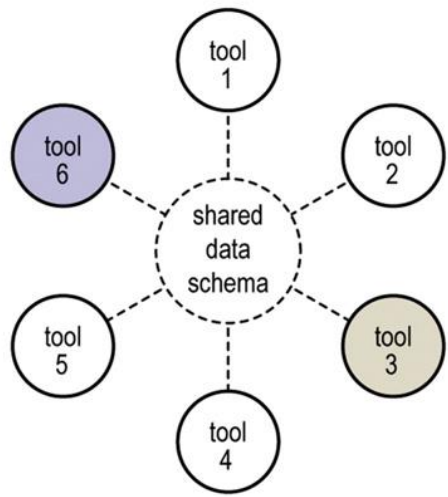

Calculation tool (BPS) c) Distributed model method

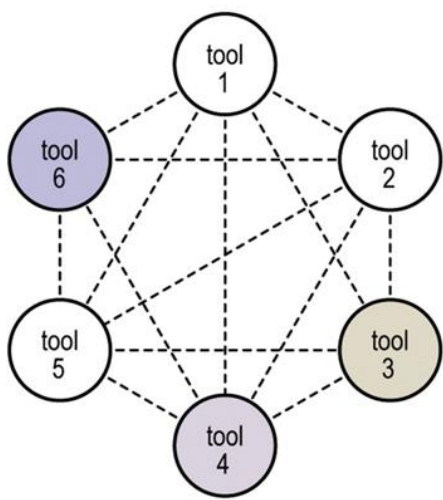

Middleware (e.g. VPL)

FigURE 2 GRAPHICAL REPRESENTATION OF THE THREE MODELLING METHODS AND THEIR COUPLING OF DESIGN TOOLS WITH BPS TOOLS. SOURCE: (NEGENDAHL, 2015)

\subsubsection{Combined Model Method}

This method has the highest level of convergence between design and BPS tools. This method uses simulation packages (e.g. IESVE (IESVE, 2015)) to allow the operator control over the precision of the model within all stages of model production, manipulation and simulation (Negendahl, 2015). The combined model method thus is 
considered to be a cliché analogy of the three modelling methods, represented in Figure 2 - the users must use the tools within the package (represented by the enclosure within a circle), and any program which tries to join the package is faced with difficulties in translating data to be used within the package. The attractive feature of this method is the consistency between the models during the design process, but the user is restricted to the options and features offered by the particular environment or tools of the package.

The protection of in-tool data sets from these packages hinder the potential for exploring different performance aspects (Cerezo et al., 2014). Most programs using this method support import and export geometry from other tools, but do not support dynamics of bi-directional updates between external tools. For example, if one program were to be updated to the latest version, it may no longer be compatible to the other program which it must couple with. The disadvantage therefore is the need for all users to be using the same package and versions. This provides a difficulty when used within a large uncoordinated group or within loose interdisciplinary groups.

\subsubsection{Central Model Method}

The central model method is widely used in Building Information Modelling (BIM), where the concept is based on centralizing building information data in a shared data schema within the 'central model'. Figure 2 provides a representation of this, where all tools data is written to a shared data schema to be read by another program. This method involves various tools which read and write to the same model and are thereby able to connect semantic ${ }^{2}$ information from a design tool to a BPS environment (Negendahl, 2015). Most notable methods are the two main BIM open file formats: Industry Foundation Classes (IFC) and gbXML. In theory, these open file formats can enable the geometric model and the calculation model to be dynamically coupled with an exchange file format.

However, this is rarely used in current practice for design exploration due to time constraints in creating the centralized model (Plume \& Mitchell, 2007). Due to the capability of the model to contain most of the data needed for BPS, the building model must be created with collaborative interchange in mind. This causes the general issue with building modelling in BIM, as there needs to be a balance between the amount of detail input within the model and the cost of creating detail (Plume \& Mitchell, 2007). Though this is positive in terms of design accuracy, it can be very time-consuming. Cerezo et al (2014) comment that "...while they offer data structures applicable to many Building Performance (BP) data inputs, they have not been designed for storing and distributing BP definitions not yet assigned to a particular geometry". In other words, BP definitions would still need to be input when doing a BPS, requiring additional work later in the process.

\footnotetext{
${ }^{2}$ Semantic rules work as natural language concepts like a wall cannot be inside a window - a solution to an ontology challenge (e.g. where 3D geometry has no meaning within BPS tools)
} 
The functionality of integrating external tools to the centralized model has been largely untested and need to be developed in a robust manner to support true and effective collaboration. The main problem therefore is the lack of software support and user support of common open file formats (Negendahl, 2015). Recently, Autodesk boasts that these issues have been resolved for Revit, a BIM tool, through the introduction of Insight 360 (Autodesk, Inc, 2015C). However, this claim has yet to be verified.

\subsubsection{Distributed Model Method}

The distributed model method (DMM) is a response to the central model method, disengaging itself from a top down control and one directional model operation (Negendahl, 2015). To reduce the amount of time required to model, the data is not located within a central model but is rather placed within a middleware component to translate data between the design tool and BPS tool. The middleware is described by Negendahl (2015) as “...not merely a simple converter between formats and platforms, but a system that is able to filter, modify and extend operator definitions to such a degree that the definitions reflect the needs of BPS environments". Figure 2 provides a representation of this, where the design tool is only coupled to the BPS tool through the middleware. The diagram also represents the interoperability of the DMM, where tools can be linked to each other through various formats. Given EnergyPlus and Rhino as an example. EnergyPlus as BPS tool (tool 6) can be used to create geometry within SketchUp (tool 5). This geometry can be baked into SketchUp and imported to Rhino (tool 3). Grasshopper (tool 4), as the middleware program, can then translate the geometry back to EnergyPlus using a third party module, Honeybee. Changes made in SketchUp cannot be directly coupled to EnergyPlus and Rhino as BPS tool and design tool because there is an additional manual step required to transform the SketchUp geometry back to thermal zones recognised by EnergyPlus. However, the middleware of Grasshopper can couple Rhino and EnergyPlus together as all translation of information is automatic.

Most distributed models are described as integrated dynamic models ${ }^{3}$, where the middleware consists of a visual programming language (VPL) (Negendahl, 2015). VPLs can in some cases be considered as design tools themselves, mainly because of the heavy use of geometric modelling functionalities. However, these programs are categorised differently to CAD tools because of their ability to handle non-geometric data, and let operators create their own algorithms. The "geometric-content-based" data exchange of a VPL allows for highly flexible and open environments due to the ability to cross-reference any relationships (both geometrical and non-geometrical) (Negendahl, 2015). However, the dependencies and rules of transferring data between compatible tools must be defined in every integrated dynamic model. The program

\footnotetext{
${ }^{3}$ An integrated dynamic model is a combined model composed of a geometric model controlled in a design tool dynamically coupled to a visual programming language, which is again dynamically coupled to a BPS environment.
} 
Grasshopper illustrates a good example of a VPL, where it works in combination with Rhino as a design tool and various BPS. The facilitation of links to the BPS is handled by third party modules, such as Honeybee for EnergyPlus and DIVA for DAYSIM.

All three model methods in theory allow for coupling between the design tool and BPS tools. The combined model has the highest level of convergence between the geometrical model and the calculation model because they were built as a package. However, the central model has least convergence due to poor support of interpolation formats, and real design process couplings for central model method is yet to be seen.

The distributed model method (DMM) has the potential to support the most variations of BPS tools as both combined and central model methods rely upon the BPS tools to be built-in to their packages, or can specifically work with the file formats. Furthermore, DMM delivers runtime couplings between the BPS and the design tool which meets the requirements for visual representation requested by users. Nonetheless integrated dynamic models require much individual scripting setting up object relationships when runtime linking a design tool to a BPS environment.

\subsubsection{Can the distributed model method (DMM) address all the wishes for future tool development?}

The recommendation categorised in the $5^{\text {th }}$ criteria, integrated building design process, specifies the need for a tool which has the 'ability for different user interfaces to communicate to different users using their familiar language'. Furthermore, other user studies' findings which have been summarised into these 'wish list' categories, suggest the need for interfaces to educate and include quality assurance processes (Donn, 2001). Thus, an important criterion in early design is selecting a modelling method where the operator would benefit from the model environment, rather than being limited by it due to needing to work in another environment that all users can understand.

From this perspective, Davis and Peters (2013) state that the most important features of the design environment is its ability to provide design feedback of the actual design whereby the limitations of the tool does not stop the design change from being implemented. This issue is also suggested by the concept of the building performance sketch, where it was stated by the authors that design exploration should not be obstructed (Donn et al, 2012). For the engineer, Donn et al. (2012) comments on the definition of the building performance sketch,

"As with the architects using the most appropriate drawing tool(s) to create a design sketch, the design analyst needs to have access to the most appropriate design analysis tool(s) to create an informative performance sketch. The basis 
of a flexible performance sketch tool is the flexibility and adaptability of a design simulation program."

(Donn et al., 2012)

Therefore, the model method must support a wide variety of design tool functionalities, various forms of BPS feedback and allow for clear illustration of results to the operator which are both valid and unambiguous (Negendahl, 2015). Negendahl (2015) conclude that integrated dynamic models provide better support in terms of BPS tool flexibility of feedback, multidisciplinary collaboration and diversity during the early design stage. Further, the use of distributed model methods has the capability of providing fast feedback to the operator. Supporting Negendahl is the recent study by Rezaee et al. (2015) where it is acknowledged that during or at the end of the early design phase, decision-making occurs under considerable uncertainty. Thereby calling for methods and tools which "account for iterative, complex, and uncertain characteristics of the design process" (Rezaee et al., 2015). The only modelling method which can meet such diverse requirements is the DMM as: a) it is not limited to specific tools like the combined model method; and b) it does not have reported issues with coupling design tools with BPS tools.

In theory, the DMM would be able to address the majority of concerns of the development community, as well as providing the ability to address all the wanted features listed in Section 2.1.2.3. However, there are currently no documented studies exploring the degree in which the DMM could address the wants and wishes of the building industry, nor how the building industry as users of BPS tools respond to such a change in designing methods. Thus, the objective of this study is to explore the views and opinions of the building industry regarding the use of the DMM to implement building performance sketching within the design process. The aim of the study is to determine whether or not future tool developments for the DMM would address all the concerns and wishes currently preventing the full adoption of building performance sketching within the design process.

However, the study has the challenge in that the means in which the DMM can make BPS feasible within the design process is only theoretical and no example of its use currently exists. 


\section{CHAPTER THREE - METHODOLOGY}

Chapter Two outlined the key barriers to the implementation of building performance simulation (BPS) to be issues in quality assurance of models and results. The chapter summarised the problems to suggest that the architect, as an inexperienced simulator, would need the aid of the engineer as an expert to ensure the building performance assessment can be reliable. Thus without changing our scenario to be "An architect and engineer are approached by a client..." the architect cannot reliably ensure their design will perform as intended. The barriers to BPS thus evolved to include issues with design team communication and collaboration to involve the engineer during such a stage of design that requires rapid development and speed.

The chapter presented a summary of literature recommendations to overcome these barriers against BPS in a form of a 'wish list' for tool developers. Despite over three decades of this 'wish list's existence, some of the wants and wishes of users have been unfulfilled. 
In considering the barriers, recommendations and the established need for integrated design process (IDP) approach within the design team, the chapter finished with the need to consider modelling methods. With the criteria of considering different users, interoperability, and result visualisation, the chapter concluded with the theory that the distributed model method (DMM) could overcome barriers with design team communication and collaboration. Furthermore, it was proposed that the thesis look at the building performance sketch approach to modelling concept design as a means to address design parameter uncertainties in simulation.

However, despite the many theoretical advantages of DMM within the design process to integrate BPS, there are no studies which can prove its feasibility. Furthermore, it seemed inadvisable to create yet another tool which does not meet the wants and wishes of the current building industry professions, on the theory that this method could encourage building performance sketching in design. Thus, before blindly launching into tool development, the thesis aimed to first understand how and why DMM can or cannot make building performance sketching feasible within the design process to guide future tool development.

To achieve this aim, the study established the need to approach the 'players' of the scenario, the architect and the engineer, of a building industry which: a) designs buildings similar to the majority of the building industries in the world; $b$ ) does not currently implement building performance sketching in practice; and c) is growing into a building industry with a focus on 'sustainable', high performance building design. As an unproven concept, no building industry in the world currently implements building performance sketching as common practice. New Zealand's building design and construction industry is largely trained in the same manner as in other countries. Therefore, the study focused upon the developed building industry of its location: New Zealand.

However, the study had a unique problem in that DMM is not a commonly established method of design within New Zealand or elsewhere. There was no case example to question the professions for feedback on the use of DMM as a means to make building performance sketching feasible within the design process, thereby gaining feedback was a near-impossible research task.

The thesis took the approach of demonstrating an example of building performance sketching using DMM by creating a conceptual template workflow for the commercial office building type within an example tool, Honeybee/Grasshopper/Rhino. This chapter outlines the methodology of the study describing how the template workflow was created, the basis for creation and the process taken to demonstrate its use as a means of building performance sketching using DMM.

Furthermore, the study aimed to gain feedback from both 'players', the architect and the engineer. As different modelling operators, the study hypothesised that the 
architect and engineer would respond differently to both the implementation and the use of building performance sketching using DMM. Additionally, to address the research question there was no need to establish some average consensus from the building industry on the use of DMM, but rather it was important to understand how and why it can or cannot make building performance sketching feasible in order to guide tool development. Thus, a focus group interview technique was selected over a quantitative survey study to gain an in-depth understanding of the professions' responses to building performance sketching using DMM.

Finally, the chapter concludes with the requirement to split the groups by profession, with the final third group being a mixture of both to explore the differences of the professions' views, and the use of directed content analysis (DCA) as a means to analyse the results of the focus groups to answer the research questions:

- Can the use of the distributed model method (DMM) address the wants and wishes of users for tool development?

- What must be improved in order to make the integration of BPS feasible within the design process?

Hence, the focus groups were split by profession and DCA was used to analyse how the participants see DMM as meeting the recommendations from literature, confirming or disagreeing with the theory that DMM can address all recommendations, and provided in-depth information regarding which features each profession found more important.

\subsection{The Interview Guide: Providing Context}

The key problem in determining whether or not architects and engineers from the building industry believe the use of DMM can make building performance sketching feasible is that there does not exist an example of its use. Hence, the interview guide contains two main stages: the workshop designed to teach participants how DMM and building performance sketching works; and the focus group interview guide designed to question the participants.

The workshop was conducted over a period of three hours, in which the participants were provided with a brief presentation on the context of building performance sketching, the processes of DMM and its unique features which differ from the methods they were familiar with. Participants were allowed to 'play' within the selected program for this study, Honeybee/Ladybug as plug-ins for Grasshopper/Rhino, within a structured tutorial exercise. The workshop was finalised with a demonstration of a workflow created within Honeybee which illustrates the application of building performance sketching on an example building form. 
The recorded focus group was conducted after the workshop to provide participants the opportunity to answer structured, open-ended questions as feedback which form the main means of data collection for this study.

\subsubsection{Thermal and Daylight Assessment as an example of Building Performance Sketching}

Due to the scope of this thesis, the discussion of the building performance sketch example is limited to thermal and daylight analysis for simplicity while still providing an example of the challenges to predicting both using the same model, and the interoperable capabilities required to enable the same model to be used for both assessments. For example, thermal models can have 'paper thin' walls in modelling to represent mathematically the relevant heat flow paths, whereas the daylight model requires wall thicknesses because paper-thin walls are prone to "leaking" light in simulations (Donn et al., 2012).

However, the difficulties faced by the design community are problems in interoperability between tools. Given thermal and daylight performance assessment as an example, the 'simplified' models for simulation of both have different levels of detail in their model properties. Commonly, prescriptive measures and guidelines have been provided to designers for daylight design - e.g. window heights and glazing area for daylight penetration - and thermal design - e.g. R-values for building elements and U-values for glazing. Generally, thermal and daylight criteria are treated and evaluated separately and are therefore analysed independently of each other. In cases where the building is specifically designed to meet both criteria, the models would need to be reproduced within the different BPS tools for thermal and daylight analysis respectively. This process can be both time consuming and risky, as important information may be missed in translation.

The design of the workflow for demonstrating the coupling of thermal and daylight assessment using the same tool uses contemporary performance metrics to assess performance. Thus, the selection of the tool used for the purposes of this study requires the capability: 'The ability to use the same model for all applicable programs, without the need for remodelling, or facing difficulties in lost information'.

\subsubsection{Coupling Tool Selection for demonstrating the 'Building Performance Sketch' Workflow}

The distributed model method currently has two integrated dynamic modelling tools in continuous development: Rhino/Grasshopper and Revit/Dynamo. The following section of this chapter will discuss the uses and issues of the two tools defined in the category of distributed model method as integrated dynamic modelling tools.

Discussion of which covers how their use in the DMM may address the recommendations from current literature and provide a means to illustrate thermal and daylight building performance sketching as an example. 


\subsubsection{Rhinoceros/Grasshopper vs Revit/Dynamo}

Both Grasshopper (Davidson, 2015) and Dynamo (Autodesk, Inc, 2015b) act as a visual programming language (VPL) for their respective design tool and BPS tools. Both VPLs are open source ${ }^{4}$, however their respective design tools are not thereby requiring a license fee for implementation. Several plugins have been developed over the years for these VPLs. The use of these algorithm based VPLs are particularly applicable to shape grammar evaluation and parametric analysis (Granadeiro et al., 2013).

Both Grasshopper and Dynamo enable the industry to combat the problem of the 'hybrid model' camp referred to in (Jakubiec \& Reinhart, 2011). Here, the hybrid model is briefly explained as a method which uses two models: one for daylight analysis, the other for thermal/energy. Both models share the same lighting and shading schedules. This method is faulted for being time consuming as it would require a lot of effort to organise and transfer data from one simulation environment to another. Since the study by Jakubiec \& Reinhart in 2011 using DIVA for Rhino, new coupling add-ons have been created for Revit/Dynamo and Rhino/Grasshopper which allow for thermal and daylight analysis using the same model constructed in the design tool. The main differences between the two is the purpose of use from their design tool. Rhino is used for conceptual exploration often through parametric design, whereas Revit is primarily used for Building Information Modelling (BIM).

\subsection{Revit/Dynamo}

Revit from Autodesk is specifically built for Building Information Modelling (BIM) and is primarily used for architectural design, MEP (Mechanical, Electrical and Plant), structural engineering, and construction. It is a detailed 3D modelling design tool which belongs to a large enterprise such as Autodesk - "a leader in 3D design, engineering and entertainment software" (Autodesk, Inc, 2015a). As BIM is increasing in popularity world-wide, the use of Revit within architectural firms has proliferated. However, modelling within Revit for early design is incredibly time consuming, as all building elements would be required to follow a BIM protocol - i.e. the naming system for building elements, assigning building properties, etc. Therefore, models created in Revit are often created during the developed-detailed phase of the design process, when a conceptual design had already been selected.

In cases where Revit is used during early design, the design tool has Dynamo as its VPL for parametric modelling and environmental analysis. Dynamo operates much the same way as Honeybee/Grasshopper does, where simulation programs such as EnergyPlus and Radiance/DAYSIM are used to conduct the thermal and daylight analysis. Future efforts by Autodesk in this field however have been largely focused on their new product, Insight 360 . This new product of Autodesk boasts a robust

\footnotetext{
${ }^{4}$ Open source in industry terms is defined as freely downloadable
} 
integration with Revit and Formlt 360 to enable direct access to guidance and recommendations from trusted simulation engines and industry benchmarks (Autodesk, Inc, 2015c).

The greatest issue faced by the use of Revit as a design tool during the early stages of design is time. Due to the nature of modelling within Revit, primarily structured as a BIM tool, the 3D geometry must be further manipulated and transformed into a language which the thermal and daylight simulation engines can understand. Due to the capability of the model to contain most of the data needed for BPS, the building model must be created with collaborative interchange in mind (Negendahl, 2015). Despite the need for more time to create the model, Revit/Dynamo or the use of Insight 360 could one day become a strong contender for the most used software package for the design of high performance buildings. However, at the time of writing this thesis, these programs had not reached a point of easy interoperability and faced several difficulties exchanging geometry from the design tool into terms which EnergyPlus could understand to make it work.

\subsection{Rhinoceros/Grasshopper}

Rhinoceros, commonly referred to as Rhino or Rhino3D, is a 3D computer aided design (CAD) modelling software package used as a free-form NURBS (Non-Uniform Rational Basis Spline) modeller (Robert McNeel \& Associates, 2015). Due to the large variety of plug-ins for Rhino and Grasshopper, Rhino is not restricted to the use in architecture, but can also be used for industrial and product design. In architecture, Rhino is commonly used for parametric design in conceptual design phases as a quick means to create and evaluate different design concepts. Developer plug-ins within Rhino/Grasshopper will enable models created in Rhino to have full interoperability throughout the design process, with some plug-ins introducing the ability to transfer designs from Rhino into Revit for the purposes of BIM (Grevit, 2016). The ability for Rhino to be coupled with thermal and daylight analysis programs is provided by plugins to the VPL, Grasshopper. These plug-ins, along with plug-ins for Rhino, can be downloaded from Food4Rhino (McNeel Europe, 2015). The three plug-ins of note for Rhino/Grasshopper are the environmental analysis plug-ins: Ladybug; Honeybee; and DIVA.

1) Ladybug: Ladybug is a plug-in made up of components which analyses weather data, particularly standard EnergyPlus weather files (.EPW), within Grasshopper and provides a variety of 3D interactive graphics visualised in Rhino to support the decision-making process during the initial stages of design. The outputs from the components within Ladybug are often used within its partnering plug-in, Honeybee, to enable more informed analysis.

2) Honeybee: Honeybee is a plug-in made up of several components which connect Grasshopper with EnergyPlus (EnergyPlus, 2016a), Radiance , DAYSIM (DAYSIM, 2016) and OpenStudio (OpenStudio, 2016) for building 
energy, thermal and daylight simulation. Both Ladybug and Honeybee combined enable a dynamic coupling between flexible, component-based, visual programming interface of Grasshopper and validated environmental data sets and simulation engines (Sadeghipour Roudsari \& Pak, 2013).

3) DIVA: DIVA-for-Rhino is a highly optimised daylighting and energy modelling plug-in for Rhino, initially developed at the Graduate School of Design at Harvard University and is now distributed and developed by Solemma LLC (Solemma, LLC, 2015). Similar to Honeybee, DIVA allows users to carry out a series of environmental performance evaluations by connecting Grasshopper with EnergyPlus (through the newly integrated ArchSim plug-in) and Radiance/DAYSIM. This plug-in is not open sourced.

The differences between the plug-ins have not been published in any comparative studies due to their recent release into the public domain, however a brief outline of the main differences are summarised and tabulated in Table 1. Ladybug is not comparable to either Honeybee or DIVA as it is purely made to analyse weather data in respect to designs.

\section{Table 1 Differences between Honeybee ANd DiVA}

\begin{tabular}{|c|c|c|}
\hline \multicolumn{2}{|r|}{ Honeybee } & DIVA \\
\hline Flexibility in Modelling & $\begin{array}{l}\text { More components } \\
\text { meaning Honeybee is } \\
\text { more open-ended, } \\
\text { customizable and has the } \\
\text { ability to have more } \\
\text { control over parameters } \\
\text { than DIVA }\end{array}$ & $\begin{array}{l}\text { Limited components } \\
\text { meaning it is faster and } \\
\text { easier to use, with less of } \\
\text { a steep learning curve to } \\
\text { master compared to } \\
\text { Honeybee. However, this } \\
\text { restricts the modeller } \\
\text { from being able to } \\
\text { perform more complex } \\
\text { design considerations and } \\
\text { restricts the transparency } \\
\text { of in-built assumptions }\end{array}$ \\
\hline $\begin{array}{r}\text { Open-sourced vs Not } \\
\text { Open-sourced }\end{array}$ & $\begin{array}{l}\text { Honeybee and any } \\
\text { derivative software will } \\
\text { forever be free under the } \\
\text { GPL licence (Sadeghipour } \\
\text { Roudsari, 2015). This } \\
\text { allows it to be more freely } \\
\text { available to users, } \\
\text { however the design tool } \\
\text { Rhino will require a } \\
\text { purchased license. }\end{array}$ & $\begin{array}{l}\text { DIVA requires a purchased } \\
\text { licence along with Rhino, } \\
\text { thereby making it less } \\
\text { available than Honeybee. }\end{array}$ \\
\hline
\end{tabular}




\begin{tabular}{|c|c|c|}
\hline Version Compatibility & $\begin{array}{l}\text { Since Honeybee is open } \\
\text { source, if a new feature in } \\
\text { one of the connected } \\
\text { programs such as } \\
\text { EnergyPlus became } \\
\text { available, the user is able } \\
\text { to add an extra line of } \\
\text { python code within } \\
\text { Honeybee to account for } \\
\text { this. }\end{array}$ & $\begin{array}{l}\text { Since ArchSim within DIVA } \\
\text { is closed source, if a new } \\
\text { feature within EnergyPlus } \\
\text { were to become available } \\
\text { the user would be } \\
\text { required to use } \\
\text { EnergyPlus' text editor } \\
\text { interface to implement } \\
\text { any additional EnergyPlus } \\
\text { features. }\end{array}$ \\
\hline Libraries and Templates & $\begin{array}{l}\text { Honeybee draws its } \\
\text { libraries and templates for } \\
\text { occupancy behaviour, } \\
\text { loading and HVAC systems } \\
\text { from OpenStudio, which is } \\
\text { supported by the US } \\
\text { Department of Energy. } \\
\text { This enables it to make } \\
\text { use of the large database } \\
\text { of building type } \\
\text { schedules/loads and } \\
\text { constructions that have } \\
\text { been assembled by the } \\
\text { OpenStudio team. } \\
\text { Furthermore, templates } \\
\text { are editable for other } \\
\text { organisations or countries } \\
\text { to add their own } \\
\text { databases. }\end{array}$ & $\begin{array}{l}\text { The libraries within DIVA, } \\
\text { particularly the Archsim } \\
\text { related libraries, were } \\
\text { created from the author's } \\
\text { own experience and are } \\
\text { therefore limited in } \\
\text { number. }\end{array}$ \\
\hline
\end{tabular}

As there is little evidence to support the full and quick use of Revit as a design tool for early design conceptual exploration at the writing of this thesis, and its inability to work using DMM, Rhino/Grasshopper was selected as the example of the DMM application within the design process presented to the participants of this study.

\subsubsection{Honeybee and Ladybug: Meeting the Recommendations from Literature}

The study recognises the lack of expertise within the New Zealand building industry to the application of DMM for building performance sketching. Hence, the interview guide must present participants with an example. With the research questions focusing upon gaining feedback of whether or not DMM can address all recommendations for tool development and make building performance sketching 
feasible, the example provided to the participants must demonstrate how this as a concept. Therefore, Honeybee and Ladybug as plug-ins for Rhino/Grasshopper are selected as these tools have the capabilities to address the following recommendations:

a) Be quick and easy to use within the early design stage - the design tool (Rhino) is coupled to the BPS tools (EnergyPlus, Radiance, DAYSIM and OpenStudio) to allow for complete exploration of conceptual designs without limiting the design due to computational restrictions. Simplified models are thus able to be created in the early stages of design, with the capability to create detailed models later.

b) Be able to perform thermal and daylight performance analysis using the same model - The model created in Rhino is able to be brought into Grasshopper for Honeybee to translate into terms the thermal and daylight engines (EnergyPlus and Radiance) can understand. Furthermore, the use of the same model is considered in terms of both assessments, where the thermal model can be simplified to 'paper thin' geometry, and window thickness and surface properties can be added to the model for daylight simulation.

c) Be interoperable between the design tool and the BPS tool(s) - the ability to change a design variable without having to rework the BPS tool model is essential for a quick and easy process during the early stage of design to be worth implementing this process

d) Enable the ability to perform parametric simulations for the purposes of uncertainty and sensitivity analysis - the most important criteria, to ensure uncertainty of unknown parameters are addressed and accounted for. In this, the tool can be easily customizable and has the ability to export data into a common format for analysis.

e) Isolate influential design parameters to highlight their importance to the modeller - based upon the recommended requirement from Berkeley et al. (2014), stating that an emphasis on user interface to highlight essential input parameters would help reduce error in inputting data. These can be addressed in a created workflow for this study.

f) Full transparency of calculations and in-built assumptions behind calculations - In response to the recommendations from Attia et al (2012), users wish to be able to 'check under the hood' to ensure reliability of calculations. Honeybee and Ladybug, being entirely Python scripts, enable the user to view the code behind every component thereby providing full transparency.

g) Comparison of results: Honeybee is able to provide result visualisation within Rhino, and the ability to compare results through various formats, including an online format - Pollination (Sadeghipour Roudsari, 2016c) 
h) Create a custom user library for sharing - to address the recommendations made by Donn et al (2012), Honeybee is able to allow the user to create their own custom library of material properties, occupant behaviour patterns and climate files.

\subsubsection{Teaching Honeybee and Ladybug}

Before the participants were demonstrated the use of the created workflow to building performance sketch using Honeybee as a DMM, the participants were given a basic introduction to the processes and benefits of Honeybee and Ladybug via a threehour workshop. The purpose of including this workshop tutorial and/or presentation within the interview guide was two-fold:

a) To provide a basis to understand the workflow and its processes: The workflow can be complex at first glance, and without a proper understanding of what the components do, or how they can be used, the participants would not be able to provide informed answers to the focus group questions.

b) To provide incentive to participate within the study: The focus group method has a large risk in recruitment, whereby a group cannot be held if the number of participants is less than three (see Section 3.2.2.2.). As Honeybee and Ladybug, along with their use in DMM for building performance simulation, was entirely new to the New Zealand building industry, the opportunity for engineers to attend a free workshop to learn the program was appealing. Furthermore, architects were given the opportunity to attend, with a further incentive of receiving Continuous Professional Development (CPD) points towards their registration as an architect by the New Zealand Institute of Architects (NZIA).

The tutorial exercise included four modules to provide the basics of:

1. The Grasshopper interface and Ladybug in its use for site analysis

2. Creating Thermal models in Honeybee

3. Creating Daylight models and reading sky files in Honeybee and Ladybug

4. Editing the created models to create customised user libraries for constructions and occupancy loads and behaviour patterns (schedules)

The tutorial exercise, along with the files for the modules, are supplied as digital assets of this thesis. 


\subsection{The Building Performance Sketch Workflow}

Due to the scope of this thesis, a conceptual workflow was created in Honeybee to provide a means to test theories from the recommendations made by literature on the participants of this study, and provide a basis for recommendations to be made for future development. The aim of the workflow was to address the recommendations from (Donn et al., 2012) in using detailed simulation engines and real-world data, along with enabling sensitivity analysis at the early stages of design to ensure reliable and useful results for the users.

Figure 3 illustrates the workflow's Honeybee components visible in the Grasshopper interface and demonstrates the significance of the features made available through the interoperability of the DMM. The workflow covers (from left to right):

1. Establishing building type parametric inputs - The parameters which the architect only needs to concern themselves with, everything else seen in the workflow was created to provide full transparency and control to the engineer

2. The process of transferring the Rhino geometry to Honeybee - The workflow was specifically created to accommodate ANY geometry no matter the complexity - the architect would simply need to connect the BREP or parametric design components to the start of the workflow

3. Creating the building performance sketch for thermal and daylight simulation using New Zealand specific building data - BEES data was used to allow realworld data to be used and demonstrated its use to the participants

4. Creating shading for thermal and daylight simulation - The workflow is able to create shading for the building automatically, additional shading can be added by the architect or engineer

5. Simulating the model with New Zealand climate data - A crucial feature of the workflow: the ability to simulate both for thermal and daylight simulation using the same model, in the same program for full interoperability of data

6. Processing the results of simulation by applying the thermal and daylight metrics - Workflow enables the ability to take the Daylight Autonomy results from the model and convert them into a lighting schedule to be used for the thermal/energy simulation, allowing for a quick energy saving assessment due to daylight harvesting

7. The ability to run parametric simulations - Essential feature for speed within the early stages of design

8. Setting up results to be visualised through Pollinator (Sadeghipour Roudsari, 2016c) - Feature for result visualisation which can be interative for both client and architect 


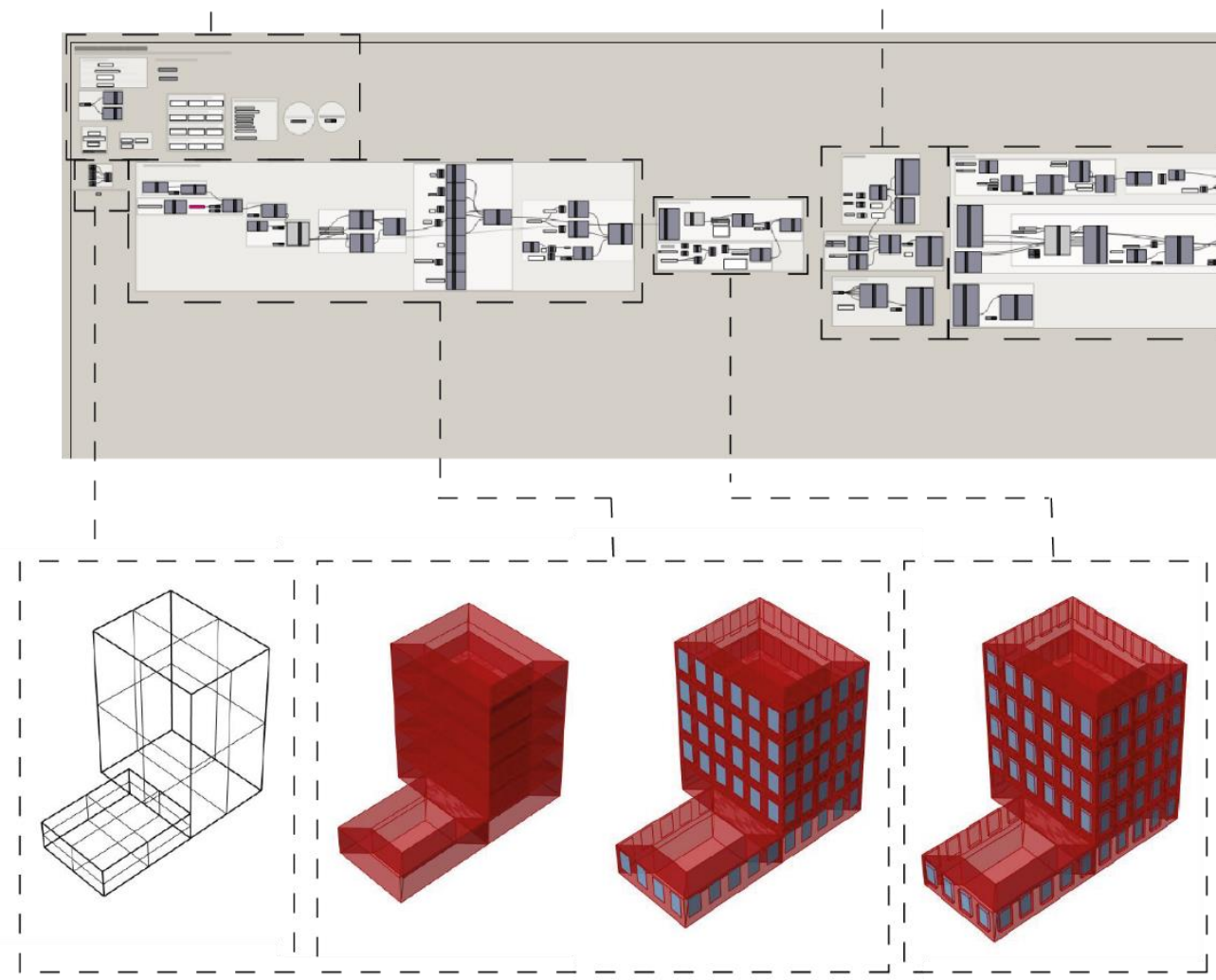

2. ARCHITECTURAL SKETCH
3. MODEL TRANSFORMATION
4. CREATING SHADING

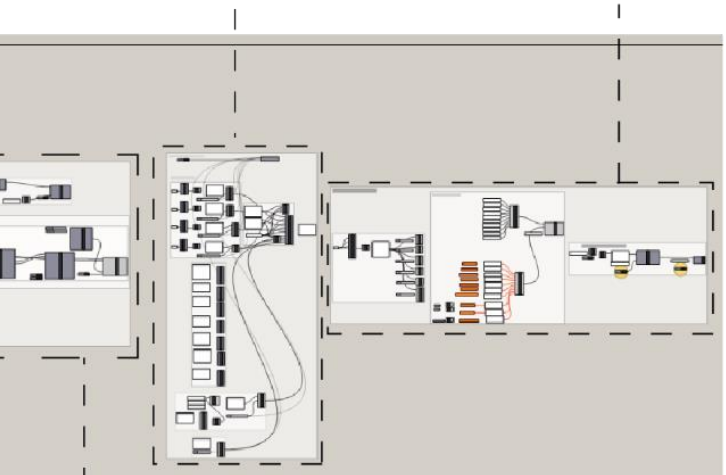

$\llcorner------$.

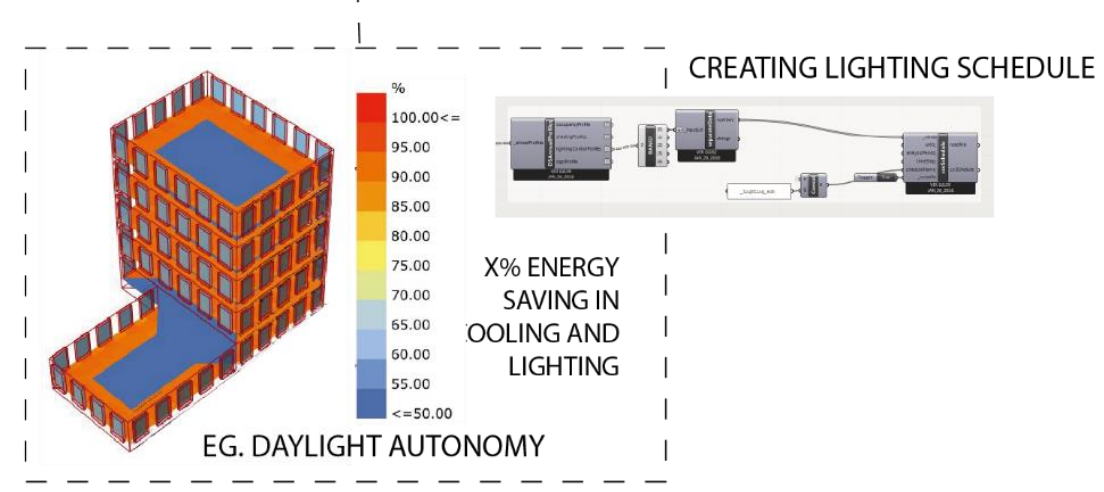

6. PROCESS RESULTS

FiguRE 3 OVERVIEW OF WORKFLOW AND ITS COMPONENTS 
A 'component' within Grasshopper and Dynamo is defined as an object-orientated code which requires inputs for calculation and generates outputs for use by other components. As a visual explanation, take the component "Honeybee_Generate Zone Test Points" illustrated in Figure 4 as an example. The component requires the inputs: HBZone (the Honeybee Zones); grid size; distance from base surface; and whether or not the user wishes to move the test mesh which would be created. The component uses the output of the component "Honeybee_Mass2Zones", which is the component responsible for transforming 'masses', or geometry, into Honeybee zones. This component requires:

- The geometry of the buildings as an input

- The names which will be assigned to the zones created

- The zones programs (which assigns a predetermined user library of constructions, materials, occupancy behaviour patterns, equipment and lighting loads)

- Whether the zones will be conditioned or not

- The maximum roof angle where the program will consider a sloped roof to still be assigned as a roof

- and a command to create the zones

The output of the component is the generated Honeybee Zones, which can then be used as the input for other components. In our example, the output is used as the input for grid generation.

Hence, the output of the "Honeybee_Generate Zone Test Points" component are test points of the grid, point vectors, the face areas and the grid mesh to be used as inputs for other components.

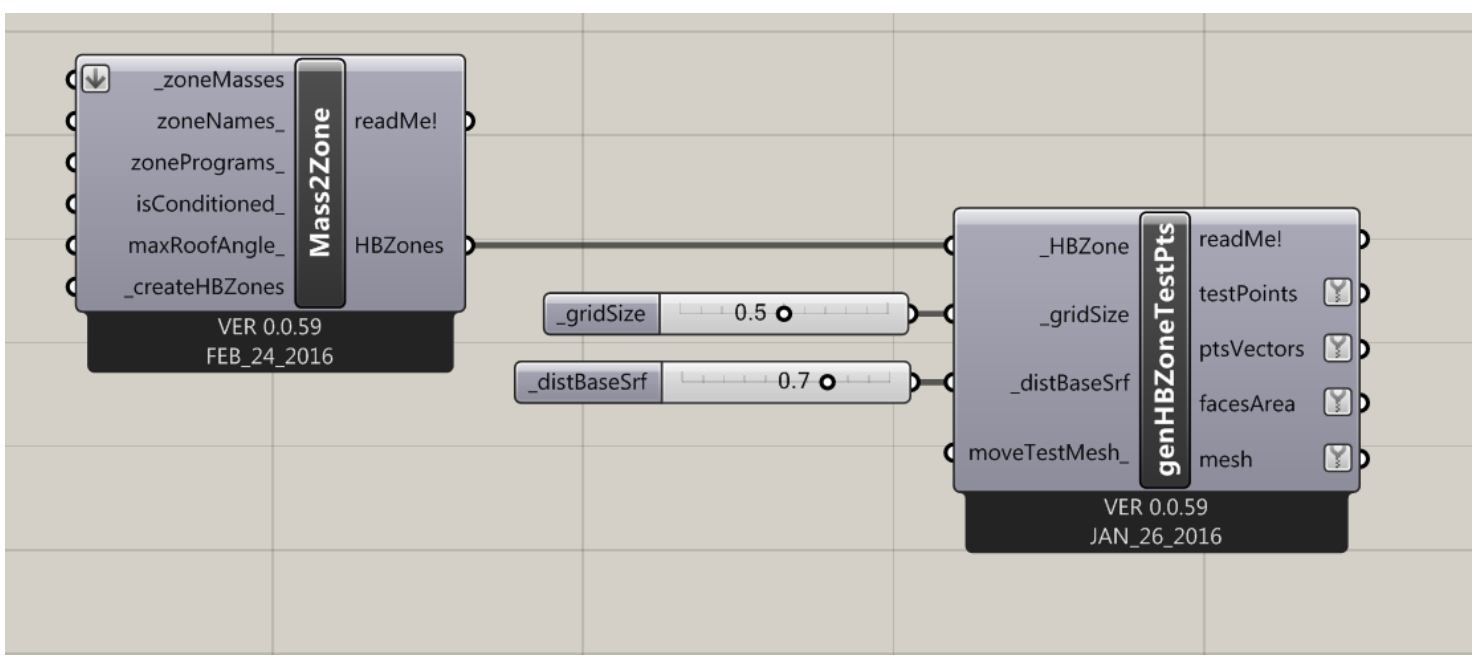

Figure 4 Example of a Component Within Grasshopper - Generating Zone test Points

Thus, the use of Honeybee/Grasshopper as a middleware for the DMM provides full control of the processes in making zones, generating objects and editing specific 
controls. The full control given by breaking down all aspects of model creation into components enables reusability and the ability to extend a given template. Modularity enables the creation of templates or aspects specific to a building type that can be copied and pasted to other parts to create customised templates. This workflow was specifically created as an example template for the commercial office building in New Zealand, with the possibility to be extended and customised.

Furthermore, the benefit which can be seen in Figure 3 is the ability to have all the processes, from transferring geometry to post-processing results, all on one single 'canvas'. Due to the linear processes of Grasshopper and its components, the user can backtrack to previous components to understand the assumptions behind certain calculations. Furthermore, the nature of Grasshopper's input-output components is that the output of one component, say, a component which creates the test grid for daylight analysis, can be used for more than one component. In this, if a change were to be needed in the size of the grid, the test grid component would only need to be changed once, and this would change the grid for every component which used the grid as one of their inputs. This feature is also present within Dynamo, therefore is not unique to Grasshopper as an example alone.

This feature is particularly important for parametric simulation and testing the variations of design iterations. For example, given a project where the researcher is interested in testing the effect of construction types on a building stock, the workflow could be connected in such a way that all geometries of these buildings are connected to the same component which alters their constructions. Thus, the construction type is changed in one single component, which then changes the construction across all buildings connected to it. This feature alone would save time in generating different scenarios for simulation, something which previously would have required a macro code to be written to alter several hundred files.

We acknowledge that this workflow has not been created to be robust or for immediate use within the industry, but rather a concept to provide feedback and explore options for future development. Therefore, all features were created at the most conceptual level to demonstrate their use, however particular attention was given to the creation of:

- The ability to add any geometry to the beginning of the workflow and have the geometry be converted into Honeybee Zones to run simulations

- The ability to parametrically run simulations for sensitivity analysis

- The ability to edit all parameters and have full control over the creation and processing of the models

- A user library specific to New Zealand from real-world data provided by BEES (Amitrano et al., 2014) 
The following sections will briefly describe the processes within the workflow, and the features demonstrated to the participants of this study.

\subsubsection{Transferring the Geometry from Rhino to Honeybee}

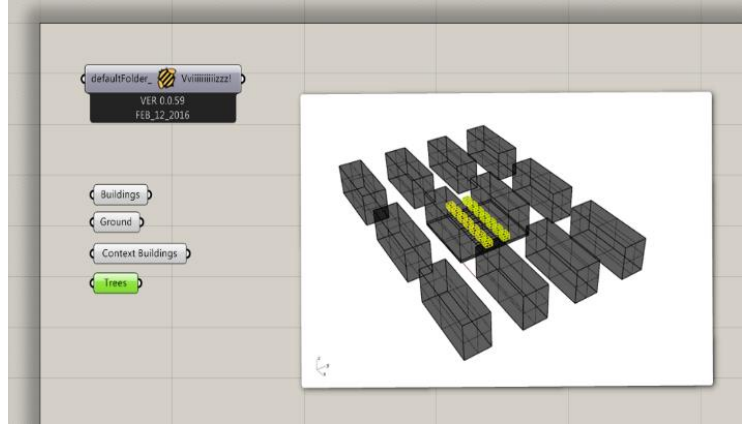

FigURE 5 USING BOUNDARY REPRESENTATION COMPONENTS (BREPS) WITHIN GRASSHOPPER TO TRANSLATE RHINO GEOMETRY ${ }^{5}$

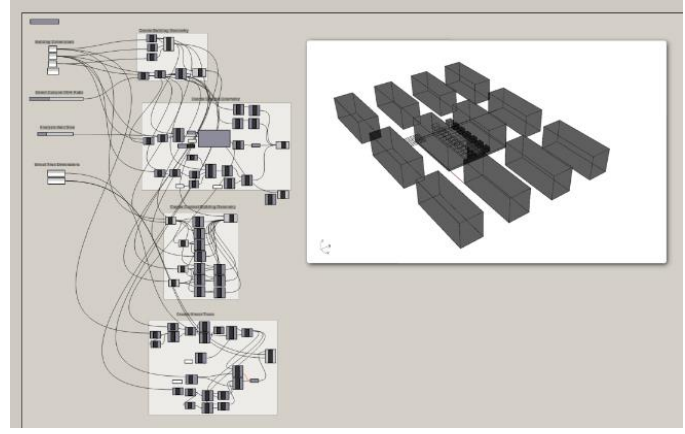

Figure 6 Creating the Geometry in Grasshopper using Parametric Design ${ }^{2}$

The participants were first demonstrated how geometry is taken from Rhino and translated into Grasshopper, the Visual Programming Language (VPL) as the middleware for distributed model method (DMM). This demonstration was focused upon highlighting the interoperability and high convergence of exchanging the 3D model from one program to the other.

Figure 5 illustrates the most common means of transferring geometry by assigning the selected geometry to a Boundary Representation (BREP) component in Grasshopper. Figure 6 illustrates the creation of the same geometry by creating the geometry in Grasshopper using the native components in parametric design (designing based upon the alteration of parameters). The view provided in the white space is what is previewed in the Rhino interface. In each figure, the gridded grey space is the Grasshopper interface, commonly known as 'The Canvas'.

${ }^{5}$ The geometry illustrated here was taken from the Outdoor Microclimate Map tutorial example file for Honeybee users (Sadeghipour Roudsari, 2016a) 


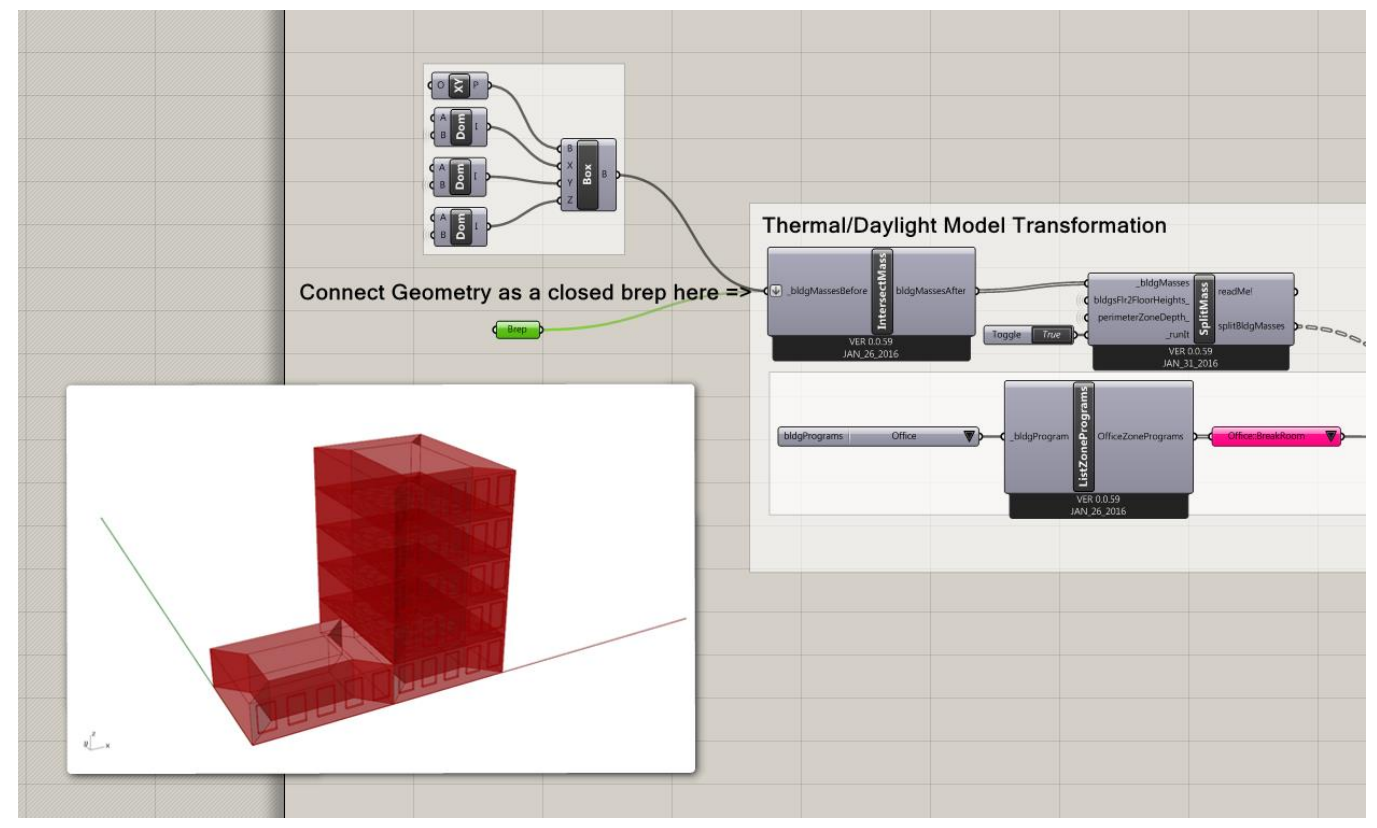

FIGURE 7 SCREENSHOT OF THE WORKFLOW'S MEANS OF TRANSLATING GEOMETRY FROM RHINO INTO HONEYBEE

The workflow allows the use of both methods of translating the geometry from Rhino to Grasshopper for use within Honeybee. Figure 7 is a screenshot of the process the workflow requires the user to input the geometry. The creation of the workflow had been made in such a way that any geometry can be connected to the beginning and can be translated by Honeybee into the creation of a building performance sketch. This saves valuable time during the early stages of design, as the design team do not need to rebuild the design model. The workflow demonstrates that both means of transferring geometry can be used at once, where the small building indicated in the Rhino preview is created using Grasshopper native components as a box, and the largest building is created in Rhino and brought in via a BREP (as indicated in the green highlighted BREP component). 


\subsubsection{Creating the Building Performance Sketch using New Zealand specific Data}

An important feature of the workflow was to demonstrate the ability of Grasshopper and Honeybee to create, store and share user libraries for building materials, constructions, occupancy behaviour schedules and climate data to meet the recommendations stated by Donn et al (2012).

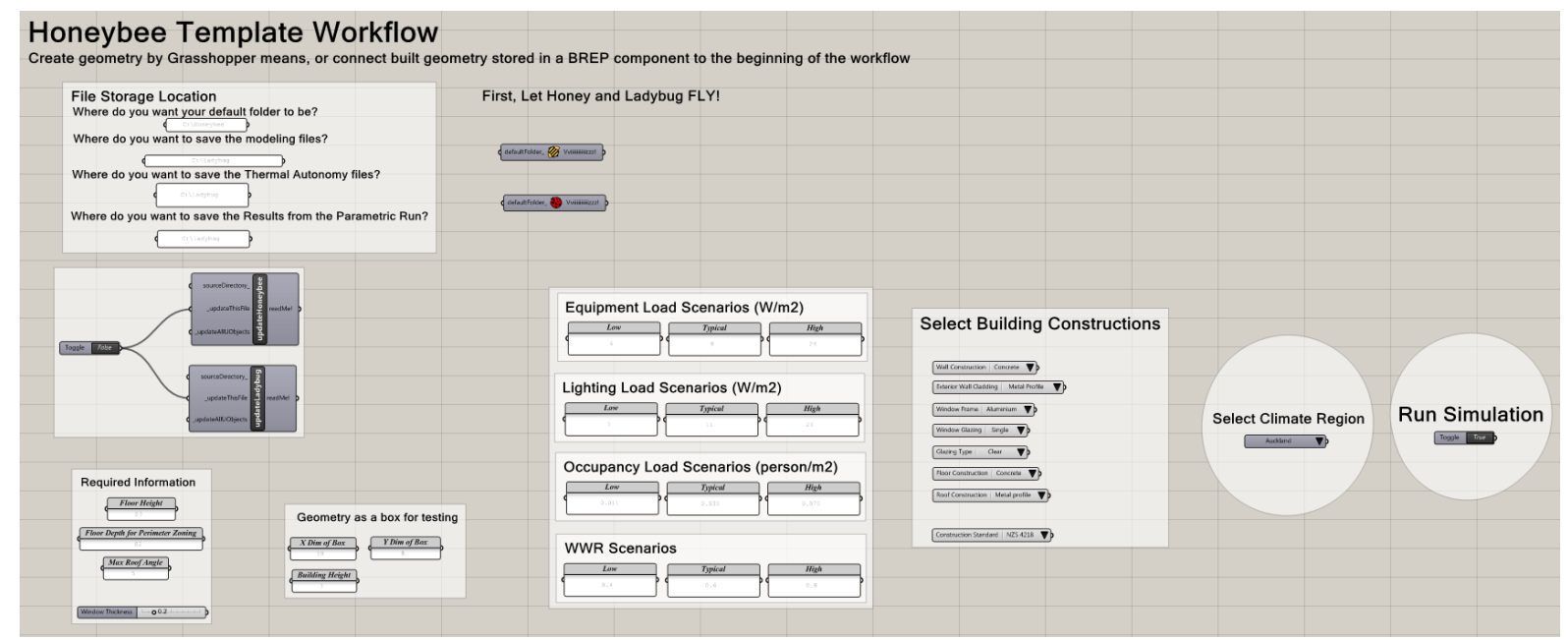

FIGURE 8 THE PARAMETER INPUTS OF THE WORKFLOW SPECIFIC TO NEW ZEALAND, AND TAKEN FROM BEES (AMitrano et AL., 2014) AND (CORY, GATES, \& DONN, 2011)

Figure 8 is a screenshot of the workflow where the parameters of the created model can be altered depending on the construction and type of building. The load specific data has been taken from the Building Energy End-Use Study (BEES). BEES started in 2007 with the purpose of establishing where and how energy and water resources are used in New Zealand's non-residential buildings and what factors drive the use of these resources (Amitrano et al., 2014). In their final report, the monitored data of 48 buildings were provided to the public and are used here to form a user library within Honeybee for low, typical and high occupancy scenarios for the commercial office building.

The construction data specific to New Zealand commercial office buildings was taken and converted from (Cory et al., 2011) into a Honeybee user library of constructions and materials.

The climate data selection is a series of URL links for Ladybug to download the specified climate location weather file in New Zealand from the EnergyPlus weather file website (EnergyPlus, 2016b). 


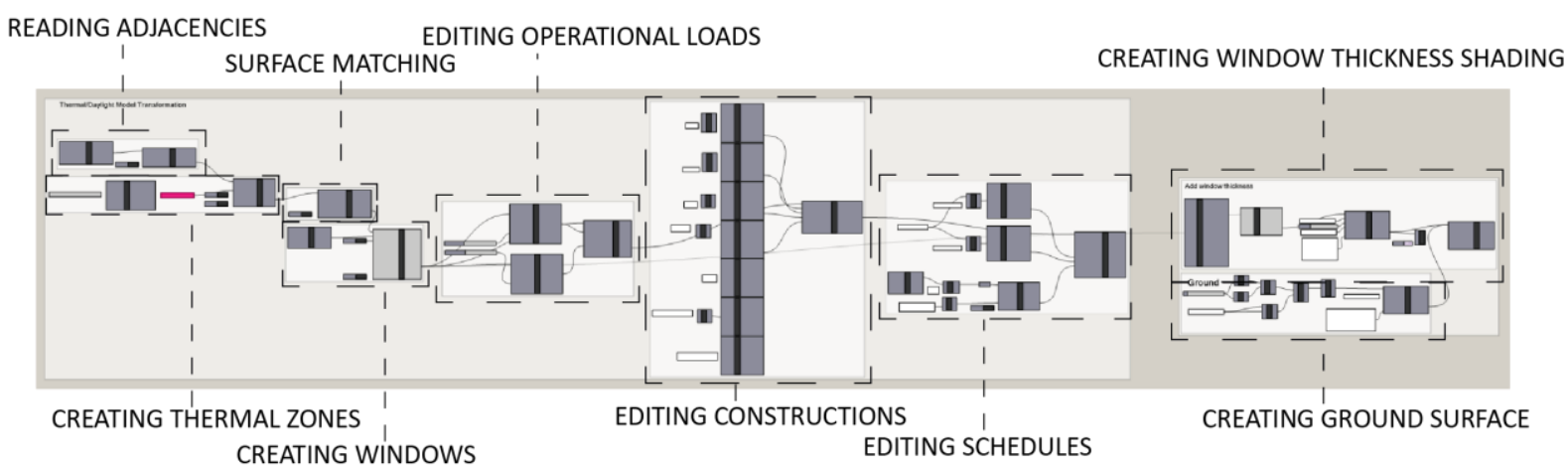

Figure 9 Thermal and Daylight Model Transformation

Figure 9 describes the components of the workflow that transform the geometry into thermal zones, adds windows and window thicknesses and provides the ability to edit loads, constructions and schedules. The workflow has been set out with two main themes: full transparency of how the model is created, and the defaults of certain components; and minimising necessary inputs. Everything which requires user input is grouped at the start of the workflow in the 'Parametric Inputs' area as a means to simplify the required input for the architects, who may not be concerned with viewing all the components which create the model, as seen in Figure 3. If the users wish to edit any particular part in creating the models, they are able to do so, given they follow the correct processes to link the change into the workflow. This therefore requires expertise from the engineer. 


\subsubsection{Simulating the Model using EnergyPlus and DAYSIM}

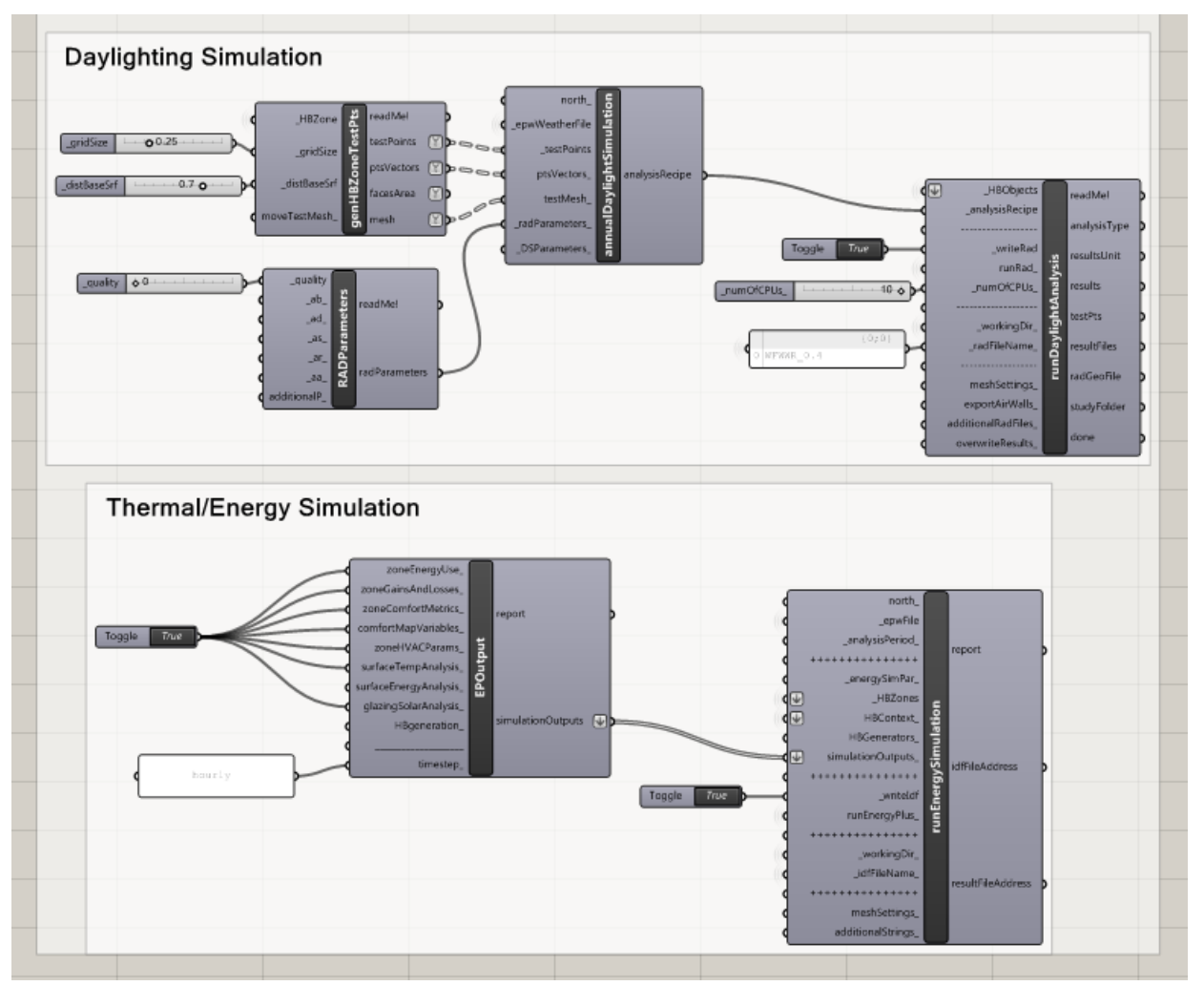

Figure 10 Components for Thermal AND DAyLight Simulation

Figure 10 provides a screenshot of the section within the workflow which simulates the created honeybee zones for thermal and daylight assessment. The purpose in illustrating these components to the participants, and providing this screenshot here, is to demonstrate the benefit of being able to simulate for both thermal and daylight assessment on the same 'canvas' using the DMM.

Previously, thermal and daylight assessments of a design would be performed in their respective separate BPS tools - EnergyPlus for thermal and DAYSIM for daylight. The daylight model would assess the amount of daylight a space would receive, and report on how much artificial lighting may be required to add to the available daylight in order to meet an illuminance threshold for lighting (i.e. H1 as part of the New Zealand building code requires a minimum of 300 lux within an office space). This lighting report can be processed by DAYSIM in a form of a lighting schedule which EnergyPlus can read into its thermal model. This process requires two models to be created, and any change in the daylight model to be altered in the thermal model.

In the workflow, using Honeybee to connect DAYSIM and EnergyPlus together within the same interface, the same model is used for both, therefore any change for daylight would be automatically made for thermal/energy. Figure 11 illustrates the process of taking the lighting results from the daylight simulation to create a lighting schedule for 
the thermal model to use in the thermal/energy simulation, all on the same canvas with no need for manual program exchange.

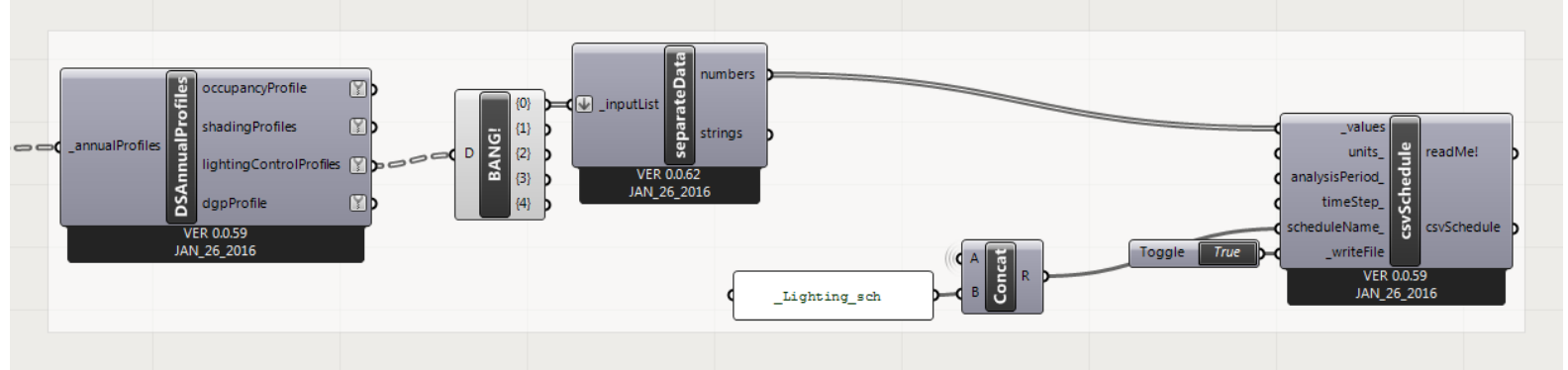

Figure 11 Creation of lighting Schedule from Daylight Autonomy Results

\subsubsection{Processing Results for Thermal and Daylight Analysis}

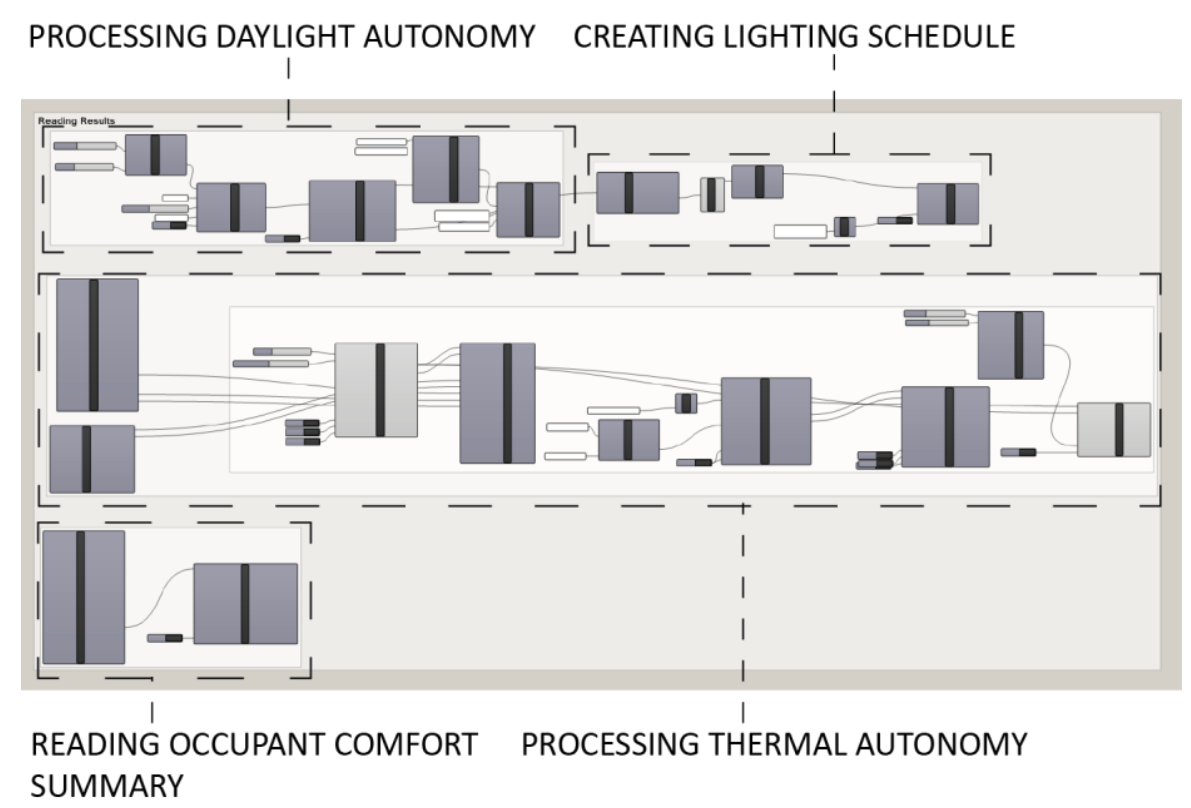

Figure 12 Processing results for Thermal Autonomy, Daylight Autonomy and creating LIGHTING SCHEDULE

The developers of Honeybee (Sadeghipour Roudsari, 2016b), as academic researchers, continuously update Honeybee to include the latest metrics for thermal and daylight assessment. Hence, Thermal Autonomy (TA) and Daylight Autonomy (DA) are able to be assessed using the coded components. These are indicated in Figure 12, along with an added summary of occupant thermal comfort. Using the components within Ladybug, these results can be visualised within Rhino depending on how the users wish to view it.

Figure 13 illustrates how Daylight Autonomy (DA) can be visualised within a conceptual design previewed in the Rhino interface in real-time. This feature was demonstrated to the participants within module three through the tutorial exercise. Here, the results of DA are presented using the test points created in generating the grid for analysis described earlier and colouring the data in a legend. This example 
allows the designer to determine possible lighting problems within their design - i.e. the back of each room was found to not receive sufficient amount of light therefore requiring artificial lighting to meet the building code requirement, or the need to improve the design for better light penetration and/or distribution.

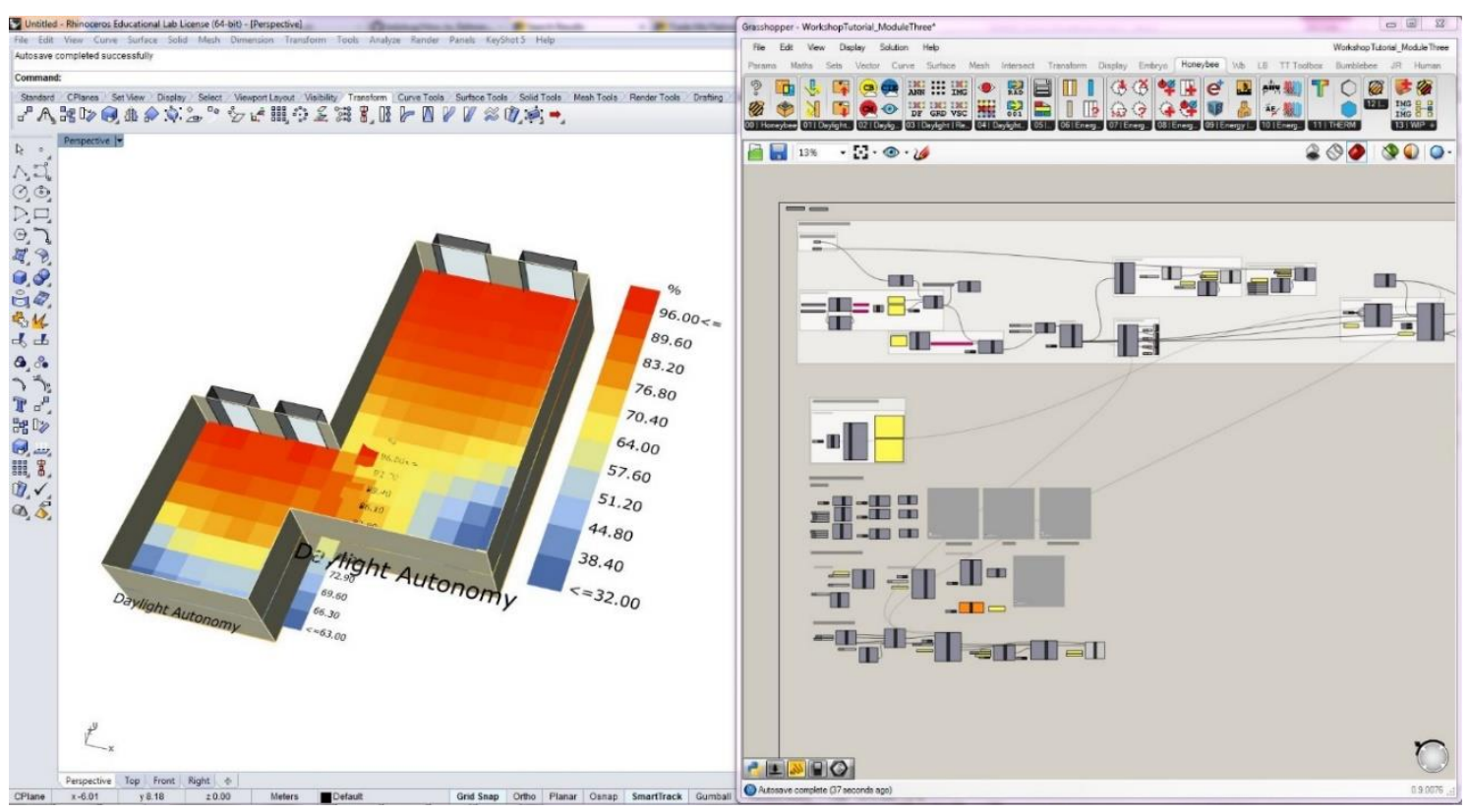

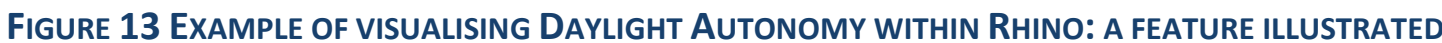
WITHIN THE TUTORIAL EXERCISE

3.2.5. Visualising the Comparison of Results from a Parametric Simulation through Pollinator RUN PARAMETRIC SIMULATION POST-PROCESS TO POLLINATOR

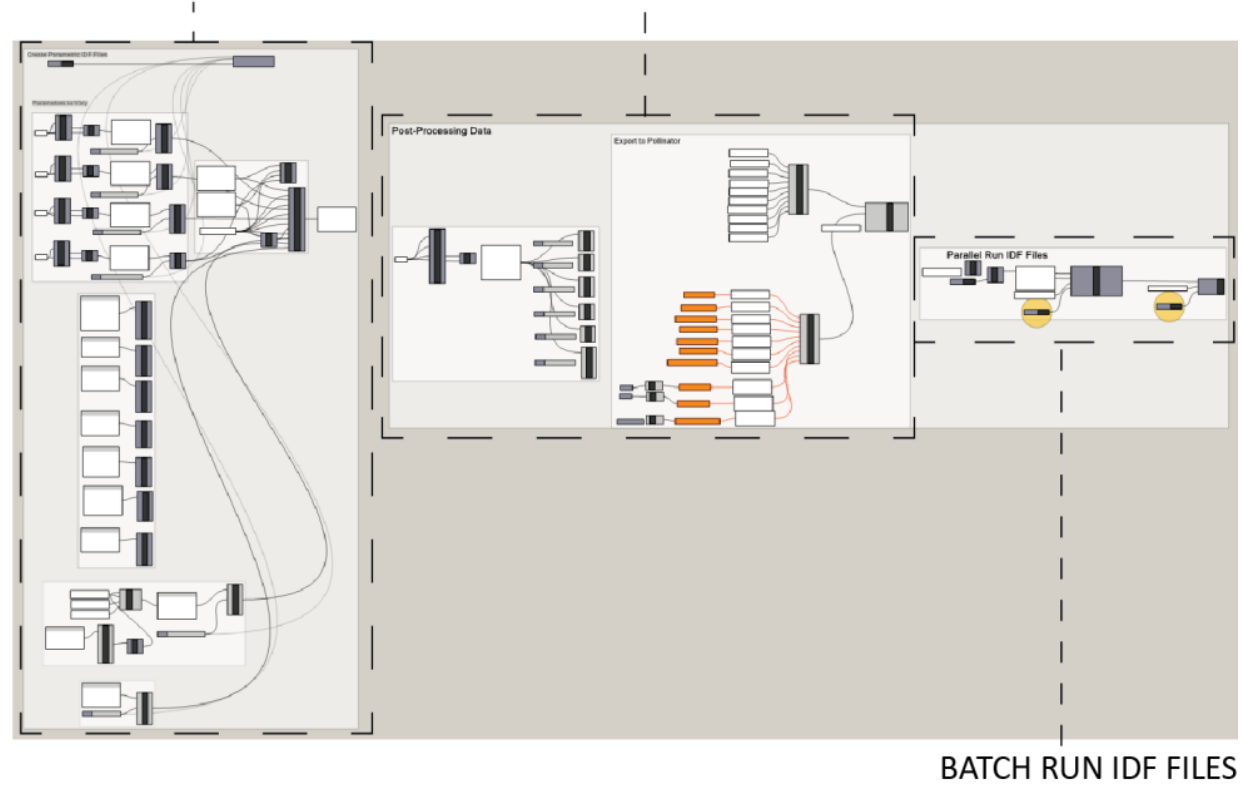

FIGURE 14 POST-PROCESS COMPONENTS OF WORKFLOW: ABILITY TO RUN PARAMETRIC SIMULATION, PROCESS RESULTS TO POLLINATOR AND BATCH RUN ENERGYPLUS FILES (IDF FILES) 
The last feature of the workflow covers the parametric capabilities of Grasshopper and the ability to record the results of each simulation into a format which can be read through pollination into Pollinator (Sadeghipour Roudsari, 2016c).

The parametric section of the workflow, illustrated in Figure 14, enables the ability to 'animate' sliders which change the index of a list of parameters thereby changing the item selected from that list. The selected item from the list of parameters are connected to their respective components. Figure 15 provides an example for us to explain how the window to wall ratio (WWR) of the honeybee model can be changed parametrically in this way. The parameters for WWR which we want to test are put into a list indicated in the white panel. The component which it is connected to reads the list and a 'slider' is connected to the component to provide it with an index. Given an index ' 0 ', the component will provide the selected item from the list to be a WWR of ' 0.4 ' (40\%). Thus an index of ' 2 ' will provide the selected WWR of ' 0.8 ' (80\%). This selected value is connected to the component which assigns the WWR to the orientations, which is used to create the windows with the glazing creator component. In 'animating' the slider, the slider will move from 0 to its max range in given steps (i.e. $0,1,2 \ldots n)$. Every time the slider changes its index, the value of the WWR changes, which then changes the name of the file and a new simulation is run. Thus, a parametric simulation can be set up using this workflow.

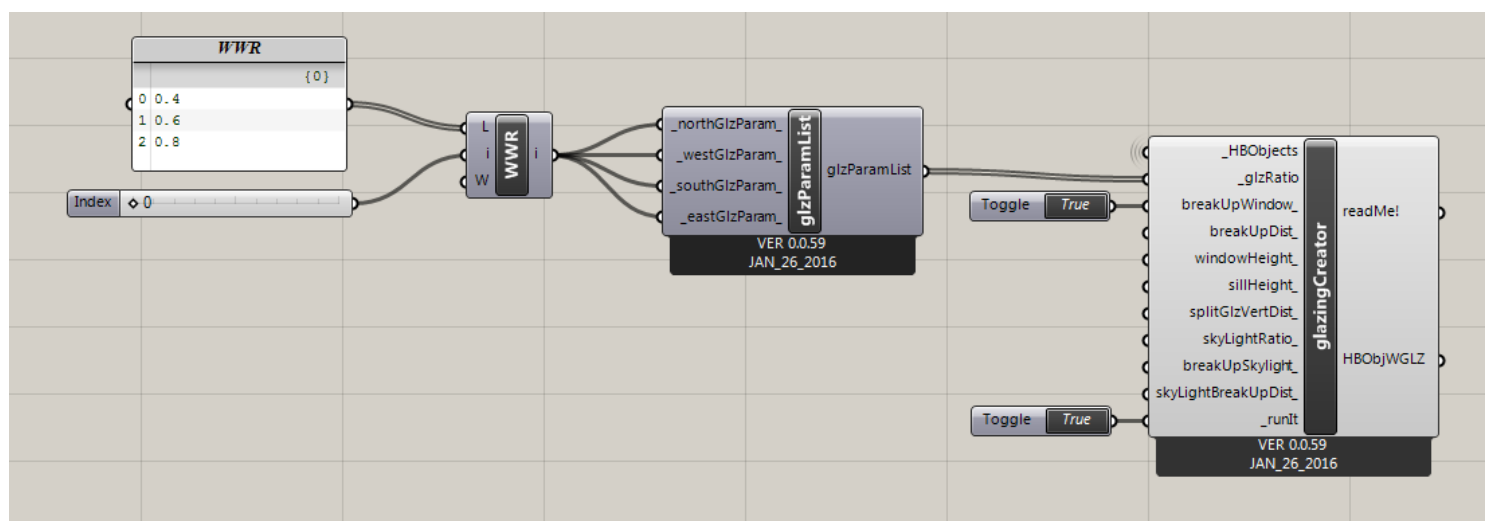

Figure 15 Parametrically changing the Window to Wall RATIO (WWR) OF the COMPONent WHICH CREATES THE WINDOWS IN THE HONEYBEE MODEL

The data from the parametric simulation is recorded using data recorded components that record the results into a list. The pollinator component takes these lists of results and creates a csv file to be read online by Pollination. Figure 16 provides an example of the interface of Pollination.

The Pollination results reader allows the user to determine design options moving forward. Figure 17 illustrates an example of a given criteria where the only things changed are equipment, lighting and occupancy density loads, and where the adaptive thermal comfort percentage as a result in the design should never be below $50 \%$. Hence, the criteria outlines some options which the designer can take for loads, 
knowing that these loads in their combination would provide the sufficient level of thermal comfort.

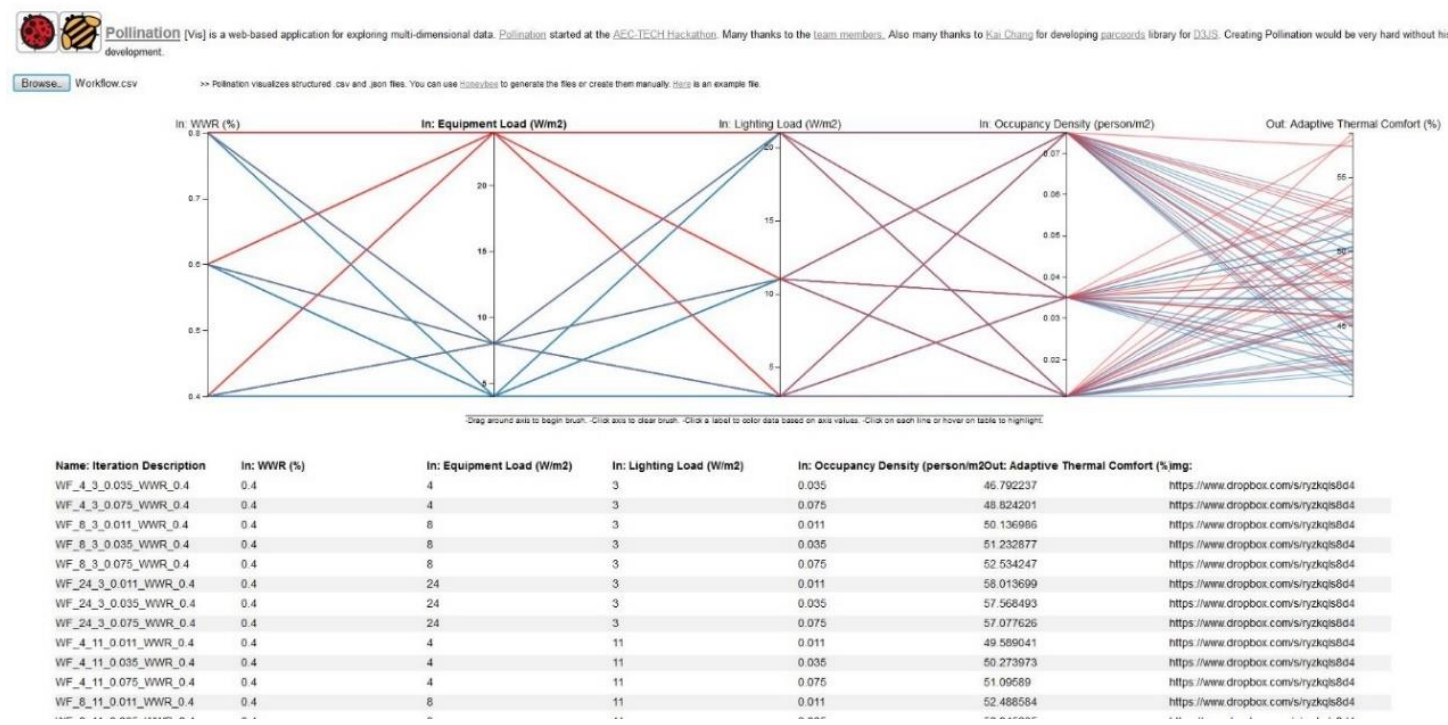

Figure 16 Example of the Pollination result ReAder (SADEghipour Roudsari, 2016C)

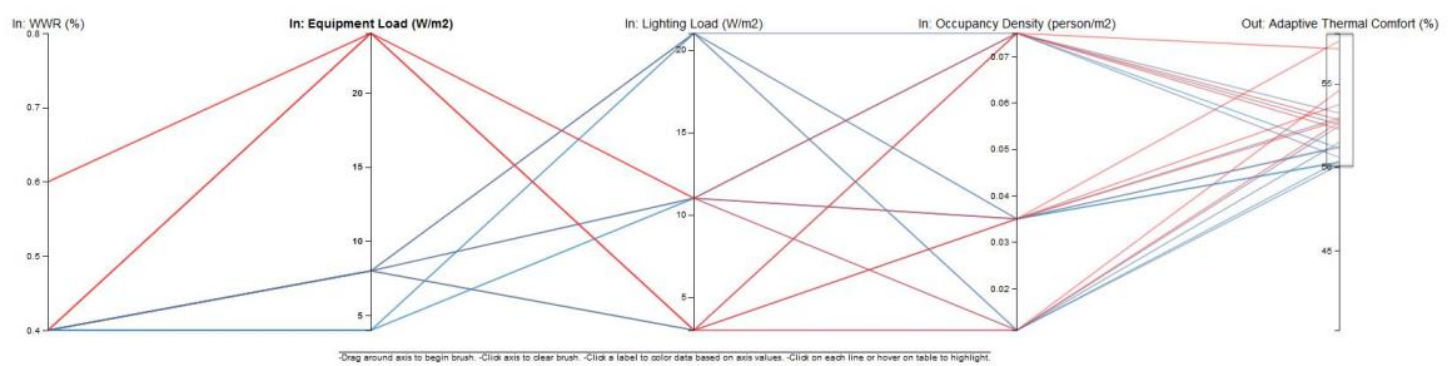

FIGURE 17 EXAMPLE OF ISOLATING CRITERIA

With these processes of the workflow outlined and described to the participants of the study, the participants are provided with a foundation to provide feedback. This workflow in particular focused upon demonstrating to the participants how the DMM can address the recommendations for future tool development in literature, to provide rapid comparison of early design concepts "with flexibility, ease and speed" (Donn et al., 2012). 


\subsection{Data Collection: Focus Group Interviews}

To obtain feedback from the New Zealand building industry in regards to their views on the feasibility of building performance sketching using the distributed model method (DMM), the research design required a method which would question participants regarding their opinion and attitudes towards the topics within the study. The key differential of the study was that the participants had to be demonstrated the topic of focus, thereby required them to be grouped in one location. As it was not the focus of the study to determine how many professionals 'hold' a certain opinion, but rather to gain feedback as a range of answers for future tool development, a qualitative approach was necessary. The common forms of qualitative methods to achieve this is through the use of interviewing techniques (Morgan, 1995).

This section of the chapter describes in detail the considerations of designing focus group interviews of three groups: architects; engineers; and a mixture of both. The key considerations in selecting both the method, and the structure of the groups were to answer the research questions by providing a means to differentiate the answers from the two different users. In this, the research question was answered in depth, with guidance for future tool development from two different perspectives. Furthermore, gaining a 'statistically representative' answer to the research questions from the building industry through the use of surveys would not have provided in-depth answers to why certain factors are important, which was invaluable for this study.

\subsubsection{Interview vs Group Interview}

The decision between using a group interviewing method over a singular interview method was based off of the need to understand the important factors to the attitudes and experiences of participants from the same professional field.

The use of group interviews has a long history in qualitative research (Hargreaves, 1967; Willis, 1977; Hammersley \& Woods, 1984). The focus group is distinguished from the broader category of group interviews by the explicit use of group interaction to generate data (Kitzinger \& Barbour, 1999). Instead of an interviewer asking questions of each person in turn, a facilitator is present to encourage participants to discuss a specific set of issues or answers to a posed question amongst one another. In this method, participants engage in interactions which can be both complementary (such as common experiences) and argumentative (such as questioning and disagreeing with each other). This synergy is defined by Carey \& Smith (1994) as the "group effect", and can offer valuable data to the researcher as to what is seen as most important to arrive at an answer (Morgan, 1995). It is used best to explore how points of view are constructed and expressed around certain experiences around specific topics. In the context of this study for example, the information gathered from one individual may provide some constructive feedback, but the information from a group of individuals 
with the same background would provide more depth to the feedback provided. This would be due to the discussion of the feedback provided which may highlight specific factors seen as more important in arriving at an answer (e.g., is cost of changing programs seen as a greater barrier to adoption than the cost of learning the program? Why?). These issues may be raised by the group in response to an individual's contribution, or by a question posed by the facilitator. Either way, it allows for a sense of consensus to a question or to highlight why a certain topic might not have one specific answer, depending on external factors (e.g., budget costs or technological development).

A group interview method was also chosen over a singular interview method as being more practical due to the logistics of meeting with the participants. The workflow discussed earlier was presented to the participants in the study via a workshop demonstration. The participants were invited to 'play' within the program, Honeybee, in order to get a sense of the practical use of such a workflow within parametric design and the speed of its interoperability features directly before the focus group session. A computer room facility was made available for use through the Victoria University of Wellington's Architecture Department, thereby having the participants of their category present. If a singular interviewing process were to be applied, participants would be required to wait for their turn. In the process of waiting, participants would need to be separated from one another in order to prevent them from discussing the workflow. This would be important for the process of interviewing the participants singularly because the opinion of the individual may be influenced by another participant who happened to discuss the topics with the individual before-hand without it being recorded. Furthermore, due to the availability of the computer facility and time constraints, it was not be possible to conduct several singular interviews.

Though the focus group method enables a better procedure to collecting the necessary feedback to achieve the objectives of this study, it is not without its faults. There are several advantages and disadvantages to the method - discussed and addressed within the following section.

\subsubsection{Advantages and Disadvantages of Focus Group Interviews}

The greatest advantage to the use of the focus group method is the opportunity it presents to collect rich experiential information and verification of information through group interaction (Carey \& Smith, 1994). In a simple interview process, the participant is not presented with different perspectives which may allow them to reevaluate their answer. Within a focus group setting, the researcher is not only able to receive an answer from an individual and/or group, but is also exposed to which factors may have influenced an individual to change their mind thereby informing the researcher that such a factor is considered important. Without directly asking about 
the importance of such a factor within an interview, the researcher may never have received this level of information.

However, there are several disadvantages to focus groups that could affect the quality of collected data and the logistics of running a focus group.

The most obvious disadvantage to the focus group method is the potential impact of censoring and conforming within a group (Carey \& Smith, 1994). Less confident individuals may change their opinions about certain topics because the majority of the group have that viewpoint, rather than for a strong reason. Furthermore, psychological factors, such as not wanting to speak up against someone else's views, can limit the quality of the data. In an attempt to address this issue, the structure of the focus group within this study included the requirement to write down the answers to a question posed by the facilitator first before the question is discussed. In so doing, when an individual changed their opinion it was firstly noted that there had been a change in opinion and it allowed the facilitator to enquire why they had changed their opinion.

Another pitfall of the focus group method was the logistics of running and collecting data. These disadvantages are presented here in the time line of a focus group method:

1. Recruitment - Gathering experts within the field to one spot can pose a problem of facility space availability and ensuring a comfortable environment for the number of participants. Furthermore, the need to travel to a certain location, and the intimidation of having to speak up to a group of potential strangers in their network, can discourage attendance.

2. Hosting a focus group - A facilitator is a person who ensures constant flow and discussion within the group, as well as keeping order and control where necessary. The facilitator must also be someone who has prior knowledge of the topic discussed in order to intervene within the focus group where necessary, or know when to keep quiet. As is recommended and discussed later in this section, to ensure reliable results the analyst should be present at the focus groups. Due to the scope and available resources of this study, the lead researcher was both the facilitator and the analyst for the focus groups. The disadvantage in this was the level of experience as a facilitator for focus groups the lead researcher had. However, Morgan (1995) commented that the experience of the facilitator should be of little concern within the preparation for focus groups. Morgan (1995) stated,

"Focus groups are relatively robust with regard to facilitator problems. In particular, participants typically will do a lot to help a facilitator out of trouble...given a well-selected group of participants and well-crafted questions, 
even relatively inexperienced facilitators will produce useful results most of the time"

(Morgan, 1995)

Other researchers like Kitzinger \& Barbour (1999) commented that a 'freer' more dynamic group could produce 'better data' than a rigidly structured, formal group. This is supported by the finding that spontaneous discussion often results in valuable information regarding the interests and important factors of concern within a group. However, to encourage discussion some studies suggested the use of photographs or diagrams to allow group discussion without the need for the facilitator to provide input. Other exercises such as group activities involving ranking or assigning topics can encourage participants to concentrate and engage one another. This in particular may force participants to explain and defend their differing perspectives which may be invaluable to the research. This approach was used in this study for these reasons.

3. The collection of data - Though in individual interviews it is always clear who is speaking, in group interviews the speaker can sometimes be blurred or unrecognisable during heated, and ironically essential, discussions. Regardless of what recording method is used, if several people talk at once during a lively discussion, the recording of what each is saying can be obscured. For this reason, even the best recording and transcription will not reproduce a session completely (Kidd \& Parshall, 2000). In an attempt to reduce the likelihood of lost information, an additional person from the research team was present at the focus group to keep notes which then later were compared to the transcription for additional information. 


\subsubsection{Focus Group Preparation}

The group size justifications, types of participants, composition of groups and the proposed focus group questions are discussed here within their respective sections.

\subsubsection{Types of Participants}

The study aimed to gain feedback from architects and engineers within the New Zealand building industry. Two particular issues were considered in the selection of participants within this study's focus group preparation: the notion of 'naturallyoccurring' groups; and the need for diversity in experiences.

The types of groups and their compositions are discussed later, though it is noted here that the groups followed a homogeneity composition. This was due to the consideration of having a group of people who already know each other, or would be exposed to each other within their network. These groups were people from their own networks, were people normally discussed the sorts of issues raised in this study, classified as a 'naturally-occurring' group which was noted to be "...one of the most important contexts in which ideas are formed and decisions made" (Kitzinger \& Barbour, 1999).

Many focus group sampling processes look towards considering age, gender, ethnical background and experience. For the purposes of this study, gender and ethnical background were used as sampling criteria. The only requirement was the need to have worked, or be exposed to, the design process within New Zealand's building industry for at least three years (including studies). Age was a small consideration, where it was the intention of the study to have a mixture of experiences in each group of practitioners. This allowed the limitation of age to not exist, as most comments made across the groups were similar, regardless of age.

The participants were part of different practicing firms/companies. This factor was due to the assumption that each firm/company would have a different process, budget for new programs or differing attitude towards spending more time and resources in order to use BPS to inform design decisions for high performance building design. The firms which participants were chosen from were selected due to the following criteria:

- Public 'sustainable' image from their website determined by the level of which they advertise 'high-performing' buildings

- The list of contributing firms to all buildings which have received Green Star ratings in New Zealand

- Availability of participants to attend a five-hour workshop/focus group event 
Due to the confidentiality agreements between participants, the names of the individual representatives and their firms are not mentioned by name, or provided means to be identified in any way.

\subsubsection{Focus Group Size}

The exact recommended number of focus groups within a research project, or the particular size of each focus group, ranges from three or four groups to well over fifty (Kitzinger \& Barbour, 1999). One orthodoxy from market research literature highly recommends a number of participants between 8 and 12. Kitzinger \& Barhour (1999) states that the appropriate number of focus groups will entirely depend on a few limiting factors: the research question; the range of people required; and time and resources. The determination of the 'appropriate' number of focus group participants does not have an aim of being statistically 'representative' of a given sample. Rather, the research method relies upon 'qualitative sampling' in order to compose a structured rather than random sample. This is often due to the need to mitigate the disadvantages of the focus group method, namely the issue of having domineering or quiet participants.

The study followed the recommendations from Morgan (1995), where it was stated that fewer participants would provide more opportunity to both tell and compare their stories in detail. This is particularly important when the participants are experts or people in authority, as Morgan (1995) commented, "They may become irritated if they do not have enough time to say what they feel is important". In respect to this, each focus group within this study aimed for four to five participants in each group, resulting in five participants in each.

\subsection{Recruitment}

Given the aim for four to five participants, the research design followed a simple recruitment process to ensure participation. A common error documented by Morgan (1995) is the lack of priority many researchers give towards recruitment. As it is the most essential step within the method of conducting a focus group, this study took extra care to ensure participation from the different professions within the building industry.

Contacts within the building industry were initially emailed to determine their level of interest in the program. Architecture firms within New Zealand were given the opportunity to register their interest through the New Zealand Institute of Architects (NZIA). For engineers and students, the lure of learning a new program which may emerge within their field was used to gauge interest. For architects, the idea of being introduced to an addition to the design process, and the incentive to receive CPD (Continual Professional Development) points from participation, was used. This incentive was also used as an attempt to reduce the limitation of bias towards those 
who wanted to do performance sketching, and those who did not. Each participant who had registered interest were told that they would be contacted later as a reminder with more information. A reminder was given to each participant via email two days before the event.

As a 'final line of defence', an over recruitment process was used. The rule of thumb for over recruitment in the focus group method is stated to be to invite two more potential participants than is needed (Morgan, 1995). This over recruitment helped to ensure the aim of four to five was reached - one architect had slipped off after the workshop before the focus groups, and one architect and one engineer in the Auckland group had to rush off to an unscheduled client meeting.

\subsubsection{Group Composition}

Another form of collecting valuable data from the focus group method is having different focus groups which may produce significantly different results due to the participants' differing background and experiences. This technique may produce results which illustrate the impact of the differing disciplines, or may present findings which indicate that differences in discipline and location do not matter. This in particular would inform the researcher and the conclusions of the study that factors to implementation may or may not be seen as important across all professions. Bringing people together with the same shared experiences will allow for the most productive of groups, however differences between participants are often illuminating.

This study was particularly interested in the feedback provided by the professions within the building industry who directly work within the design process of the early stage of design. The study thereby had homogeneity in the first two focus groups, with the intention that the information from each group could be compared against another group of a different profession. In this comparison, it became clear what the priorities were from each profession.

The groups were segmented depending on their profession. The theoretical reason for segmenting in this way was that it facilitated an analysis of similarities and differences across the groups which represented different points of view (Morgan, 1995). The technical reasons were the most obvious for preparing a well-constructed focus group: have participants of similar backgrounds (same company/network) to maintain an active and free-flowing discussion. This allowed for a more 'naturally-occurring' group. However, the one of the main drivers for this segmentation of disciplines in this study is due to 'theoretical sampling' in analysing the data produced.

\subsection{Theoretical Sampling}

The process of theoretical sampling originally belongs to the grounded theory method (GTM)(Glaser \& Strauss, 1967). This approach to data collection was applied within this study primarily to test emerging concepts from the previous focus groups. The 
focus groups were therefore conducted in sequence, and varied depending on discipline and location. A student group was initially used to test the interview guide (refer to Section 3.4. for more detail) and the analysis process.

Emerging concepts from the student group were thus tested on the architecture group using the developed coding scheme. Emerging concepts from the architecture group were then tested on the engineering group. The difference in disciplines were assumed to produce different results, but emerging concepts from the architectural group were incorporated at the end of the interview guide for the engineering group to test their views and opinions on the specific concept. This was done at the end of the interview guide in order to: a) determine whether or not the group raised the same concept without prompting and $b$ ) to ensure the introduction of the concept by the facilitator did not pollute the entire focus group session. The concepts from both the architecture group and engineering group were tested upon the Auckland mixed group to: a) determine again whether or not the concept emerged from a mixture of disciplines, b) determine whether the mixture of disciplines had an effect on what the participants felt comfortable discussing. Perhaps the emerging concepts from each segmented groups were sensitive to the 'opposing' group and c) determine whether or not the mix of disciplines would produce any counter arguments which may prove to be valuable for the study. These focus groups included professionals from the two cities, Wellington and Auckland, to ensure equal opportunity for the majority of architects and engineers within New Zealand to participant within the study.

Data was determined to be 'theoretically saturated' as no new concepts emerge from the final data collection of the mixed group (Glaser \& Strauss, 1967).

Hence, the focus groups were split into three categories: five Architects (Wellington); five Engineers (Wellington and Auckland); and a mix group of two architects and three engineers (Auckland).

\subsubsection{Confidentiality and Ethics}

The politics within the design community between different firms were considered within the structuring of focus group questions and the overall research design. Unlike interviews, participants from focus groups cannot be guaranteed that confidences shared in the group will be respected, particularly if participants are part of the same network (Kitzinger \& Barbour, 1999). Ethical issues such as these were addressed through setting ground rules prior to the group meet.

Participants were made aware of these circumstances, and were asked to sign consent forms for confidentiality at the beginning of the focus group session. Due to the confidential nature of this study, no information is provided to identify the participants and the names of the firms which the participants represent are not reported. Only their profession is reported for the sake of comparison. 


\subsubsection{Focus Group Question Design}

The questions addressed by the participants within the focus groups followed the recommendations from literature to use "...nondirective questions to elicit spontaneous expression among participants" (Morgan, 1995). The questions were constructed to focus the participants on the potential issues surrounding performance sketching, and how certain features of the general act of performance sketching might be improved to encourage its use, and therefore implementation, within the design process. Careful consideration of sequencing and the potential for one question to answer another was made and tested within a trial process, explained later within this thesis.

It was essential to limit the number of structured questions asked within the focus group due to time constraints and expert audience. Given an allocated time of 1-2 hours for the focus group session, only six questions were asked. The structure of these six questions were designed to lead the participants towards a certain focus within the broad topic of building performance simulation. To begin, participants were asked to consider the greatest barriers within their practice that would need to be overcome in order to implement performance sketching into their typical design process and write them down on cards to display to the rest of the group. In forming a set of answers to work with, the group are then encouraged to discuss amongst themselves which of the barriers would be the most significant in the New Zealand industry by ranking them greatest to least. These two questions indirectly resulted in the participants challenging each other's views of the barriers within the current industry, and allows the researcher to determine which factors are the most important in deciding whether or not a barrier is greater than the other, or to be considered of equal importance and why.

This strategy was employed due to three main reasons: (a) to provide possible answers which may align with the findings of Attia et al (2012) specific to the barriers perceived in the use of simulation, (b) to minimise the potential limitation of having an inexperienced facilitator, and (c) to ensure all participants take part in providing an answer.

The focus group questions continued to lead the participants in the direction of considering the physical use of performance sketching, whereby question three asked which features of performance sketching should be improved to overcome their determined barriers. In this question, the participants were encouraged to consider the use of the DMM given Honeybee as an example, and form an answer based upon their attractions or deterrence's of performance sketching using this method. This question was open-ended and participants were expected to mention certain features mentioned by the findings of Attia et al (2012) to be attractive to the use of BPS tools. In their discussion, the participants were hypothesised to breach the issues regarding 
the value of what performance sketching could offer, leading onto the next question which contained another activity. This question was structured as an activity to encourage once again an answer from every participant and to expose participants to certain qualities of performance analysis documented within the academic field, but hardly used within practice. In the act of ranking them, the participants once again provided invaluable information to the researcher on the important factors to the ranking process.

Finally, the focus group was ended with a lasting question on the opinions of the participants regarding the DMM and its ability to lead performance sketching to future implementation. This question directly answer the research question, "Can the use of the distributed model method (DMM) overcome the barriers to implementing performance sketching within the design process as perceived by the New Zealand building industry?" and summarised any indicative answers to the question built up from the previous questions.

\subsection{Pretesting the Interview Guide}

In order to develop the interview guide, familiarise the facilitator with the process of a focus group, and test the logistics of the interview guide, a trial run of the method was conducted on three $5^{\text {th }}$ year students and one PhD student from the Victoria University of Wellington's School of Architecture. Within the test trial, two building science students, one computer science PhD student studying building science and one architecture student were invited to participate. The selection of these students were based on the need for feedback from all aspects of the interview guide, where the architecture student may comment on the inability to understand the performance assessment process, the building science students may comment on the need for more questions and the computer science student can comment on the workshop's flow and structure. Feedback was sought regarding:

a. The structure and process of the workshop: whether or not the workshop for Honeybee and the performance sketching process could be understood. The participants within this study would have little to no experience with the program due to limited introduction to the industry. It is essential therefore that the workshop demonstrating the use of this program, and by extension an application of performance sketching, be communicated well enough to allow participants to conceptualise how performance sketching could work for them.

b. The structure and wording of focus group questions: pretesting the questions with the students allowed the facilitator to realise which questions require further clarification, which questions have already 
been answered by earlier questions, and which questions may result in irrelevant information for the purposes of this study.

c. The need for more questions: in pretesting the interview guide, concepts emerge from the participants which may not have been considered during the design of the questions. These concepts, which are significant to the study, would be added to the interview guide to test for data saturation and/or verification.

d. Testing the logistics of running the interview guide: with a three-hour workshop, lunch break, focus group and signing of consent forms, it was essential to have a trial run in order to ensure the facilitator is familiar with the process and be ready to rectify any uncontrollable variables which may come up during actual data collection.

\subsubsection{Lessons Learnt from Student Trial}

The interview guide was edited after the student trial based upon their feedback and the issues raised during the workshop and focus group sessions.

Preparation: Participants responded well to having everything set up for them within the computer program, however the signing of the consent form, and looking over the participant sheet was changed to be done at the very beginning of the workshop. This session resulted in the participant sheet being attached to the reminder of the event email for participants to read over outside of the workshop.

Workshop: The following changes were made to the workshop structure:

- A brief tutorial of the basics of Grasshopper was included for those participants with no experience using the program.

- Template exercises were created to include all components, rather than asking the participants to search for the components themselves while keeping up with the instructor - students indicated that finding the components amongst the endless amount of components was overwhelming, and though it conveyed the complexity of Honeybee and the capabilities well, it was too much for a beginner level.

- Setting modules and having a timer for when each module was expected to be finished helped to keep on time for the workshops

- Finishing earlier rather than going overtime was preferable, as two hours of Honeybee was already enough to overwhelm the participants and the participants believed they were given sufficient information to answer the focus group questions

Focus Group: The following recommendations were made in restructuring and editing the focus group session: 
- Recommended to have the workflow demonstration AFTER lunch so that everyone is refreshed and the focus can be put on performance sketching instead of Honeybee

- The facilitator needed to respond less with comments such as "right", "exactly", "true", as a neutral party.

- Audio should be placed a little closer to the participants or they need be asked to speak up more if the facilitator felt they are being too quiet

Having four participants was more than enough for a decent discussion, given that two were very dominant and had very different backgrounds. Due to time constraints, one question was removed that was found to generate repeating answers from previous questions. 


\subsection{Focus Group Data Analysis}

In selecting a method for analysing the data of a focus group interview, the key considerations were the selection of a technique which:

- enabled the comparison of literature and qualitative data

- complimented the comparison of answers from different focus groups

- and provided a means to summarise a large variety of answers to answer the final research question - What must be improved in order to make the integration of building performance sketching feasible within the design process

Thus, this section describes the process of selecting Directed Content Analysis (DCA) as a method of analysing and formatting the data to be comparable to literature findings, and illustrate the difference in priorities, views and opinions of the two different professions: architects and engineers. By comparing the findings to literature, the research design enabled the ability to answer the first research question, "Can the use of the distributed model method (DMM) address the wants and wishes of users for tool development?" Furthermore, by providing a means to represent the differences of the professions views and opinions, the last research question can be answered with in-depth responses.

\subsubsection{Types of Qualitative Analysis Methods}

Qualitative analysis emerged primarily as a framework for exploring the realms of social science and anthropology to capture contextual understanding of human behaviour (Hatch, 2002). Leech \& Onwuegbuzie (2007) explain the use of qualitative research to be "focused on studying phenomena in their natural setting and striving to make sense of or interpreting phenomena with respect to the meanings people bring to them". In the field of psychology, the debate of quantitative vs qualitative rages on due to their entrenchment in their respective positions (Todd, Nerlich, McKeown, \& Clarke, 2004). The ideological or epistemological positions, commonly called paradigms, of the quantitative are accused by qualitative researchers of positivism, reductionism, determinism, and objectivism, whereas the quantitative researcher accuses the qualitative of 'fuzziness' and subjectivity (Todd et al., 2004). To summarise these accusations; their differences are explained as 'measurement vs. meaning' (Todd et al., 2004; emphasis in original). Much of the arguments surround the idea of validity and reliability of qualitative data, as the qualitative approach is reflexive in nature (acknowledging that the researcher holds a central position in the construction of knowledge) and relies much upon the interpretation of the researcher to the meaning of the research data. Table 2 below tabulates a quick summary of the differences between the two methods. 
TABle 2 Qualitative vs Quantitative Research

\begin{tabular}{|c|c|c|}
\hline \multicolumn{2}{|r|}{ QUALITATIVE } & QUANTITATIVE \\
\hline PURPOSE & $\begin{array}{l}\text { To describe a situation, gain } \\
\text { insight to particular practice }\end{array}$ & $\begin{array}{l}\text { To measure magnitude - How } \\
\text { widespread is a practice }\end{array}$ \\
\hline FORMAT & $\begin{array}{l}\text { No pre-determined response } \\
\text { categories }\end{array}$ & $\begin{array}{l}\text { Pre-determined response categories, } \\
\text { standard measures }\end{array}$ \\
\hline DATA & $\begin{array}{l}\text { In-depth explanatory data from } \\
\text { a small sample }\end{array}$ & $\begin{array}{l}\text { Wide breadth of data from large } \\
\text { statistically representative sample }\end{array}$ \\
\hline ANALYSIS & $\begin{array}{l}\text { Draws out patterns from } \\
\text { concepts and insights }\end{array}$ & $\begin{array}{l}\text { Tests hypotheses, uses data to } \\
\text { support conclusion }\end{array}$ \\
\hline RESULT & $\begin{array}{l}\text { Illustrative explanation \& } \\
\text { individual responses }\end{array}$ & $\begin{array}{l}\text { Numerical aggregation in summaries, } \\
\text { responses are clustered }\end{array}$ \\
\hline SAMPLING & Theoretical & Statistical \\
\hline
\end{tabular}

In the field of building science, this study used qualitative research as a means to obtaining in-depth insight on the particular experiences or views of the architects and engineers from the New Zealand building industry.

The challenges faced within this study related to the selection of data analysis method for focus groups interviews. Onwuegbuzie et al. (2009) observed that few specific frameworks exist within current literature to guide the analysis of focus group data. Nearly all papers which provide reviews of qualitative research analysis methods comment on the apparent lack of studies which explicitly explain how the analysis is undertaken (Onwuegbuzie et al., 2009). Consequently, there are many kinds of qualitative research methods due to each researcher's view on how the analysis is meant to be done, each with its own characteristic that developed and originated from the earliest formalised qualitative data analysis techniques conceptualised in 1960s (e.g., constant comparison analysis; Glaser \& Strauss, 1967) and the 1970 s (e.g., domain analysis, taxonomic analysis, componential analysis; (Spradley, 1979)). Infact, Leech \& Onwuegbuzie (2005) identified 21 different qualitative data analysis techniques, some of which seem similar enough to practically be the same method. In exploring the different methods in coding, Saldana (2012) commented that each and every method are chosen and adapted depending on the research question and research context. The noted methodologist, Michael Quinn Patton (2002), believed that, due to each qualitative study being unique, the analytical approach used would be unique. This vague statement of qualitative method selection creates a challenge for the new qualitative researcher to determine which method may be 'best' suited for their study. Luckily, there exists practical guides such as Saldana's (2012), "The Coding Manual for Qualitative Researchers", which provide advice on the appropriate 
selections of analytical methods for the purposes of answering the study's research question.

The following table presents a comparison and brief review of the various qualitative data analysis techniques available and applicable to focus group data analysis. Each technique is briefly introduced and presented in Table 3 in terms of its use within qualitative research and the steps involved for analysis, for more information the reader is encouraged to refer to the referenced material for each technique.

TABLE 3 BRIEF DESCRIPTION OF APPLICABLE QUALITATIVE DATA ANALYSIS TECHNIQUES

\begin{tabular}{|c|c|c|c|}
\hline QUALITATIVE METHOD & USE & PROCESS & REFERENCE \\
\hline $\begin{array}{l}\text { CONSTANT } \\
\text { COMPARISON } \\
\text { ANALYSIS (CCA) }\end{array}$ & $\begin{array}{l}\text { Can be } \\
\text { deductive, } \\
\text { inductive or } \\
\text { abductive in } \\
\text { coding an } \\
\text { entire dataset } \\
\text { to identify } \\
\text { underlying } \\
\text { themes. } \\
\text { Originally part } \\
\text { of Grounded } \\
\text { Theory Method } \\
\text { (GTM) as an } \\
\text { inductive } \\
\text { analysis } \\
\text { method, } \\
\text { constant } \\
\text { comparison } \\
\text { analysis } \\
\text { evolved from } \\
\text { analysing data } \\
\text { collected over a } \\
\text { series of } \\
\text { rounds through } \\
\text { 'theoretical } \\
\text { sampling'. }\end{array}$ & $\begin{array}{l}\text { Open/Initial coding of } \\
\text { data (from data as } \\
\text { inductive, using } \\
\text { concepts/categories } \\
\text { from literature as } \\
\text { deductive or } \\
\text { iteratively as } \\
\text { abductive) and } \\
\text { constantly comparing } \\
\text { coding labels to } \\
\text { ensure proper similar } \\
\text { coding of data. } \\
\text { Selective coding } \\
\text { (grouping data of } \\
\text { similar codes together } \\
\text { based on categories } \\
\text { for research } \\
\text { question). Theme is } \\
\text { identified based on } \\
\text { each grouping. }\end{array}$ & $\begin{array}{l}\text { (Boychuk } \\
\text { Duchscher \& } \\
\text { Morgan, 2004; } \\
\text { Glaser \& } \\
\text { Strauss, 1967; } \\
\text { Leech \& } \\
\text { Onwuegbuzie, } \\
\text { 2007, 2011; } \\
\text { Urquhart, } \\
\text { 2012) }\end{array}$ \\
\hline $\begin{array}{l}\text { GROUNDED THEORY } \\
\text { METHOD (GTM) }\end{array}$ & $\begin{array}{l}\text { A systematic } \\
\text { theory } \\
\text { developed } \\
\text { inductively, } \\
\text { based on }\end{array}$ & 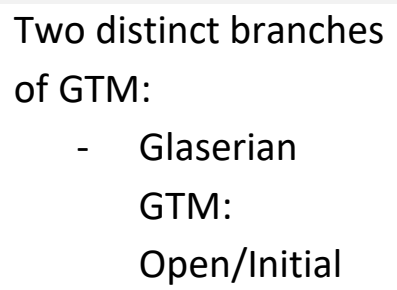 & $\begin{array}{l}\text { (Boychuk } \\
\text { Duchscher \& } \\
\text { Morgan, 2004; } \\
\text { Glaser, 1992; } \\
\text { Glaser \& }\end{array}$ \\
\hline
\end{tabular}




\begin{tabular}{|c|c|c|c|}
\hline & $\begin{array}{l}\text { observations } \\
\text { that are } \\
\text { summarised } \\
\text { into conceptual } \\
\text { categories, re- } \\
\text { evaluated in } \\
\text { research } \\
\text { setting and } \\
\text { gradually } \\
\text { refined and } \\
\text { linked to other } \\
\text { conceptual } \\
\text { categories } \\
\text { through a } \\
\text { process of } \\
\text { constant } \\
\text { comparison } \\
\text { analysis and } \\
\text { theoretical } \\
\text { sampling. The } \\
\text { generation of } \\
\text { theory based } \\
\text { on grounded } \\
\text { data and } \\
\text { theoretical } \\
\text { memoing }\end{array}$ & $\begin{array}{l}\text { coding (CCA), } \\
\text { selective } \\
\text { coding, } \\
\text { theoretical } \\
\text { sampling, } \\
\text { theoretical } \\
\text { memoing and } \\
\text { theoretical } \\
\text { coding } \\
\text { Straussarian } \\
\text { GTM: } \\
\text { Open/Initial } \\
\text { coding (CCA), } \\
\text { axial coding, } \\
\text { theoretical } \\
\text { sampling, } \\
\text { theoretical } \\
\text { memoing and } \\
\text { theoretical } \\
\text { coding }\end{array}$ & $\begin{array}{l}\text { Strauss, 1967; } \\
\text { Strauss \& } \\
\text { Corbin, 1990) }\end{array}$ \\
\hline \multicolumn{4}{|l|}{$\begin{array}{l}\text { CLASSICAL CONTENT } \\
\text { ANALYSIS (CLCA) }\end{array}$} \\
\hline $\begin{array}{l}\text { - CONVENTIONAL } \\
\text { CONTENT } \\
\text { ANALYSIS } \\
\text { (CVCA) }\end{array}$ & $\begin{array}{l}\text { An inductive } \\
\text { approach to } \\
\text { content } \\
\text { analysis, similar } \\
\text { to constant } \\
\text { comparison } \\
\text { analysis in most } \\
\text { ways and } \\
\text { mainly differs } \\
\text { as a result of } \\
\text { counting the } \\
\text { number of } \\
\text { times each }\end{array}$ & $\begin{array}{l}\text { Open/Initial coding of } \\
\text { data, creation of } \\
\text { coding scheme from } \\
\text { emerging codes, } \\
\text { categorisation, } \\
\text { comparison of existing } \\
\text { theories }\end{array}$ & $\begin{array}{l}\text { (Hsieh \& } \\
\text { Shannon, } \\
\text { 2005; Leech \& } \\
\text { Onwuegbuzie, } \\
\text { 2005, 2007) }\end{array}$ \\
\hline
\end{tabular}




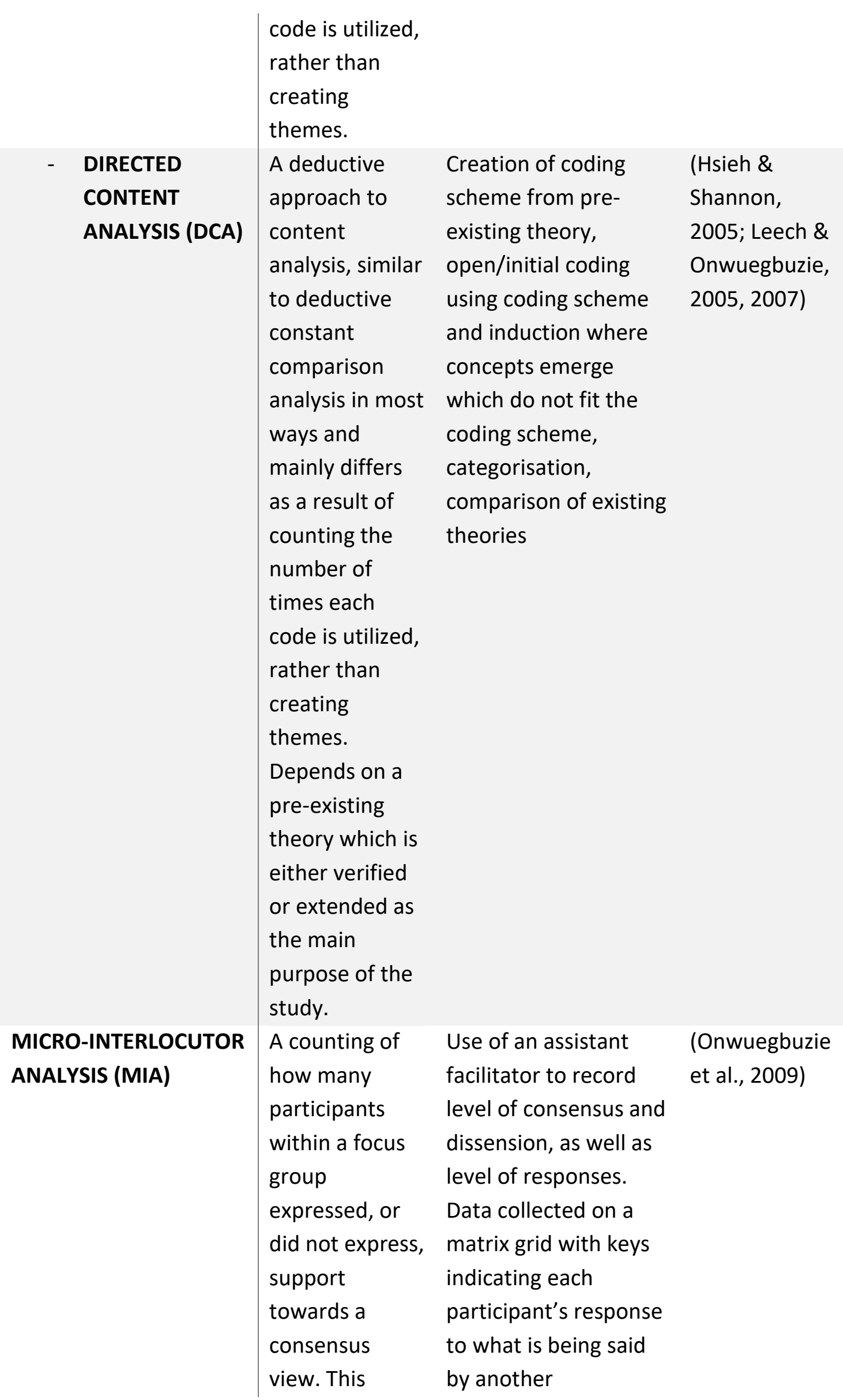




\begin{tabular}{|lll} 
analysis aims to & participant. Refer to \\
present & reference for \\
additional & example. \\
information & \\
regarding & \\
emerging & \\
themes, and to & \\
help to validate & \\
any inferences & \\
made about & \\
the level of & \\
consensus & \\
Defining & Immersion in data, \\
concepts, & Thematic framework \\
mapping range & (open coding \& \\
and nature of & memoing), Indexing \\
phenomena, & codes, charting \\
creating & (grouping categories), \\
typologies, & mapping and \\
finding & interpretation \\
associations, & \\
providing & \\
explanations, & \\
and developing & \\
strategies & \\
&
\end{tabular}

For the sake of brevity, this section does not compare and describe the use of qualitative data analysis techniques focused on human culture or social behaviour. Specifically, methods which analyse the way conversation is structured to make an argument (conversation analysis), analysis that focus on cultural behaviour (ethnography), or analysis which studies the idea of symbolic cultural significance (domain analysis, and by inclusion, taxonomic and componential analysis as these depend on the use of domain analysis (Spradley, 1979)) as these methods would not produce a means to answer the research questions. It was not the intention of this thesis to analyse how architects and engineers discuss topics amongst themselves as a social study. The specific background and experiences of the participants might very well produce interesting insights, but it was not the intention of this thesis to consider how a participant from India, for example, would communicate to a participant from New Zealand. Further, this section does not present a full review of the methods, but instead discusses the merits and weaknesses of each analysis technique for the sake of selection justification in Table 4. 
The majority of existing qualitative data analysis methods centre on the focus of human interaction, culture, behaviour and attitudes. Due to the elimination of these analyses techniques, the few analyses left to compare all originate from processes established by Grounded Theory (Glaser \& Strauss, 1967).

Grounded theory was 'discovered' by Glaser \& Strauss' pioneering book, 'The Discovery of Grounded Theory' in 1967 as a response to the author's irritations that most researchers of that period only follow the methods addressed by the 'great men' of research, rather than challenging them. Their greatest ambition was to encourage young sociologists to 'generate' theory rather than verifying 'grand theory'. The method of analysis in generating grounded theory, The Grounded Theory Method (GTM), primarily uses an inductive approach to coding and connecting categories to build relationships between constructs. The heart of GTM is the process of constant comparison analysis, where the researcher must constantly compare instances of a data labelled as a particular category with other instances of data in the same category. Urquhart (2012) explained it as a rule of thumb, where the researchers must constantly ask themselves, 'How does this instance labelled as X compare with all the other instances labelled as $X$ '? Through the process of constant comparison analysis, theoretical saturation occurs when no new concepts emerge from the data. The specific processes of GTM differ between the two distinct strands: Glaserian and Straussian. These two distinct strands of GTM split from the core when Glaser wrote a correctional rejoinder, 'Basics of Grounded Theory Analysis: Emergence vs. forcing' (1992), as a response to Strauss \& Corbin's published book on the procedures and processes for generating grounded theory (1990). Glaser believed that the method of analysis described by Strauss were too restrictive and forced concepts into preconceived moulds. The two fundamental differences between the two strands revolve around this idea of emergence vs forcing data:

- Glaserian and Straussian have two distinct processes which illustrated their philosophical ideals of generating data:

- Glaserian: Open coding, selective coding, theoretical coding

- Straussian: Open coding, axial coding, selective coding and coding for process

- Straussian recommended the use of a coding paradigm and the 'conditional matrix' that are designed to provide ready-made tools to assist the conceptualisation process. Glaser objected, stating that to 'force' coding through one paradigm and/or down one conditional path ignores the emergent nature of the method.

Urquhart (2012), among other researchers of the turn of the century, noted that most methods which analyse data for emerging concepts, patterns and relationships derived from Grounded Theory but lack the last missing step in generating theory. The varying methods differ from one another due to these strands of GTM and the 
processes, which the emerging methods preferred for their studies. This is demonstrated in the comparison between Constant Comparison Analysis (CCA), Framework Analysis (FA), and the approaches to Classical Content Analysis ( $\left.C_{L} C A\right)$. Whether they have differing names for the processes involved, all of the above follow the same underlining process, depending on the approach to coding. These methods have been adapted from GTM to suit the differing research question and/or as a response for validity and reliability of data as qualitative researchers continue to justify themselves against the positivists quantitative researchers.

This study aimed to answer its research question by firstly comparing the answers from participants of a focus group to current literature findings, and then analysing the differences of the focus groups in their answers to the second research question. The main objective of the study was to discover emerging concepts, categories and/or relationships produced by a group of professionals when these individuals were exposed to an emerging method of design and performance sketching in order to extend the findings in literature.

Therefore, the analysis technique implemented within this study followed a deductive approach based on current theory, but allowed for inductive coding to establish new emerging concepts. This reliance on pre-existing theory from literature, largely focused around the findings of Attia et al (2012) described in Chapter Two, eliminated the use of Grounded Theory Method (GTM) and the purely inductive approach to Classical Content Analysis ( $\left.C_{L} C A\right)$ as the driving research method of this study. GTM heavily relies upon the researcher being untainted by preconceived ideas while coding, in order to be sure that concepts emerging from the data are 'grounded' by the data. This, in its logistics, can be one of the largest weaknesses to justifying the use of GTM, as most students undertaking dissertations such as this study must present proposals based on literature.

Thus, the study required an analysis method which used a deductive approach based upon literature. This by definition left the following qualitative data analysis techniques open for use: Constant Comparison Analysis (CCA), Directed Content Analysis (DCA), and Framework Analysis (FA).

CCA, DCA and FA are largely similar in that they all use pre-existing theory to establish a coding scheme, use open/initial coding for inductive and deductive code labelling, and group these codes into predetermined categories and emerging categories. CCA emphasises the need to compare coding labels throughout the process of coding to ensure validity of codes across the analysis, and includes a process of 'theoretical sampling', where additional data is collected to reach 'theoretical' data saturation. DCA emphasises the need for counting, a mixed-method use of both qualitative and quantitative to provide additional information to the emergence and importance of concepts within the analysis. FA differs from the rest in its emphasis for mapping in 
order to illustrate the relationship between categories and their meanings for interpretation.

TABle 4 StrengthS AND WeAKNesSES Of FILTEREd QualitATIVE dATA ANALYSES

\begin{tabular}{|c|c|c|}
\hline QA TECHNIQUE & STRENGTHS & WEAKNESSES \\
\hline $\begin{array}{l}\text { CONSTANT COMPARISON } \\
\text { ANALYSIS (CCA) }\end{array}$ & $\begin{array}{l}\text { Code labelling validity and } \\
\text { process for data } \\
\text { saturation }\end{array}$ & $\begin{array}{l}\text { Coding based on } \\
\text { researcher's } \\
\text { interpretation }\end{array}$ \\
\hline $\begin{array}{l}\text { DIRECTED CONTENT } \\
\text { ANALYSIS (DCA) }\end{array}$ & $\begin{array}{l}\text { Counting of concepts } \\
\text { within the categories to } \\
\text { provide additional } \\
\text { information }\end{array}$ & $\begin{array}{l}\text { Coding based on } \\
\text { researcher's } \\
\text { interpretation }\end{array}$ \\
\hline $\begin{array}{l}\text { FRAMEWORK ANALYSIS } \\
\text { (FA) }\end{array}$ & $\begin{array}{l}\text { Mapping and charting of } \\
\text { categories to enable } \\
\text { better representation of } \\
\text { the processes followed } \\
\text { within research }\end{array}$ & $\begin{array}{l}\text { Coding based on } \\
\text { researcher's } \\
\text { interpretation }\end{array}$ \\
\hline
\end{tabular}

As the above techniques for qualitative data analysis all have the same underlining processes, Directed Content Analysis (DCA) formed the core analysis method within this study complimented by the strengths of each method presented in Table 4 to increase the validity of the findings. Constant Comparison Analysis (CCA), being largely inductive in its approach, was applied where new categories emerge from the data which cannot be matched to predetermined categories from the coding scheme. Furthermore, the process of constantly comparing labels across the entire dataset was used to increase concept validity. Due to the structure of the focus groups, theoretical sampling was implemented to explore further the concepts which emerge from the previous group to reach theoretical saturation. The categories created throughout the analysis were mapped for representation and documentation, following the processes established in Framework Analysis (FA).

Finally, the counting analysis within DCA provided additional information on the concepts which emerge or verify those established by current literature. The weaknesses of all the techniques were accounted for by allowing the participants to verify the concepts and observations made by their statements. More information on the validity and reliability of the qualitative data analysis is provided in Section 3.4.3. 


\subsubsection{Directed Content Analysis (DCA)}

Directed Content Analysis (DCA) is one of the three approaches to classical content analysis (Hsieh \& Shannon, 2005). This analysis approach is deductive in nature, and aims to validate or extend conceptually a theoretical framework or theory. By applying 'deductive category application', the initial coding scheme or relationships between codes can be deduced by the predictions about the variables of interest or about the relationships among variables, depending on the theory and research question. Elo \& Kengäs (2008) describe content analysis as, "a research method for making replicable and valid inferences from data to their context, with the purpose of providing knowledge, new insights, a representation of facts and practical guide to action". This description emphasises the structured and replicable nature of DCA, where a more structured guide than the inductive conventional approach of analysis is created (Potter \& Levine-Donnerstein, 1999). The initial step to DCA involves identifying key concepts or variables from existing theory as initial coding categories. The process follows on to derived category definitions for each category from the theory. This coding scheme is used immediately to code the data in an open/initial coding format. Where data cannot be coded, these instances are identified and analysed later to determine whether they represent a new emerging category, or a subcategory of an existing code (Hsieh \& Shannon, 2005).

The findings of DCA are discussed via visual representation through mapping of categories and ranked order of frequencies.

\subsubsection{Key Limitations of the Analysis}

Fundamentally, the use of theory includes inherent limitations in that researchers approach the data with an informed bias. Hence, the researcher would be biased towards supporting rather than nonsupporting evidence to the theory. Furthermore, an overemphasis of the theory can blind the researcher to other emerging concepts or 'contextual aspects of the phenomenon' (Hsieh \& Shannon, 2005).

To minimise the impact of these limitations, Hsieh \& Shannon (2005) recommend the use of trialling and auditing of the process of creating operational definitions in order to "greatly increase the accuracy of predetermined categories". This process is followed through the use of the student trial mentioned earlier in Section 3.3. The process of refining the analysis technique is described in Section 3.4.2.2.1.

\subsubsection{The Coding Scheme}

To answer the first research question, "Can the use of the distributed model method (DMM) address the wants and wishes of users for tool development?", the data from the focus group interviews had to be made directly comparable to these 'recommendations from literature'. Thus, the coding scheme for DCA was based upon 
the theory from literature that DMM can address all recommendations from literature. These recommendations by (Attia et al., 2012), commented that most barriers would be overcome where certain requirements within the tool are met. These requirements were categorised into five major 'criteria' that BPS tools must meet in order to stand a chance for effective implementation within the design process. These five categories were:

1. Usability and Information Management (UIM) of the interface

2. Integration of Intelligent design Knowledge-Base (IIKB)

3. Accuracy of tools and Ability to simulate Detailed and Complex building Components (AADCC)

4. Interoperability of Building Modelling (IBM)

5. Integration with Building Design Process (IBDP)

These five categories were used as the main categories for the coding scheme. An additional category, 'External Influences on the Design Process', was added to the coding scheme to address the external barriers raised within literature which did not relate to the use of BPS tools but rather the design process, namely issues surrounding the client and cost of building performance sketching. These were used to create the coding scheme to identify whether the participants, when exposed to a new method of modelling, would express the need for these requirements, consider these requirements met, or have additional requirements to extend the findings from literature. This required a constant development of the coding scheme in order to analyse the entire dataset equally. To develop the coding scheme, the method of constant comparison analysis was implemented within the process, along with a process of iteration to test new emerging categories from one group with the new group, until such a point was reached where no new categories emerge. By this definition, 'theoretical sampling' (Glaser \& Strauss, 1967) was applied.

\subsection{Initial Coding Scheme}

The categories were broken down into the following predetermined subcategories provided in Table 5 to explore concepts, which emerge to verify and extend the findings from Attia et al (2012) in the specific issues discussed for each category. 
TABle 5 InItIAL Coding SCHEME

\begin{tabular}{|c|c|c|c|c|c|c|}
\hline CATEGORIES & $\begin{array}{l}\text { USABILITY AND } \\
\text { INFORMATION } \\
\text { MANAGEMENT } \\
\text { (UIM) OF THE } \\
\text { INTERFACE }\end{array}$ & $\begin{array}{l}\text { INTEGRATION OF } \\
\text { INTELLIGENT } \\
\text { DESIGN } \\
\text { KNOWLEDGE- } \\
\text { BASE (IIKB) }\end{array}$ & $\begin{array}{l}\text { ACCURACY AND } \\
\text { ABILITY TO } \\
\text { SIMULATE DETAILED } \\
\text { AND COMPLEX } \\
\text { BUILDING } \\
\text { COMPONENTS } \\
\text { (AADCC) }\end{array}$ & $\begin{array}{l}\text { INTEROPERABILITY } \\
\text { OF BUILDING } \\
\text { MODELLING (IBM) }\end{array}$ & $\begin{array}{l}\text { INTEGRATED } \\
\text { BUILDING DESIGN } \\
\text { PROCESS (IBDP) }\end{array}$ & $\begin{array}{l}\text { EXTERNAL } \\
\text { INFLUENCES } \\
\text { ON DESIGN } \\
\text { PROCESS }\end{array}$ \\
\hline \multirow{5}{*}{ 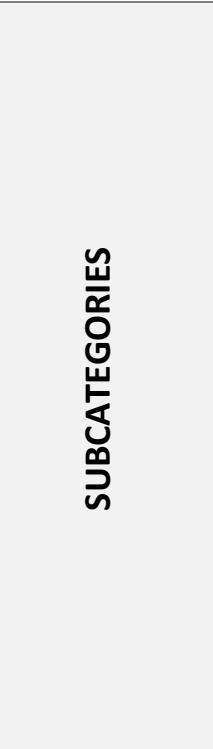 } & $\begin{array}{l}\text { Graphical } \\
\text { Visualisation of the } \\
\text { interface }\end{array}$ & $\begin{array}{l}\text { Informing design } \\
\text { decision making }\end{array}$ & $\begin{array}{l}\text { Accurate and realistic } \\
\text { results }\end{array}$ & $\begin{array}{l}\text { 3D Model Exchange } \\
\text { Feature }\end{array}$ & $\begin{array}{l}\text { Fluidity of } \\
\text { modelling within } \\
\text { different phases }\end{array}$ & The Client \\
\hline & $\begin{array}{l}\text { Graphical } \\
\text { representation of } \\
\text { output results }\end{array}$ & & Accuracy of model & & $\begin{array}{l}\text { Multidisciplinary } \\
\text { communication }\end{array}$ & $\begin{array}{l}\text { Designer } \\
\text { Perception on } \\
\text { Workload }\end{array}$ \\
\hline & Training & & $\begin{array}{l}\text { Examination of } \\
\text { sensitivity and } \\
\text { uncertainty of design } \\
\text { parameters }\end{array}$ & & & Cost \\
\hline & $\begin{array}{l}\text { Transparency of } \\
\text { Assumptions and } \\
\text { Calculations }\end{array}$ & & & & & Expertise \\
\hline & Adaptive GUls & & & & & \\
\hline
\end{tabular}




\subsection{Developing Coding Scheme}

The coding scheme was initially developed through a process of testing against an 'emergent' focus group: the student trial group. After testing the interview guide, the data from this group was analysed against the coding scheme to ensure the scheme was valid and to check for any emerging categories, which may occur due to the structure of the interview guide. Data was initially coded using descriptive coding, and then followed with analytical to match them within the predetermined categories.

Data which did not fit any predetermined categories were underlined and coded after the initial round. For example, the following exert between the engineering and architecture student was analysed to be coded within the UIM category (descriptive in lowercase, analytical matching subcategories in uppercase):

\begin{tabular}{|c|c|c|}
\hline Speaker & Quote & $\begin{array}{l}\text { Coding (describing what the spe } \\
\text { is talking about as a descriptive } \\
\text { and context meaning of what th } \\
\text { are saying as analytical code) }\end{array}$ \\
\hline $\begin{array}{l}\text { Architecture } \\
\text { Student: }\end{array}$ & $\begin{array}{l}\text { I think as [engineering student] said, } \\
\text { the smaller factors that you're } \\
\text { going to need to change to } \\
\text { simulate, the more it's going to be } \\
\text { used }\end{array}$ & $\begin{array}{l}\text { Rule of thumb for interface } \\
\text { ADAPTIVE GUIS }\end{array}$ \\
\hline $\begin{array}{l}\text { Engineering } \\
\text { Student: }\end{array}$ & The fewer inputs & $\begin{array}{l}\text { Correction } \\
\text { EXPERTISE }\end{array}$ \\
\hline $\begin{array}{l}\text { Architecture } \\
\text { Student: }\end{array}$ & $\begin{array}{l}\text { Yeah, the fewer inputs, but in } \\
\text { saying that you also want it } \\
\text { accurate and to give an accurate } \\
\text { sketch you need to have more } \\
\text { inputs }\end{array}$ & $\begin{array}{l}\text { Contradiction to requirements } \\
\text { ACCURACY OF MODEL }\end{array}$ \\
\hline
\end{tabular}

Other information, which can be drawn from this exchange, was the terminology knowledge of the architecture student compared to that of the engineering student. Where the architecture student refered to 'factors' the engineering student corrected them in saying 'inputs'. This was indicative of the continuing theme which emerged from the focus group: expertise.

An emerging concept which became very fundamental to the interactions and discussion points within the focus group of the student trial was this idea of expertise, knowledge and awareness. This became an emerging subcategory of 'training', where the students discussed the main barriers to be 'lack of knowledge' to know how to even do performance sketching, let alone look at implementing it, and structuring their advice around the idea of improving the features within interoperable tools to educate the designers on how best to use performance sketching to inform their 
designs. This emergence became evident when the architecture student summarised the groups' answers:

"Yeah the client expectations of not knowing the expected results and the students understanding, or the industry member's understanding of what needs to be analysed because they're essentially the same thing. You've got a client who doesn't know what to expect and you've got this person in the industry who doesn't know what needs to be analysed".

The barriers which the student group constantly referred to were lack of knowledge to know what to assess in conceptual stages, and external influences such as the client awareness of the value of performance assessment to the design decision making process. The lack of understanding from the client, the need for rapid concept development due to time constraints to get a tender out, and other factors such as cost and training came up during the discussions. For example, the first question within the focus group interview asked participants to write down which barriers they believed exist to prevent building performance sketching in industry. This question produced five answers, three of which related to external factors: 'rapid concept development'; 'knowing the design intent, it changes too rapidly based on external factors'; and 'client expectations - not knowing the expected results can limit the decisions I make as a designer'. Given the inexperience of the students within the design industry, and their constant exposure to training, it was hypothesised that the professionals may include more barriers which would relate to the external factors of the industry such as training. Due to this hypothesis, this subcategory was included within the coding scheme to test for its emergence within the next focus group dataset.

In the practice of coding the data into these categories, the challenge of recoding, subcoding and merging subcategories emerged in the subtle differences between the codes. These were merged based upon context, theoretical memoing and categories which would suit the research question. For example, the codes 'Time constraints', 'Efficient use of Time', 'Double Handling' and 'Workload' were merged together into 'Designer's perception of Workload' after considering the theoretical memo regarding a reflection on how little designer's understand about the processes of performance analysis: 
[Engineering Student] argues that the process of performance sketching would actually inform the designer on which should be analysed - idea of informing not the design, but the designer on what they should focus upon to make their design better (EDUCATIONAL). This is an interesting concept, and is used by [engineering student] to combat the idea that [architecture student] brings forward in that designers often have no idea what needs to be analysed in their designs to assess their performance. How can design be improved if you do not know how to perform the test? In not understanding HOW something is done, perhaps this perception makes the workload seem that much more, incorporating the idea of "rapid development" and "double handling" in the sense that the value of performance sketching isn't seen because it might be too much work to do and by that point the concept would have already changed to something else due to EXTERNAL INFLUENCES.

Designer perception plays a large role in how they interpret certain factors of the Performance Sketch. Where they do not have a good amount of knowledge on the HOW the process may work, the perception of the designer is that it will take a long TIME to do the analysis and therefore during RAPID DEVELOPMENT, Performance Sketching would not be implemented. If this would need to be used, or to encourage its use, the perception of the workload would need to be minimised in an obvious way. In the case of the designer, this could simply be visually where you have less inputs to change "the smaller factors that you're going to need to change to simulate, the more it's going to be used".

It became clear as the students discussed the issue of rapid concept development that the designer's lack of knowledge surrounding the how of performance analysis gave the designer a perception of heavy workload. This process of theoretical memoing and constant comparison analysis of coding lead to merging emerging categories and subcategories for the developed coding scheme.

Thus the new coding scheme is illustrated in Table 6. 
Table 6 Developed Coding Scheme

\begin{tabular}{|c|c|c|c|c|c|c|}
\hline CATEGORIES & $\begin{array}{l}\text { USABILITY AND } \\
\text { INFORMATION } \\
\text { MANAGEMENT } \\
\text { (UIM) OF THE } \\
\text { INTERFACE }\end{array}$ & $\begin{array}{l}\text { INTEGRATION OF } \\
\text { INTELLIGENT } \\
\text { DESIGN } \\
\text { KNOWLEDGE- } \\
\text { BASE (IIKB) }\end{array}$ & $\begin{array}{l}\text { ACCURACY AND } \\
\text { ABILITY TO SIMULATE } \\
\text { DETAILED AND } \\
\text { COMPLEX BUILDING } \\
\text { COMPONENTS } \\
\text { (AADCC) }\end{array}$ & $\begin{array}{l}\text { INTEROPERABILITY } \\
\text { OF BUILDING } \\
\text { MODELLING (IBM) }\end{array}$ & $\begin{array}{l}\text { INTEGRATED } \\
\text { BUILDING DESIGN } \\
\text { PROCESS (IBDP) }\end{array}$ & $\begin{array}{l}\text { EXTERNAL } \\
\text { INFLUENCES } \\
\text { ON DESIGN } \\
\text { PROCESS }\end{array}$ \\
\hline \multirow{7}{*}{ 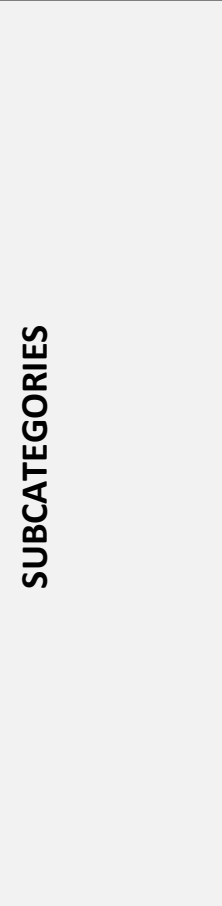 } & $\begin{array}{l}\text { Graphical } \\
\text { Visualisation of the } \\
\text { interface }\end{array}$ & $\begin{array}{l}\text { Informing design } \\
\text { decision making }\end{array}$ & $\begin{array}{l}\text { Accurate and realistic } \\
\text { results }\end{array}$ & $\begin{array}{l}\text { 3D Model Exchange } \\
\text { Feature }\end{array}$ & $\begin{array}{l}\text { Fluidity of } \\
\text { modelling within } \\
\text { different phases }\end{array}$ & The Client \\
\hline & $\begin{array}{l}\text { Graphical } \\
\text { representation of } \\
\text { output results }\end{array}$ & & Accuracy of model & & $\begin{array}{l}\text { Multidisciplinary } \\
\text { Communication }\end{array}$ & $\begin{array}{l}\text { Designer } \\
\text { Perception on } \\
\text { Workload }\end{array}$ \\
\hline & Adaptive GUIs & & $\begin{array}{l}\text { Examination of } \\
\text { sensitivity and } \\
\text { uncertainty of design } \\
\text { parameters }\end{array}$ & & & Value \\
\hline & $\begin{array}{l}\text { Transparency of } \\
\text { Assumptions and } \\
\text { Calculations }\end{array}$ & & & & & Cost \\
\hline & $\begin{array}{l}\text { Interface as } \\
\text { Educational }\end{array}$ & & & & & Prioritisation \\
\hline & & & & & & Training \\
\hline & & & & & & Expertise \\
\hline
\end{tabular}




\subsubsection{The Process of Coding}

Over the past decade, the process of coding has become easier by the emergence of computer assisted qualitative data analysis software (CAQDAS), such as NVivo (Leech \& Onwuegbuzie, 2011). These programs have the ability to take qualitative data analysis much further than manual analysis, whereby it has the ability to efficiently compare categories and codes in a relatively short time.

The CAQDAS program, NVivo, was utilised within this thesis to assist with Constant Comparison Analysis (CCA) and Directed Content Analysis (DCA).

\subsection{Initial Coding}

The coding of data followed a process of initial coding using the coding scheme, recoding and cross checking. The unit of analysis was considered to be a paragraph (where the participants discusses a topic until the next person talks), rather than coding the data line by line. This was considered a means to eliminate problems in not considering context, which is often a problem in focus group analysis.

The coding scheme, tested through the analysis of the student trial group as an 'emergent' group', was applied to the 'systematic' groups and developed iteratively: The architect group, the engineering group, and the mixed group. The systematic groups produced the usable data for this study, and data collection was done in sequence in order to test emerging concepts.

The concepts, which emerged from the architect group, were tested on the engineering group to determine whether or not there was a level of agreement between the groups, or if the discipline difference made a significant difference. This same principle was implemented in the mixed discipline group, where the emerging concepts from both architect and engineering groups from Wellington were tested against their Auckland counterparts. The coding scheme for DCA was developed through this process, and the final coding scheme was rechecked across all groups using CCA, which was used throughout the coding process to ensure consistent coding.

Three stages of initial coding were used to develop the coding scheme to test more emerging categories on the systematic groups until data reached theoretical saturation. These three stages are as follows:

1. data was highlighted where they fall within the predetermined categories of the coding scheme, and data which did not match the predetermined categories were coded into a temporary "Emerging" category to be coded later

2. highlighted data was coded into subcategories within the coding scheme, or added to the "Emerging" category to belong to an emerging subcategory within the main category 
3. Analytical codes were assigned to all emerging data. These were used to establish a new category and/or subcategory.

For example, the following extract from the architect group had data coded into 'Prioritisation' and a new subcategory for External Influences on Design: 'Legislation'.

TABLE 7 EXAMPLE OF CODING PROCESS: INITIAL CODING ASSIGNS DESCRIPTIVE CODES (LOWERCASE) AND ANALYTICAL MATCHING CATEGORIES (UPPERCASE), THESE ARE THEN COMPARED ACROSS ALL CODES TO BE ASSIGNED TO A PREDETERMINED CATEGORY OR AN EMERGING ONE IN FINAL CODING.

\begin{tabular}{|c|c|c|c|}
\hline Participant & Quote & Initial Coding & Final Coding \\
\hline Architect 1 & $\begin{array}{l}\text { I can also say aesthetics is always } \\
\text { important. You've probably got a ton } \\
\text { of windows which is probably totally } \\
\text { bad for the environment for thermal } \\
\text { efficiency but it looks good because } \\
\text { it's got a great view. }\end{array}$ & $\begin{array}{l}\text { Prioritising aesthetics } \\
\text { over thermal comfort } \\
\text { EXTERNAL } \\
\text { INFLUENCES ON } \\
\text { DESIGN PROCESS > } \\
\text { PRIORITISATION }\end{array}$ & $\begin{array}{l}\text { Prioritising aesthetics } \\
\text { over thermal comfort } \\
\text { EXTERNAL } \\
\text { INFLUENCES ON } \\
\text { DESIGN PROCESS > } \\
\text { PRIORITISATION }\end{array}$ \\
\hline Architect 2 & $\begin{array}{l}\text { Like, we talk about codes, right, } \\
\text { whether designing a shed or whether } \\
\text { you're designing Te Papa, the building } \\
\text { code is same for everyone. Similarly, } \\
\text { energy or energy simulation is NOT } \\
\text { like that. You know, it is NOT a } \\
\underline{\text { requirement. In many other countries, }} \\
\text { it is a requirement for all the buildings } \\
\text { across the board, it is not a } \\
\text { requirement in New Zealand. }\end{array}$ & $\begin{array}{l}\text { Stating an issue that } \\
\text { New Zealand has no } \\
\text { building code that } \\
\text { requires simulation } \\
\text { EXTERNAL } \\
\text { INFLUENCES ON } \\
\text { DESIGN } \\
\text { EMERGING } \\
\text { BUILDING CODE }\end{array}$ & $\begin{array}{l}\text { Stating an issue that } \\
\text { New Zealand has no } \\
\text { building code that } \\
\text { requires simulation } \\
\text { EXTERNAL } \\
\text { INFLUENCES ON } \\
\text { DESIGN PROCESS > } \\
\text { LEGISLATION }\end{array}$ \\
\hline t 3 & $\begin{array}{l}\text { I think if it became standard, like } \\
\text { everyone expected it. If everyone } \\
\text { expected it, and if everyone knows it's } \\
\text { part of the price of doing then you're } \\
\text { going to do it, yeah. }\end{array}$ & $\begin{array}{l}\text { Suggesting a solution } \\
\text { to cost barrier } \\
\text { through making } \\
\text { simulation a standard } \\
\text { known by all } \\
\text { EXTERNAL } \\
\text { INFLUENCES ON } \\
\text { DESIGN } \\
\text { EMERGING } \\
\text { PUBLIC STANDARD }\end{array}$ & $\begin{array}{l}\text { Suggesting a solution } \\
\text { to cost barrier } \\
\text { through making } \\
\text { simulation a standard } \\
\text { known by all } \\
\text { EXTERNAL } \\
\text { INFLUENCES ON } \\
\text { DESIGN PROCESS > } \\
\text { LEGISLATION }\end{array}$ \\
\hline
\end{tabular}

The interview guide was altered to question participants within the new focus group on the emerging concepts from the previous. This process was repeated for each focus group until the data reached theoretical saturation. The final coding scheme was checked again against all group data to ensure consistency. Data was then processed through the secondary coding process. 


\subsection{Emerging Concepts and their Development of the Coding Scheme}

\section{The First Systematic Group - The Architects:}

The architecture group produced several emerging concepts which were included within the 'External Influences on Design': Legislation and 'Old School'. The emergence of legislation and 'Old School', came out of the conversation between two participants discussing the issue of having "people from the old school" and needing "everybody on the same page" surrounding the barriers of cost. As a response to these comments, the participant mentioned the fact that New Zealand does not have a requirement for energy simulation as a driver, but rather corporate image can often be a driver:

"In many countries, it is a requirement for all the buildings across the board, it is NOT a requirement in New Zealand so that's why whoever the client is, whether it's a private client or a government client, or whether we have someone like, you know, corporate they choose their project, which they want as energy for their branding purposes or for their... very rarely it has come about when they've done energy analysis for saving money in the long term, or for showcasing that what can be done." (Emphasis in conversation tone)

The emerging categories from the student group were verified within the architecture group, where discussions surrounding designer perception and value as barriers were very dominant throughout the discussion on performance sketching. As an example of such category verification, the client as a barrier was heavily discussed, along with cost and value perception as two key connecting barriers:

Architect:

Architect in response
"I would say there is now more awareness than it was five years ago. Most of the people do understand that we need to do this, but still, people don't understand that or people are not ready yet that we HAVE to do it.. the whole industry as such is not ready to spend money for projects across the board, it will take some time..."

"Yeah. I also think it's also the client awareness, it's the client being aware of such designs and the value, the long-term value that these designs could actually have and if the client was quite aware of it, then I think they would promote it as well or if not in terms of cost, at least in terms of time. They will understand that it takes time rather than wanting things quickly and stuff they would understand the value of it."
Lack of knowledge for the value of performance sketching EXTERNAL INFLUENCES ON PROCESS > DESIGNER PERCEPTION ON VALUE

Client as main barrier to performance sketching and value awareness as solution to cost and time constraints EXTERNAL INFLUENCES ON PROCESS > THE CLIENT 
Finally, the subcategory of 'Training' became apparent to not only belong to training in terms of the use of the program, but rather broader in the training of knowledge of the performance sketching as a skill.

\section{The Second Systematic Group - The Engineers:}

The only emerging concept from the engineers against the coding scheme was the concept of 'Engagement' within the design process. This notion of timing was not discussed, or raised, during the architect group session. However, the concept of engagement was one of the engineer's greatest barriers to implementing the performance sketch. They commented that:

"They don't engage, like often services won't be engaged, even structure wouldn't be engaged."

"With my experience, the designs are accepted before you even think about the building services. So they already have their preliminary design developed and then you don't really get the chance to even go back and be like, 'What about the windows size?'”

"Time of engagement and too late in the process, and we receive plans once complete and have limited ability to change things"

This emerging concept was verified by the final mixed group of engineers and architects, where the barrier of time of engagement was once again at the very top of the list: "My comment was about the timing about access into having the conversation about the
concepts..."

"Sometimes we're not even aware of a project, so the client might engage a project manager and then architect and then [quantity surveyor] and then formulate a rough concept... so that's a timing thing."

"Well sometimes, like a building will be created by the architects like the floor plan. And they'll have windows at certain locations and then we come in and go, 'well, actually, these windows are not a very desirable location. Can we move it?' and the answer is usually, 'No. The concept is set. It's already done, signed off'."

Finally, in comparing the codes from 'Graphical Visualisation of Interface' and 'Adaptive GUIs', these categories became merged. Thus, Graphical Visualisation of Interface was removed. No new emerging concepts were found within the Auckland mixed focus group. The final coding scheme therefore is presented in Table 8 on the next page. 
TABle 8 FinAl Coding SCHEME

\begin{tabular}{|c|c|c|c|c|c|c|}
\hline CATEGORIES & $\begin{array}{l}\text { USABILITY AND } \\
\text { INFORMATION } \\
\text { MANAGEMENT } \\
\text { (UIM) OF THE } \\
\text { INTERFACE }\end{array}$ & $\begin{array}{l}\text { INTEGRATION OF } \\
\text { INTELLIGENT } \\
\text { DESIGN } \\
\text { KNOWLEDGE- } \\
\text { BASE (IIKB) }\end{array}$ & $\begin{array}{l}\text { ACCURACY AND } \\
\text { ABILITY TO SIMULATE } \\
\text { DETAILED AND } \\
\text { COMPLEX BUILDING } \\
\text { COMPONENTS } \\
\text { (AADCC) }\end{array}$ & $\begin{array}{l}\text { INTEROPERABILITY } \\
\text { OF BUILDING } \\
\text { MODELLING (IBM) }\end{array}$ & $\begin{array}{l}\text { INTEGRATED } \\
\text { BUILDING DESIGN } \\
\text { PROCESS (IBDP) }\end{array}$ & $\begin{array}{l}\text { EXTERNAL } \\
\text { INFLUENCES } \\
\text { ON DESIGN } \\
\text { PROCESS }\end{array}$ \\
\hline \multirow{11}{*}{ 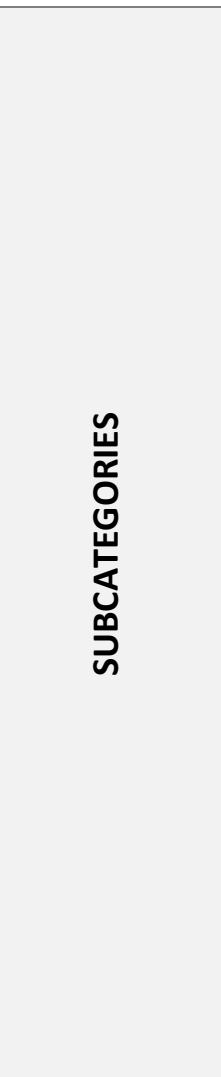 } & $\begin{array}{l}\text { Graphical } \\
\text { Representation of } \\
\text { output results }\end{array}$ & $\begin{array}{l}\text { Informing design } \\
\text { decision making }\end{array}$ & $\begin{array}{l}\text { Accurate and realistic } \\
\text { results }\end{array}$ & $\begin{array}{l}\text { 3D Model Exchange } \\
\text { Feature }\end{array}$ & $\begin{array}{l}\text { Fluidity of } \\
\text { modelling within } \\
\text { different phases }\end{array}$ & The Client \\
\hline & Adaptive GUIs & Templates & Accuracy of model & Exporting to BIM & $\begin{array}{l}\text { Multidisciplinary } \\
\text { Communication }\end{array}$ & $\begin{array}{l}\text { Designer } \\
\text { Perception on } \\
\text { Workload }\end{array}$ \\
\hline & $\begin{array}{l}\text { Interface as } \\
\text { Educational }\end{array}$ & $\begin{array}{l}\text { Parametric } \\
\text { Capabilities }\end{array}$ & $\begin{array}{l}\text { Examination of } \\
\text { sensitivity and } \\
\text { uncertainty of design } \\
\text { parameters }\end{array}$ & & & Value \\
\hline & $\begin{array}{l}\text { Transparency of } \\
\text { Assumptions and } \\
\text { Calculations }\end{array}$ & & & & & Old School \\
\hline & & & & & & Cost \\
\hline & & & & & & Prioritisation \\
\hline & & & & & & Legislation \\
\hline & & & & & & Engagement \\
\hline & & & & & & Training \\
\hline & & & & & & User \\
\hline & & & & & & Expertise \\
\hline
\end{tabular}




\subsubsection{Group Observation Recording}

To assess the nonverbal communications, the assistant facilitator in the focus groups used an adapted matrix for assessing level of consensus in the focus group, originally outlined within Onwuegbuzie et al. (2009), and tabulated below in Table 9.

TABLE 9 AsSISTANT FACILITATOR TABLE TEMPLATE FOR DOCUMENTING PARTICIPANT RESPONSES

Question One:

Speaker:
1
2
3
4
5
6

The following notations are entered in the cells to document each participant's response/reaction to what the current speaker is discussing:

$A=$ Indicated agreement (i.e., verbal or nonverbal)

$D=$ Indicated dissent (i.e., verbal or nonverbal)

$\mathrm{PA}=$ Passionate response suggesting agreement

$\mathrm{PD}=$ Passionate response suggesting disagreement

$\mathrm{NR}=$ No response

This table was adapted from the original suggested matrix within (Onwuegbuzie et al., 2009), where the axis were the questions and the member responding to the questions. During the student trial, it was found to be easier by the assistant facilitator to keep track of how people respond to what other participants are saying. This information provided additional levels of consent/dissent, rather than the number of times a participant responded to a question.

\subsubsection{Validity and Reliability of the Results}

Universal to all qualitative research, the validity and reliability of results is best demonstrated by providing a clear link between the data and results (Elo \& Kyngäs, 2008). For content analysis, Elo and Kyngäs (2008) stated that successful content analysis application requires the researcher to analyse and simplify the data to form clear categories which are conceptually and empirically grounded. Furthermore, categories must reflect the subject of study "in a reliable manner". Here, Potter \& Levine-Donnerstein (1999) explained that the categories can only reflect the subject of study reliably by forming the coding scheme which is faithful to the theory by orientating coders to the focal concepts of the theory (Potter \& Levine-Donnerstein, 1999). In this, the scheme is considered valid and becomes a standard to which the 
researcher must code against. Potter \&Levine-Donnerstein (1999) stated that where the codes match the standard for correct decision making, "the coding is regarded as producing valid data". This coding standard is further tested by the use of more than one coder. The focus of the reliability of the analysis is determined by how consistently the coders agree with one another across decisions. Potter \& Levine-Donnerstein (1999) stressed the point that reliability is not measured by how widespread the agreement is across different coders, but rather the reproducibility of the coding scheme.

Thus, the assistant facilitator was employed to review the data and analysis to determine whether or not they made the same coding decisions as the lead researcher. Where the team disagreed, the coding was fixed to come to an agreement. 


\section{CHAPTER FOUR - RESULTS}

The previous chapter, Chapter Three, described the research design to answering the research questions: 'Can the use of the distributed model method (DMM) address the wants and wishes of users for tool development?'; and 'What must be improved in order to make the integration of BPS feasible within the design process?'. The creation of a conceptual workflow template within an example coupling tool using DMM was outlined, and the structure of data collection through interviewing three focus groups was described.

This chapter presents the findings of the three focus groups: architects; engineers; and the mixture of both. The data from the focus groups were coded into categories established through Directed Content Analysis (DCA) described in Chapter Three. The analysis uses the six-category coding scheme to compare and contrast the responses of three focus groups. The chapter concludes with a synthesised data map which illustrates the relationships between these categories forming basis for discussion in the next chapter to draw lessons for future research. 


\subsection{Barriers to Implementing Performance Sketching}

As discussed in Chapter Two - Literature Review, the barriers to implementation of performance sketch analysis surround issues of model simplifications, model interoperability and trustworthiness of modelling assumptions. In their exposure to a new emerging modelling method, that of DMM, practitioners pointed to several other barriers which they perceive as preventing this form of performance sketching, and their views upon the current use of other modelling methods to sketch the performance of a design. In particular, these barriers relate to external influences on the design process, issues surrounding current integrated design process (IDP) approaches to designing as a team, and the general lack of expertise surrounding BPS.

\subsubsection{External Influences to the Design Process}

The first question of the focus group interview asked the participants to establish barriers which exist within their design processes that they perceive would prevent the implementation of performance sketching. They were then asked to rank these in order of greatest perceived barrier to least. Two of the three groups had the same 'greatest' barrier to overcome in order to sketch performance in current practice. However, the greatest barrier(s) determined by all groups was an external influence to the design process. No group was able to provide a linear ranking order when asked to establish and rank their perceived barriers from greatest to least, but rather provided answers 'similar' in importance to each other. In this exercise, the participants raised relationships which they believed overcame other barriers, thereby reaching their answers. These relationships are discussed in more detail throughout this chapter.

Table 10 below documents the answers provided by each group for the first question. The mixed and architect groups agreed that persuading clients of the need to pay for this process is the greatest barrier to implementation of performance sketching in their practices, whereas the engineering group focused upon the external issues which may affect the client's willingness to pay for extended time during the early stages of design. 
TABLE 10 FoCUS GROUP DIRECT ANSWERS TO RANKING THE GROUP'S ESTABLISHED BARRIERS AGAINST PERFORMANCE SKETCHING IN PRACTICE FROM GREATEST TO LEAST, AS WRITTEN BY THE PARTICIPANTS. DESCRIPTIONS SEPARATED BY / INDICATE SIMILAR OR EQUAL PERCEIVED LEVEL OF BARRIER IN RELATION TO GREATEST OR LEAST.

\begin{tabular}{|c|c|c|}
\hline Architect Group & Engineer Group & Mixed Group \\
\hline $\begin{array}{l}\text { Cost (client buy-in to pay for } \\
\text { professional fees to take more } \\
\text { time in the conceptual stage } \\
\text { than 'normal') * }\end{array}$ & $\begin{array}{l}\text { Time of Engagement (i.e. Too } \\
\text { late in the process to reduce } \\
\text { initial fee cost, or demand as } \\
\text { not required. Business as Usual) }\end{array}$ & $\begin{array}{l}\text { Client buy-in - will they be } \\
\text { willing to pay for this? Will they } \\
\text { want to extend out the concept } \\
\text { design time? }\end{array}$ \\
\hline $\begin{array}{l}\text { Skills to Assess/ Knowledge } \\
\text { Base to actually use } \\
\text { performance sketching }\end{array}$ & $\begin{array}{l}\text { Lack of appreciation from } \\
\text { stakeholders of value, } \\
\text { therefore inadequate time } \\
\text { allocated for this process }\end{array}$ & $\begin{array}{l}\text { Acceptance by wider consultant } \\
\text { group (including project } \\
\text { manager) to the process. } \\
\text { Education, inertia, etc. / Access } \\
\text { to participate during } \\
\text { development of building } \\
\text { concept and formulating project } \\
\text { objectives }\end{array}$ \\
\hline \multirow[t]{6}{*}{$\begin{array}{l}\text { Skills within the office / time } \\
\text { and training }\end{array}$} & $\begin{array}{l}\text { Receiving plans once } \\
\text { completed and having limited } \\
\text { ability to alter design by the } \\
\text { stage that the building services } \\
\text { design is considered }\end{array}$ & $\begin{array}{l}\text { Time/deadlines. Client } \\
\text { understanding to do something } \\
\text { different instead of status quo }\end{array}$ \\
\hline & $\begin{array}{l}\text { Clients don't drive for } \\
\text { optimised design regarding } \\
\text { thermal and daylight and less } \\
\text { money is allocated to } \\
\text { preliminary design stages }\end{array}$ & $\begin{array}{l}\text { Expertise in the team - needing } \\
\text { to train/learn which will effect } \\
\text { utilisation. }\end{array}$ \\
\hline & $\begin{array}{l}\text { Lead design ego (i.e. Not } \\
\text { quantitative design) }\end{array}$ & \\
\hline & $\begin{array}{l}\text { Lack of knowledge to know } \\
\text { what to design to test for (i.e. } \\
\text { translation of design intent in } \\
\text { terms of emotive space } \\
\text { qualities to performance } \\
\text { criteria) }\end{array}$ & \\
\hline & $\begin{array}{l}\text { Attitude that we don't do } \\
\text { things that way - That is not } \\
\text { early design }\end{array}$ & \\
\hline & $\begin{array}{l}\text { Expertise in their software / } \\
\text { Ease in developing a basic } \\
\text { model and resulting time taken } \\
\text { / staff training / skill level / cost } \\
\text { of process due to new or } \\
\text { unfamiliar workflow }\end{array}$ & \\
\hline
\end{tabular}

* This particular answer was contradicted by two participants out of the five present: firstly, stating that for one participant's company, cost is not a large issue due to the ability to apply for grants to do the extra work; secondly the other participant stated 
that cost would not be an issue if the architect had enough knowledge regarding performance sketching and saw the value of it, the architect would 'write off the cost' themselves.

Sections 4.1.1.1-9 present the data coded into their respective concepts, and the findings from the participants of the focus groups for each concept within the category, 'External Influences on the Design Process'. These concepts provide the results for the first question of the focus group interview.

\subsubsection{The Client}

Though none of the groups explicitly wrote down the greatest barrier to be the client, their discussions surrounding why their greatest barriers are what they are surround the issue of the client's awareness of the value towards performance sketching. Where the engineers claim the greatest barrier to be time of engagement, this was further explained by an engineer, stating:

"They [the client] don't have that appreciation of how much value they're going to get. They think it's appropriate to not engage a services engineer or an energy consultant until much later in the process."

This lent itself to the connection that the client had to the concept of 'Old School' attitudes within the industry towards the way in which the design process works. As indicated in Table 10, the engineers discussed the emerging concept of 'That's not how we do things'. Clients, being uneducated in the ways in which the design process worked, expected the architect to perform this work in current practice. This frustration was displayed by the architect group, where one participant passionately described the issues of professional fee allocation, with all other participants noted to have been nodding earnestly in consensus:

"Clients are not willing to pay. They are like, "this is the professional fee I am going to pay, it's up to you whether you want to do it or not..."

Furthermore, the architects discussed issues surrounding cost and time allocation by identifying that the client must first become aware of the long-term value to the designs they receive:

"It's the client being aware of such designs and the long-term value that these designs could actually have and if the client was quite aware of it, then I think they would promote it as well or if not in terms of cost, at least in terms of time. They will understand that it takes time rather than wanting things really quickly..."

\subsubsection{Cost}

The issue of cost was only brought up in terms of the client's 'buy-in' to invest in performance sketching during the early stages of design. It was noted by the mixed group that cost was not a large issue in terms of buying programs, or paying for training. Rather, it related only to the client due to the competitive nature of tendering 
for a project. This statement was supported by the participant's background, being the director of a multi-disciplinary firm, thereby provided an indication of the level of adoption tools can have within industry:

"I think the cost barrier for me only relates to the client willing to commit a little bit more money up-front."

For the engineering group, the barrier of cost was hardly discussed, and was only mentioned in relation to when they are engaged within the design process. They commented instead on a 'cost risk perspective', arguing that the reason they believed they were not often engaged early was because there was a certain risk up-front to the client:

"Fundamentally, there is a cost risk perspective. It is until effectively, even if they got resource consent, the project is very speculative for whoever's showing the money out. So then you want to put as minimum amount into the fees as possible until the job becomes very, very real..."

However, they also raised that engaging them early could save them money in the long run. One of the engineers provided as an example their experience with a client dealing with a quantity surveyor before engaging with their daylighting specialists, illustrating both their expertise and need to approach them first:

"They said, 'Well what would our pay-back-period be for this certain building?' and we were like, "Oh well, it will cost this much' and they were like, 'Oh no, no, no. Our QS has told us it will cost this much'. We were like, 'What? That figure is like four times what we will give you as an estimate of how much it will cost. Of course the pay-back-period's like 30 years.' Where does the QS get this data from?"

However, two of the five architects within the architect group raised the notion that, where the architect can see the value that performance sketching can provide their designs, and the architect prioritises the need to design for comfort along with aesthetics, they would 'do it from their own pocket'. This discussion was raised in response to deciding upon the greatest barrier to be cost. One architect disagreed saying,

"I know cost seems like the most relevant one, but I just feel it's probably knowledge and the skills because usually we've seen architects working, they usually do it from their own pocket if they're quite passionate about it..."

\subsubsection{Prioritisation}

The concept of prioritisation emerged from the architect group when it became clear that there was a distinct difference between the participants of the group in terms of being 'converted' to performance sketching. One architect in particular was very passionate about designing buildings which provide 'above average' indoor environments but faced the problem of 'paying the bills'. Another architect had already begun performance sketching with the tool Sefaira (Sefaira, 2016) within their own company which pride themselves on having a sustainable image. One outlier was 
clear within the group, stating that they would always prioritise aesthetics over the comfort of the created space.

"I can also say aesthetics is always important. You've probably got a ton of windows which are probably totally bad for the environment for thermal efficiency, but it looks good because it's got a great view..."

This prioritisation of the architect was particularly felt by the engineering participants to be another obstacle within the design process. Their barrier, namely the 'Lead design ego', was explained to be a frustration with communication between consultant and designer, particularly how the designer set priorities in their designs.

"One of the key motivations has to be that their [the architects] end product is going to be really energy efficient, or have really great daylighting but if that's not on their list of priorities, their list of priorities is just an architectural one..."

This perception was hinted at in the discussion between the engineer and architect within the mixed group when faced with this idea of 'design ego'. The architect explained that the findings from the engineer can sometimes 'obstruct the design' and the engineer stated that the architect is unwilling to change their design, despite the recommendations from the consultant.

Architect "If you're stating right at the beginning that we want the space to be day-lit in this way, and you're looking at specific things which is around specific numbers and metrics. But as a designer you're trying to create a sense of the building form, the street, or as an object. And then suddenly you have someone saying that your windows are too big, early on, you kinda start going, 'Oh well do I change my windows'? What if this glazing façade's really important? There's a possibility that it can obstruct that design..."

Engineer "A building will be created by the architects and they'll have windows at certain locations, and then we come in and go 'Well, actually these windows are not a very desirable location, can we move it?' and the answer's usually, 'No. The concept's set. It's already done, signed off'"

Architect "But there are ways around that..."

\subsubsection{Designer Perception on Workload}

The engineers, and, indirectly, the architects, believed that another barrier against implementing performance sketching within the design process was the perceived extra workload that the architects would need to add. The architect focus group focused heavily on time, cost and training during their discussions surrounding the implementation of the performance sketch. For many of them, their lack of expertise in building performance simulation led them to believe that this process would take a long time to do, in addition to their usual workload. Most provided comments such as, "it's more getting an understanding of how long this takes", or more to the point, "If 
this is going to take an extra week to do this, it's going to be the first thing that get's shelved".

The engineering group believed that the architects would 'have a fear of it', but the engineers viewed it as "a job that someone else is doing for you":

"Their fear is, when the project starts, the architect's under massive pressure to churn a concept out really fast and it's not easy for them to get that done. They've got to produce a winning design in two weeks so that's hard and so when you tell them there's an extra piece of work to do, then they freak out. But these kinds of workflows enable us potentially in a day to turn around a huge amount of information and give it back to them...the architect shouldn't be afraid of it. They should see it as an opportunity."

Here, the link between the designer perception of workload and the value of performance sketching was raised by the self-proclaimed 'converted' architect, where the architect stated that they would do performance sketching as part of their work if they were not blocked by the issues provided by the client:

"I would like to create spaces which are so comfortable and so efficient and so good for people who are using it, the only thing that protrudes me is the deadlines, the time, the cost I want to do it day in and day out absolutely. I don't think anything has to change over here [the workflow] because whatever the process is for sketching, it is the process and it will remain because it's lots of calculations and lots of simulations..."

\subsubsection{Value}

The argument between the architect and engineer surrounding the idea of consultation or performance sketching, as mentioned earlier, became a question of whether the designer sees the value in the process of performance sketching. The engineers believed that the designers should 'embrace' performance sketching as a form of informing design:

"They should embrace it because if we can tell them, 'Based on the brief that you need to meet, in terms of energy or comfort requirements, your window to wall ratios for the North façade need to be between this and this'. That might save them a few hours' worth of sketching ideas that aren't even close to what you actually feasibly get. It's like, 'Let's do this analysis to give us information, that will help inform the design, that's going to save us time and effort as well'."

Both architect and engineer believed that the value needs to be seen by the client, whether they convince them of it, or the market as a whole becomes more aware of the value of performance sketching. The engineers mentioned that the "perception of the market is whether it's worthwhile doing or not" and outlined the main issue of time to understand the value as being an issue: 
"Because in the market, they move really quickly if the value is clear..."

"But the analysis of that value takes decades of people doing it, so to suddenly say, 'Oh, actually there was value in that'..."

"But if that could be changed and if they could understand where that value was going to come from, I think it would change their opinion."

\subsubsection{Old School}

However, the current attitude of the market was reported to be against change within the design process. The architects mentioned that the implementation of performance sketching fundamentally presented itself as a different means of designing which most architects in the current generation are unfamiliar with:

"Architects are quite used to working iteratively...this is quite a different type of design, when you're having to factor in everything else architectural as well..."

The engineers claimed that their barrier towards being able to engage earlier within the design team is due to the current attitude of 'We don't do it that way':

"We've gone out in industry and been talking to some people in a stakeholder group and the attitude or the thing that we constantly come against is the statement of, 'we just don't do it that way' or 'What you're asking for, you know, that's not early design'."

In providing a final comment for the architect group on all the barriers which they mentioned, one architect summarised the issues saying:

"But these problems that you're dealing with are probably with the current industry, with the current times, with the current architects, but the new generation will come out, if they're taught a different way of design like doing the performance sketch as part of their design right from the beginning. But when we came up with the old school way of designing, so it's just the whole mind set of reversing it and looking at designing as such in a different format..."

\subsubsection{Training}

Another barrier for the 'Old School' generation, though commented to not be very large, was the notion of having to train current employees to use the software. Some of the engineers mentioned that, "there's training in everything", and brushed off the issue of training. Training in general was therefore seen as an extra cost factor, rather than being a barrier in itself - "As a skill level is only a barrier because of the cost of the employees. It's not a barrier in itself. It just means extra cost."

However, the engineers explained further that training to use software, particularly software which relies upon the user to have a basic-advanced knowledge base, can take time which the business may not have: 
"A barrier within my business, if I was to go and tell my boss that I'm going to do this on a project but it's going to take me three weeks, just spending nothing but learning how to use the software $-A$, the answer needs to be out tomorrow not in three weeks and B, who's going to pay for that?"

The architects, when faced with the question of why they placed training to be relatively at the bottom of the list of barriers discussed the fact that they could just "outsource that" stating that they do not feel like they need to have the expertise. This brought out the quieter architect to disagree with the group in their opinion of cost being the greatest barrier, simply stating that:

"In my practice, we probably could afford the small purchase, we're doing predominantly residential, but the fact that we don't have the knowledge or the skills to actually do the performance sketching right at the start and not being able to outsource that is probably the bigger barrier..."

\subsubsection{Expertise}

Given this barrier of the Old School mind set, another large problem which architects faced was their lack of knowledge, their expertise in using building performance simulation tools. Mentioned earlier, one of the architects believed that cost is not so much of an issue as lack of knowledge was when it came to facing the implementation of performance sketching. Given a new reality where perhaps the client could upfront the cost for performance sketching to be a part of the design process, the current generation of architects would be inexperienced in attempting it and would require consultant help.

The problem facing the current industry therefore is the architect's: lack of expertise in using building performance simulation tools; the lack of knowledge surrounding what to assess for within their designs; and the inexperience in analysing data to spot errors or problems in modelling.

\subsubsection{Model Operator}

The architects have little experience working with Building Performance Simulation (BPS) tools and therefore are not familiar with the necessary design parameters which go into producing a thermal or daylight model. In their studies, the architects reported they were simply not trained to know which elements of BPS are required, thereby felt overwhelmed by the interface which provided them with "lots of buttons".

The discussions surrounding the use of any performance sketching tools within all three groups differed depending on their professions. The architects, though reluctant to consider having to add this process to their workload, attempted to consider how they would use the tool to implement performance sketching. In their discussions, they stated that the interface would need to be 'dumbed down for architects' and made simpler for them to use. The engineers however disliked the idea of allowing architects to be the main user of any tool for performance sketching due to their lack 
of expertise in modelling. These concerns were centred primarily on the accuracy of the model created by the architect. They argued that, though a tool could be programed to detect errors and produce error ranges, the architect does not have the training required to analyse and understand these error reports. Due to their lack of experience and expertise, the architect is heavily reliant on the program directing them.

In support to this, one of the engineers, another director of a firm, shared their example of current performance sketching tools, Sefaira and Ecotect, which architects rely upon today to do building performance assessments during early design stages. In their discussion of both Ecotect and Sefaira, they commented upon it in terms of their worry about architects relying upon the program assumptions, to which they are unaware of.

"What concerns me is, given Ecotect as a good example. You had an awful lot of architects picking up Ecotect and just putting crap in and getting crap out and they were fully convinced by what they were getting out. So it is kind of a danger between the level of experience when you make a software too point and press..."

"With Sefaira, you're just tasking back and forth to the tech department saying, 'Why is this coming out with this result?' Then they kind of beat around the bush and then you eventually get to the fact that they've just made this wholesale assumption of something and you're like, 'Shit, that's fundamenta!!'”.

The engineers therefore believed that performance sketching should first and foremost always remain with the specialist, as producing inaccurate results at the very beginning can result in worse consequences. This process would call for the need to have the consultant in during the early stages of design in partnership with the architect.

\subsubsection{Integrated Building Design Process (IBDP)}

The barriers faced in regards to an integrated design process (IDP) approach are: issues in engagement of the full team at the beginning of design; problems with multidisciplinary communication between programs; and the inability to communicate effectively at different stages of design.

As mentioned earlier, engineers believed that the current market attitude is the primary reason why they are not engaged at the very outset of the project. Additional to this attitude, the design team as a whole is stated to not have an understanding of what the engineer can bring to the discussion.

"The team needs to understand the value that we [the engineers] could bring into it, and then also, at least it's that curve isn't it [referring to the cost/effort graph]? That you actually need to front load a little bit more analysis and effort into that..."

However, in communicating this value, the participants commented on the importance of communication that the DMM example, Honeybee/Grasshopper/Rhino, 
enables. In discussing the attractive features of the DMM, as demonstrated to them through the use of Honeybee with Grasshopper, the engineers and architects heavily discussed multidisciplinary communication for an effective integrated design process.

"They'll have a vision in their mind about how they want the space to be but there's that disconnect between translating an architects design intent, into what we can actually test for and then communicating the results back."

This particular feature was commented to be missing from the current application of tools. Given Revit as an example, an architect from the mixed group mentioned the difficulty in transferring models from Revit into a BPS tool for assessment due to the way in which Revit creates its geometry and the means in which it exports its geometry:

"The comment that we get a lot is we've modelled [in Revit] our concept stuff really poorly, where walls aren't meeting the right way."

In many of the recommendations given by the participants towards improvements, it became clear that these features are not currently available to them. The next section describes in more detail the wants and wishes of the professions, along with the features which they already find attractive from the DMM.

\subsection{Barriers overcome by the Distributed Model Method}

The second question of the focus group interview focused the participants upon providing answers to how they believed the DMM, as demonstrated by Honeybee as an example, could overcome the barriers they established. They believed that certain features would overcome specific barriers surrounding the integrated design process approach, improving the designer's perceived workload, enabling a better means of communication between client and team members, and resolved the issues engineers have with current tools which promote performance sketching.

\subsubsection{Interoperability}

The most attractive feature of the DMM was its high interoperability with different programs. This feature was received very well by the engineers, who generally have difficulty in exchanging models between programs or requiring the need to recreate a model within a different program. Architects enjoyed the ability to gain information across programs to help inform their design without having to recreate their models.

"Everything talking to everything else, and getting information that you need out if it to assess those issues...Those sorts of sketches, just as a visualisation tool, but if you can get all of the other data at the same time, that's a huge move." 
An example of this attractive feature was provided by one of the engineers, where he expressed his pleasure in being able to couple daylight and thermal models together in order to gain a full analysis for both metrics:

"One of the great things I think about what [author] showed us, is the whole mix of the EnergyPlus engine, the Radiance engine, the Daysim engine, all from that one model because, I've optimized many buildings for energy and then gone, "Oh, they're a bit fucking dark." You know, which is normally later on."

Comments surrounding the reasons why the participations found the interoperability to be such a strong feature centred around the efficient use of time, the speed of iteration simulations and the reduced time it would take to analyse a model due to not needing to recreate a model.

For the mixed group, they saw it as an opportunity to arrange for more competitive fees, while having the ability to set up a form of module or template to be used for future projects.

"That's a powerful tool. In terms of doing this sort of work on more projects reasonably efficiently within the context of us putting in a competitive fee, it probably lines up quite well."

This in particular was seen to overcome the barrier of time and perception of workload by the designer and allows for a smoother transition between the design tool and BPS tools for the different users.

\subsubsection{Graphical Representation of output Results}

However, the most discussed topic regarding the DMM is the means of communication it can offer a design team. Its 'real-time' feature of being able to see instantaneous results was considered to be largely important by both professions:

"Real-time, definitely it's a massive thing if you can start changing the height of your windows or percentage of glazing in the project environment, not just in a separate spreadsheet and as you're changing it, as you're adding windows, it will update automatically beside you of your predicted energy performance."

This form of translating the results of the simulation in a format which the architect and client can understand was recognised by both professions to be essential to improving communication:

"It's improving communication between the numbers, the physics you know, and the data side and it's translating it into the visual language that clients and architects can understand."

"As long as it keeps improving communication between everybody on the design team. I think that if it's kept to the forefront of development, that's the most important part."

This feature was seen to overcome the barrier of multidisciplinary communication, in order to inform the design team and demonstrate the value of building performance analysis to the team as a whole, and the client. 


\subsubsection{Transparency of Assumptions and Calculations}

In the engineer's worries regarding level of experience, tools which have inapplicable assumptions and modelling with correct inputs for the New Zealand industry, Honeybee as an example of DMM stood out to overcome these barriers. This feature does not specifically belong solely to the DMM, however the visual programming language, Grasshopper, allows the transparency of the calculations behind Honeybee be a possibility.

In comparison to other building performance simulation tools, such as Sefaira as previously mentioned, Honeybee in its use as a DMM for designing was seen to provide users the ability to 'lift the lid' of their interface to understand the assumptions and defaulted inputs behind it. This feature was commented by the engineering participants to be highly valued:

\section{"I like it because you can lift the lid" \\ "I think that it's great that you can lift the lid. So simplifying the workflows is really, really good but then also, being able to drill in when you need to and get that, which is obviously the benefit of open source"}

"It's not that I wish to edit what's under the hood. I wish to KNOW what's under the hood."

The architects did not raise the concern of transparency of assumptions and calculations during their discussions regarding the use of BPS tools. Furthermore, when asked in the fifth question of the focus group interview to rank predetermined answers from greatest perceived value of BPS to least, all architects placed the ability to know default options at the bottom of the list, brushing it aside as unimportant information.

\subsection{Recommended Improvements for Future Development}

The second half of the focus group interview focused the group upon providing feedback and recommendations on how tools and processes of design should be improved for future development, with particular emphasis on the DMM and overcoming established barriers. The points which were made by the participants relate in particular to: introducing legislation to make performance sketching mandatory; implementing performance sketching as part of the architect's training; creating a benchmark feature to compare results against for quality assurance; and improving the GUI to be adaptable for different users of the tool. 


\subsubsection{Legislation}

The participants in this study all agreed that the greatest barrier faced by industry, to implementing performance sketching is the client. The process of performance sketching will add extra work within the early stages of design, hence would require additional cost allocated for the early stage of design. The client is unaware that this process is not common practice, and that the architect does not currently provide this service in all firms. Given this barrier, those architects who wish to do the performance sketching process are restricted by deadlines.

To overcome this barrier, the participants felt that the client must be made aware of the value of performance sketching and/or be given a driver through legislation to provide more time and cost for the early stages of design.

"If there was a driver, where your clients are asking for it that's what mandatory legislation actually would be, is a driver."

Architects stated that, where performance sketching is mandatory, the process would eventually become the 'norm within the design processes'.

"If it became standard, like everyone expected it. If everyone expected it, and if everyone knows it's part of the price of doing then you're going to do it."

\subsubsection{Education}

For the architects in particular, their lack of knowledge in BPS processes was expressed to be a large barrier in implementing any form of performance sketching in the near future. It was stated to not be valued or used within the design studio. Both the old and the new generation of architects lack a structure for becoming educated in how these processes work, or what may be involved. The participants made a couple of recommendations in terms of education, namely: providing publicly available resources for the current generation of architects to access for help; and training new architects to emerge in the industry with these skills already learnt.

The available resources were mentioned by both architect and engineer in response to facing the possibility of an emerging modelling method. The architects requested external help from either the government, or their professional institute to help architects if they require it, or provide training to educate professionals within the field:

"If we have an institute where we could gain access to quite easily and say, 'hey, we're doing this project, you've got maybe someone who can help us out' and get funding from the government or from the union to help up professionals in the field to teach the software."

The engineers recognised that there is no current standard or available reliable guideline for New Zealand in particular for others to follow. In terms of publically 
available training resources, "the more of that stuff that is available, the faster everyone gets to a common skill level and the faster they can adopt the process".

However, regardless of whether the architects have learnt the processes, there needs to be a driver for performance sketching. Architects commented that until the market sees the value of performance sketching, it will not become a reality for their current generation. Hence, their recommendations were largely placed on graduates graduating from tertiary education. Architects claimed that in the current age of technology, the graduates within the practice are employed for their skills and expertise in the software which the firm is attempting to implement.

"Grads are good because when they come in they know how to do it. The grad in our practice knows Rhino and he knows all this stuff where no one else does."

"If you had a person sitting in front of you for an interview saying 'I'm already an expert' then you'd start using him immediately."

The architects suggested that education of new architects would allow the process of performance sketching to become the norm of the design process, whether the client asked for it or not. As the current architect generation put it,

"It's really just a question of making it norm within the design process."

\subsubsection{Quality Assurance of Results}

Both professions were aware that modelling the design to absolutely predict how the building will perform when real people are using it under real climate variations was impossible. However, models only require to be accurate when comparing different design options given standard operating conditions. Accuracy in building modelling can be difficult without experience or guidance. The engineer group suggested that any tool development in the future should always include some form of quality assurance to measure the results against. In this recommendation, the engineers in consensus agreed that the future tool should include a function to benchmark the results against buildings in use.

"How are you assured that the results you get are right, trustworthy, robust, and the biggest thing I think that the building performance sketch needs is some sort of quality assurance thing...there should be a comparison of simulation results to benchmarked buildings in use."

"It's really important to have that grounding of your simulation results, compared to reality in some way."

Furthermore, as previously described in Chapter Two, the industry lacks standardised guidelines for modelling which can be trustworthy and accurate to New Zealand's specific industry. Engineers and architects commented that a standardised process for 
quality assuring a model would be welcome, not only for use in DMM, but across the board:

"A lot of data analysis comes from experience, but if there was a standardized process that you could follow to how you model validate..."

The engineers commented on the importance of using relevant data specific to their industry, rather than relying upon the in-built assumptions from tools. In one comment made by an engineer currently working in research, the use of real, monitored data from buildings within New Zealand from the Building Energy End-Use Study (BEES) from the Building Research Association of New Zealand (BRANZ) (Amitrano et al., 2014) as part of the workflow created for demonstration within this study was appreciated. Honeybee is given in comparison again to the performance sketching tool, Sefaira:

"It comes back to high quality assumptions. So for example, the inputs in [the author's] workflow in Honeybee is based on the BEES data, which is statistically representative of existing commercial New Zealand buildings which is well and good but you know, we need more of that kind of stuff available. So we're not relying on overseas defaults like a lot of these simulation programs are. I know talking to some people in the design community, especially around Sefaira. They bought it and you know, they're getting numbers out of it and I said to them, 'Have you changed the inputs, so that they reflect New Zealand constructions, instead of American?' And they just looked at me like, 'What?'”

\subsubsection{Adaptable Graphical User Interfaces for Different Users}

The last recommendation made by both professions was that of providing adaptable graphical user interfaces (GUIs) for the users of the program. Architects believed that the example, Honeybee, included too many 'buttons' and can be overwhelming. For the inexperienced, non-simulation expert, the GUI must be "more user-friendly". However, the interface should not be over-simplified, as warned by the engineers in making software too 'point and press'. Instead, the GUI must be adaptable for various workflows, with the suggestion of modules and templates. Where engineers wish to explore various parameters and functions, the architect wished for a smooth interface:

"Obviously, the interfaces need to work well for it to be convenient."

"There's nothing you can improve unless you just improve the UI to be able to find those things easier"

Furthermore, the most significant concept discussed for the purposes of this study is the idea of a 'Template' for the use of performance sketching by the architect under the category of 'Adaptive GUIs'. In their discussions, the architects never explicitly stated that they believed they should alone be the operator of the model within this method of modelling. Instead, they discussed solutions around its use and 
implementation within the design process by working alongside the consultant. In many instances, the idea of a template is discussed to make the process of performance sketching simpler. One particular architect related it to the differing templates for the sustainable rating tool Green Star, saying that the same application could be done with the example case of Honeybee:

"Like Green Star has 'Green Star for commercial buildings', 'Green Star for schools', 'Green Star for residential'... we can do similar where you have a general source code which architects don't have to understand in detail and then all they have is a basic knowledge where they have to change or add and then they can use for commercial, or institutional or this. So, all this big drama that's happening here is taken care of by [the engineering consultant] and architects pull and then just connect few dots which are missing, which is very particular to their building and their site then it will get probably more easier and would save time."

In this, the architect was discussing being in partnership with an engineer, where the engineer would set up the workflows and the architect would 'close the hood' and only use the parts deemed necessary to change by the engineer:

"Our architect could download the scripts, which makes the workflow a lot easier so there's not many stuff you need to fill out to get to your end point and so if there's things that make it easier... it's simply going to be used".

\subsection{Is the use of the Distributed Model Method for Building Performance Sketching feasibility headed in the right direction?}

Finally, the last question addressed to all three focus groups was that of whether or not they believed the use of DMM, given Honeybee as an example, may lead to full implementation of performance sketching in the future. All groups indicated a strong 'yes'. In their answers, the architects commented that they believed the parametric abilities, and high interoperability along with real-time visual feedback of results allow the DMM to be highly attractive. However, they believed that workflows, such as the example created for this study, should lead the development of such methods.

Engineers commented that the parametric capabilities through the visual programming language (VPL) provided potential to speed up their simulation processes, but future developments should be aimed at making the process easier for the consultant to help the architect.

"I think it opens up a whole new round of possibilities that to me didn't exist five years ago. I've been a consultant for a bit more than 10 years. When I first started, programs like IES were relatively new and they offered a level of computing power that wasn't there before. I feel like it's stayed about the same, most of the time that I've been working. But the ability to run numerous iterations and parametric simulations like that, is a new thing I think that wasn't available and I can't see it going away." 


\subsection{Summary of Results: Mapping the Categories and their Relationships}

The architects discussed four main reasons why they do not implement performance sketching: the time and cost provided by the client/stakeholder; the perception of time in relation to understanding the program interface; their prioritisation on architectural aesthetics and method of design; and their lack of expertise as a user. They discussed the only ways in which they perceive these to be overcome would be if: the interface would be made adaptable and educational; they could see the value in performance sketching in informing design decisions; if they would be provided with training; and if the client could see the value in the process in order to allow for more time and money.

However, they noted that architects cannot be fully trained to the point where they would replace the expertise of the engineer. Therefore, the groups suggested the need for a partnership with the engineer in order to facilitate the creation of easier, but accurate, interfaces. Hence, the barriers of the engineer need to be overcome along with those for the architect. The engineers believed that their barriers are: time of engagement within the project; effective communication between team members; the use of programs which do not make their assumptions and calculations transparent; the inability to continue models through into different phases of the design process; and the assessment of design parameters for their accuracy. The engineers indicated within this study that all but the barrier of engagement can be overcome by the use of the example, Honeybee, using the DMM.

The barrier of engagement was rooted in the 'Old School' market attitude of 'We just don't do it that way'. Engineers and architects alike suggested that in order to overcome the current market attitude, building performance sketching should become legislation and the new generation of architects should be trained to design using performance sketching within their process. Thus, the designer would include comfort in their list of priorities, and the client would be required to include performance sketching within the early stages of design, thereby allocating cost and time to the process. 


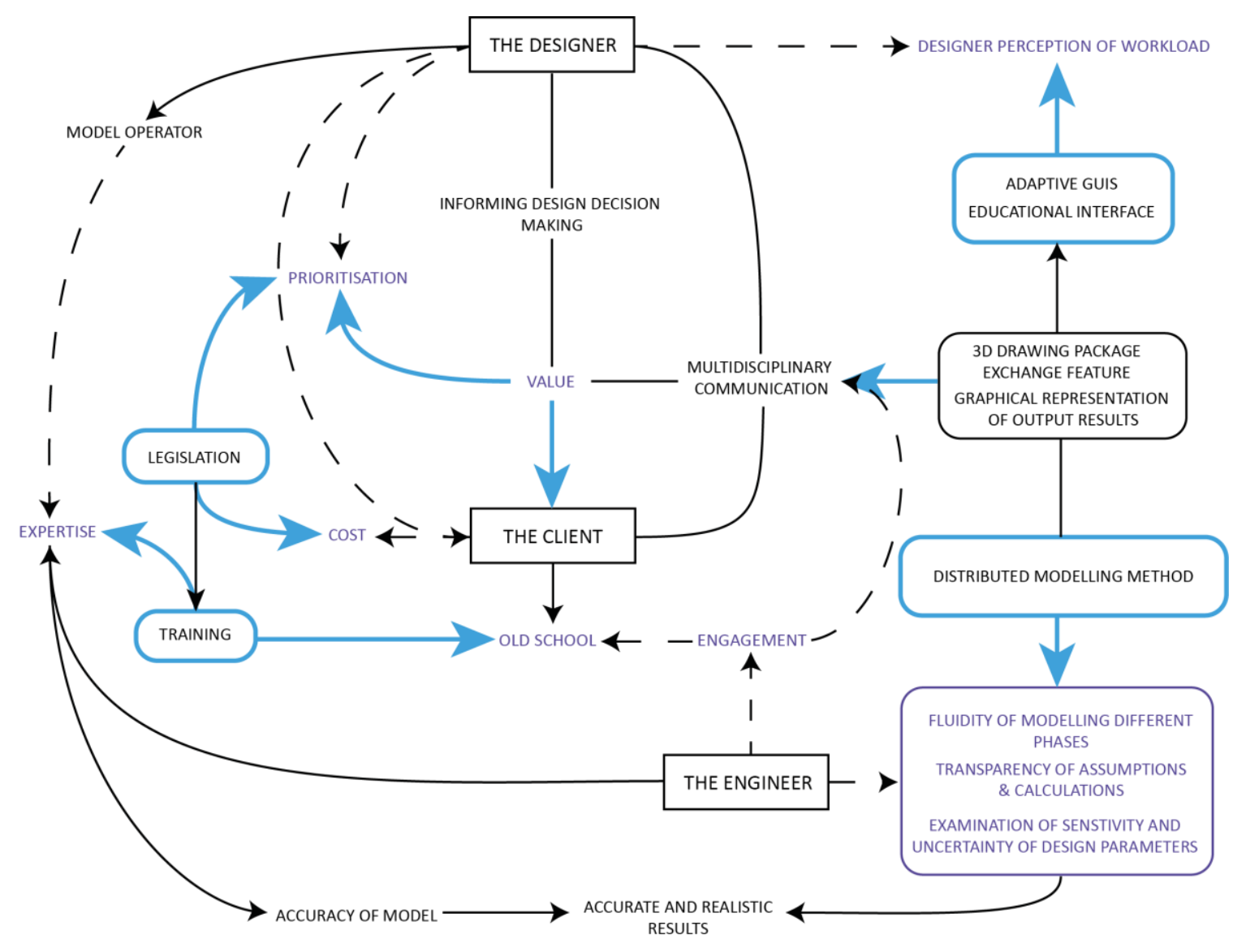

LEGEND

PERCEIVED BARRIER

$\begin{array}{llll}X \longrightarrow Y & X I S Y & X-Y & X \text { XVERCOMES } Y \\ X \rightarrow Y & X I S \text { BLOCKED BY } Y & X-Z \rightarrow Y & X \text { CAN SEE Y BECAUSE OF } Z\end{array}$

FIgURE 18 MAPPING ConcePTS AND theIR RELATIONSHIPS

In the process of mapping connections, as suggested by Framework Analysis in interpreting data using operational model diagram (Saldana, 2012), the diagram in Figure 18 was created. Figure 18 illustrates the relationships indicated by the participants between various concepts/categories brought up in their discussions. This mapping exercise illustrates the means in which recommendations made by the participants overcome the barriers they have established which prevent the implementation of the building performance sketch.

In creating the category connections through mapping, the categories which described the participant's established barriers were firstly identified in relation to their descriptions by the participants and which concepts represented the recommendations made by the participants to 'overcome' the barriers. Given the example of 'Expertise' as a category within the diagram, the data coded into this category describe the designer, where the designer is the user, being blocked from producing accurate models in performance sketching by the barrier of inexperience and lack of knowledge. The engineers stated that, due to their expertise, they would 
be able to generate accurate models which produce accurate and realistic results. Hence in reading the diagram using the provided legend of the connections, the designer IS the user BUT is blocked by their level of expertise in order to make accurate models to produce accurate and realistic results. The engineer IS an expert and therefore, as seen by the participants, can generate accurate models to produce accurate results. As suggested by the participants, training, either from education of new graduates, or standardised processes set through legislation, can OVERCOME the issues of level of experience faced by the designer. These statements are all supported by the comment,

"But I still think it's really important though, to have that grounding of your simulation results, compared to reality in some way [referring to a standard process or structure to follow for model validation]. I mean for us as experts, a lot of that's just going to come intuitively, through our own experience. I know I can look at a model and I can look at it and I can say, "Hey, that doesn't feel right." If we're taking this to outside of this group, to more of the design community or as a larger thing looking at architects or whatever you know, they might not have that kind of level of experience."

This means of summarising the results through mapping an operational model diagram highlights four areas for future development and discussion, and are highlighted in blue borders: Legislation; Education through training and available resources; improvements of the interface; and features specific to quality assurance using DMM. 


\section{CHAPTER FIVE - DISCUSSION AND CONCLUSIONS}

Chapter Four presented the findings of the study which suggest the need to change the imagined scenario introduced in Chapter One. The architects and engineers of this study believed that the scenario has to change to: "An architect and engineer are approached by a client to design a 'sustainable', energy efficient building with excellent indoor environmental quality". Where the engineer is engaged along with the architect, the participants of this study believe building performance sketching within the design process using the distributed model method (DMM) has the potential for the design team, rather than just the architect, to ensure the design will perform as intended.

Directed Content Analysis (DCA) described in Chapter Three was used to code the data from the focus group interviews into a coding scheme specifically created to allow the comparison of results to the recommendations in literature for tool development. This chapter presents the results of DCA in sections respective to the categories in the coding scheme. This presentation enables the comparison of results to literature in order to answer the first research question: 'Can the use of the DMM address all recommendations from literature for tool development?'. Furthermore, the numerical identification of which focus group contributed the most to a certain concept within 
the coding scheme is presented in diagrams to enables us to discuss the priorities, views and opinions of the two different disciplines, architects and engineers. This analysis provides depth to the answers provided for the second research question, in that improvements can be addressed for both users rather than just one: 'What must be improved in order to make the integration of building performance sketching feasible within the design process?'.

Thus, the study concludes that DMM cannot currently address all wants and wishes of users established in literature, but has the potential to given future development. Future research efforts are required to focus upon adaptable GUIs for the different modelling operators of the VPL, quality assurance measures including standards for modelling and guidelines for model validation, and creating industry specific templates for building types. Finally, the study concludes with future work required beyond tool development: Introducing legislation; and improving education of architects.

\subsection{Discussion: The Distributed Model Method as focus for Future Tool Development?}

In Chapter One, we established the problem of the typical scenario of an architect approached by a client to design a building which demands careful consideration of passive techniques, such as windows. The problem of this scenario was that the architect could not rely upon their usual rules of thumb technique for informing design, nor could they copy precendents and apply to their design what they did not understand. Rather, the architect required a new approach, that of building performance sketching, to evaluate their concepts based upon building performance simulation (BPS). The scenario then evolved going into Chapter Two to suggest the need for the expertise of an engineer as consultant and partner to ensure reliable and trustworthy performance predictions. We were able to understand that BPS required expertise attention and follow quality assurance procedures. However, quality assuring a 'simplified' model for BPS has its challenges, and along with these, the engineer and architect partnership presented itself as another large challenge to overcome. Literature suggested that a means to overcome these challenges, and lead way to implementing BPS within the design process in the future, tool developers must concentrate their efforts on methods which provide high interoperability.

The distributed model method (DMM) presented itself within literature as the best means to overcome the challenges within the integrated design process (IDP) approach, to enable effective design team collaboration and to provide the capabilities to address quality assurance barriers. However, there was no documented proof of concept to show that DMM could have the potential to meet these requirements. Thus, the following sections of this chapter will discuss where DMM was viewed by the 
participants of this thesis, architects and engineers, to meet or not meet the wants and wishes established within the 'wish list' from literature.

This chapter introduces the discussion surrounding the observations made across the three groups, and their underlining perspectives in answering the questions of the focus group. The architects concentrated on thinking about how the workflow and the use of the DMM could be feasible in their current practices in regards to how well it can fit within their current Buiding Information Management (BIM) processes. Matters of the interface and interoperability which the DMM could provide were discussed in relation to how quickly they could create and assess the architectural sketch before moving on to integrating it into a BIM process. The engineers focused their discussions and feedback upon the matter of quality assurance: expressing their concerns in having the inexperienced simulator as the designer creating simulation models. The mixed group commented upon both, BIM integration and quality assurance, but focused their attentions on the feasibility of implementing a new tool such as the example tool Rhino within their design studio. Their comments surrounded the idea of competitive fees and 'backing the wrong horse' - viewing a new emerging tool as a gamble to invest in:

"We'd have to back one horse but if it's not Honeybee and Grasshopper, it's something else."

"It will improve the level of analysis that we can provide early on. I think internally, our biggest barrier might be lining up all this software to be honest. Actually getting some of that 3-D business, and making sure it interfaces well with Rivet."

These considerations are not clear in literature, and raise a need for further exploration into business decisions surrounding adoption of new tools within the design studio. These comments suggest that the implementation of new tools should focus upon not only making the use of the tool easier and efficient in a design team context, but also consider interoperability to current tools used in industry. This would increase the likelihood of adoption within the design studio, as it would be seen as a means to improve current operations rather than demanding a radical change in processes which would take time and training to implement successfully.

These recommendations for future development from the participants, among others, are presented in their respective categories of the coding scheme. 


\subsubsection{Usability and Information Management (UIM) of interface}

TABLE 11 LITERATURE RECOMMENDATIONS FOR USABILITY AND INFORMATION MANAGEMENT (UIM) OF INTERFACE AND WHETHER OR NOT THE PARTICIPANTS OF THIS STUDY BELIEVED THE DMM HAS ADDRESSED THESE RECOMMENDATIONS, OR REQUIRE FURTHER DEVELOPMENT.

\begin{tabular}{|c|c|c|}
\hline Recommendations from Literature & $\begin{array}{l}\text { The DMM example } \\
\text { addresses this } \\
\text { recommendation }\end{array}$ & $\begin{array}{l}\text { Desirable, not yet } \\
\text { answered and } \\
\text { could readily be as } \\
\text { the DMM process } \\
\text { facilitates this }\end{array}$ \\
\hline $\begin{array}{l}\text { The ability to provide transparent } \\
\text { default options }\end{array}$ & $x$ & \\
\hline $\begin{array}{l}\text { The ability for users to be aware of } \\
\text { in-built assumptions }\end{array}$ & $x$ & \\
\hline $\begin{array}{l}\text { Features which enable adaptive } \\
\text { graphical user interfaces (GUIs) to } \\
\text { provide a balance between extensive } \\
\text { and basic data input in relation to } \\
\text { the user type and expertise }\end{array}$ & $x$ & $x$ \\
\hline
\end{tabular}

Usability and Information Management (UIM) of interface

(43)

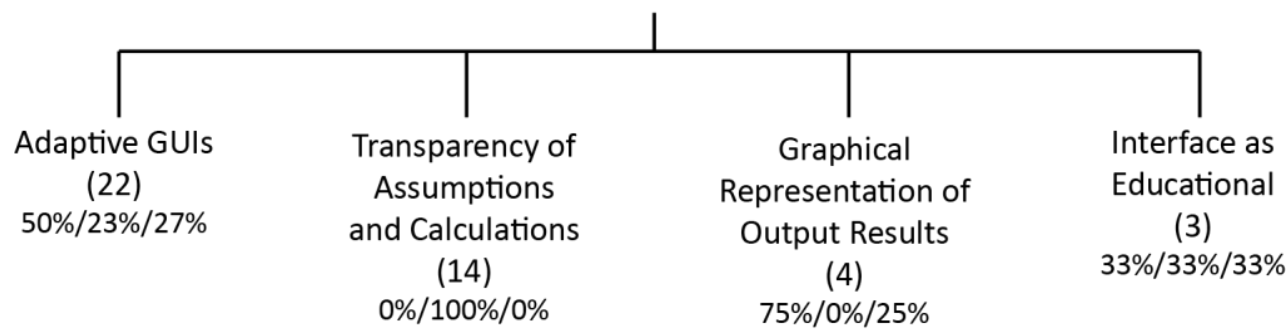

FigURE 19 CONCEPTS UNDER THE UIM CATEGORY, ALONG WITH INDICATED TOTAL NUMBER OF CODED DATA IN BRACKETS AND THE PERCENTAGE OF CONTRIBUTION TO THE TOTAL FROM EACH GROUP: ARChiteCts/EngineERS/Mixed GROUP

In relation to the usability and information management of the interface presented to the participants, their comments varied between groups and reflected their priorities and level of expertise in modelling. All groups expressed a liking of the approach of DMM but briefly requested more in-built learning modules - indicated in Figure 19 where the concept 'Interface as Educational' only had three quotes assigned to it, one from each group. Participants provided brief comments in acknowledging the appeal of the visual representation of results within the design tool, but architects wished for a simpler interface, and engineers expressed their concern in meeting that request. In 
their discussions, the participants argued their views and opinions towards the interface in regards to their skill level and quality control.

The most discussed topic regarding the interface of the example of DMM centred on the adaptability of the interface of the components within Honeybee as an example to cater for the different users, their skill levels and their priorities in modelling. Figure 19 illustrates that the architect group focused the most on this idea of adaptability, with $50 \%$ of data from the concept 'Adaptive GUIs' contributed by the architects. Their comments were mainly on the need to provide a "dumbed down" version for the architect as evidence given by Section 4.3.4. They expressed their concerns in having the ability to change almost every design parameter input for BPS, stating that they do not have the knowledge or confidence to trust themselves to be in control of so many parameters. Thus they requested an interface which only provides certain design parameters for them to change, leaving the rest 'under the hood' for the engineer to change for them.

The user interface discussed by the participants in our example is not the graphical user interface of Grasshopper, but rather the structure of the demonstration workflow interface of the Honeybee components. The architects stated that the user interface of Grasshopper itself would become less overwhelming the more they use it, thus requiring a simpler workflow module to work with, rather than demanding a simple interface overall.

The engineers' comments to this topic surrounded only the need to make the interface easier for the consultant, and their concerns for quality assurance if the architects interface is "too point and press". Their comments regarding the architects' reliance on the tool interface to guide them towards model accuracy complements the statements made by Augenbroe (2002), where designers treat the BPS tool as a 'black box'. This is further emphasised when considering that none of the architects within the architect group discussed the transparency of assumptions and calculations provided by the example, Honeybee, with a contribution of $0 \%$.

The engineers used the tool Sefaira as an example of a "too point and press" tool. This tool was discussed with enthusiasm in the architect group, however the engineers expressed their displeasure at the lack of transparency of the "wholesale assumptions" built into the tool. The engineers thus raised the question of whether or not a simplified, "dumbed down" version for architects would be such a good idea.

The comments made by the participants for the user interface highlighted the need to consider the inexperienced, non-simulation expert as recommended by current literature (Morbitzer, 2003) but also to encourage the designer to be more aware of quality control with the interface. Architects should be aware of any default assumptions made when they are presented with a simplified version. Furthermore, as indicated by Table 11 and Figure 19, only the engineering participants regard the DMM 
as being able to provide a means to check in-built assumptions and calculations. However, this conclusion may be due to the architect's ignorance ofthe impact unknown default assumptions can have on the accuracy of the model, an indication of this being provided in Section 4.2.3.

When questioned about the direction forward for the DMM and/or performance sketching, the architects concluded in consensus that workflows such as the one presented to them in this study should be developed for use in such tools. They suggested that the workflow be developed to have different GUIs, or 'modes', where the engineer creates all the necessary changes, covers them and then hands it over to the architect as a "dumbed down" version. The engineer can alter the parameters where necessary for the specific building design and indicate within the interface which parameters can be changed by the architect, and by what range (low bounds and high bounds set to ensure going below or above these would not cause performance issues). Thus, the partcipants suggested a highly intelligent form of modelling, cross checked by the qualified professionals whose lessions from performance analysis can be trusted. This would be a significant change to current modelling, where for example a model created in Revit would have no intelligence, no quality assurances of the model results. Hence, the significance of the proposed development is that the engineer provides the quality assurance for the architect's models, leaving the architect to focus upon what they are good at - form, façade, planning - and allowing them to trust that someone else with more experience ensured the performance predictions are valid.

"Like Green Star has 'Green Star for commercial buildings', 'Green Star for schools', 'Green Star for residential'... we can do similar where you have a general source code which architects don't have to understand in detail and then all they have is a basic knowledge where they have to change or add and then they can use for commercial, or institutional or this. So, all this big drama that's happening here is taken care of by [the engineering consultant] and architects pull and then just connect few dots which are missing, which is very particular to their building and their site then it will get probably more easier and would save time."

Thus, a feature for future tool development within DMM is to create 'modes' within the interface of the visual programming language (VPL) for the different users. As the VPL within DMM is created entirely of code, this feature can be readily created within the middleware program. 


\subsubsection{Integration of Intelligent design Knowledge-Base (IIKB)}

TABLE 12 LITERATURE RECOMMENDATIONS FOR INTEGRATION OF INTELLIGENT DESIGN KNOWLEDGEBASE (IIKB) AND WHETHER OR NOT THE PARTICIPANTS OF THIS STUDY BELIEVED THE DMM HAS ADDRESSED THESE RECOMMENDATIONS, OR REQUIRE FURTHER DEVELOPMENT.

\begin{tabular}{|lll|}
\hline Recommendations from Literature & $\begin{array}{l}\text { The DMM } \\
\text { example } \\
\text { addresses this } \\
\text { recommendation }\end{array}$ & $\begin{array}{l}\text { Desirable, not yet } \\
\text { answered and could } \\
\text { readily be as the } \\
\text { DMM process } \\
\text { facilitates this }\end{array}$ \\
\hline $\begin{array}{l}\text { Features for benchmarking and results } \\
\text { comparison }\end{array}$ & $\mathrm{X}$ \\
\hline $\begin{array}{l}\text { The ability to store and/or create and } \\
\text { share user libraries for contextual } \\
\text { material properties, occupant } \\
\text { behaviour patterns and climatic } \\
\text { design characteristics }\end{array}$ & $\mathrm{X}$ \\
\hline $\begin{array}{l}\text { The ability to inform different users at } \\
\text { different stages of design to optimise } \\
\text { and identify optimum building design } \\
\text { strategies }\end{array}$ & $\mathrm{X}$ & $\mathrm{X}$ \\
\hline $\begin{array}{l}\text { The ability to create and share } \\
\text { template workflows for different } \\
\text { building types }\end{array}$ & $\mathrm{X}$ & \\
\hline
\end{tabular}

Integration of Intelligent design Knowledge-Base (IIKB)

(30)

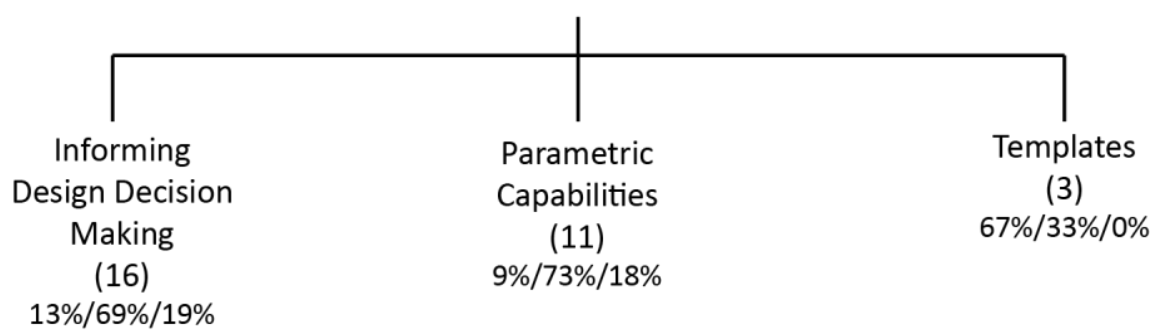

FIGURE 20 CONCEPTS UNDER THE IIKB CATEGORY, ALONG WITH INDICATED TOTAL NUMBER OF CODED DATA IN BRACKETS AND THE PERCENTAGE OF CONTRIBUTION TO THE TOTAL FROM EACH GROUP: ARCHitects/EngineERs/Mixed Group

The ability of DMM to meet the recommendations made from literature in regards to improving an intelligent design knowledge-base was mostly felt by the engineers.

Figure 20 illustrates that the engineers believed that the intelligent design knowledgebase offered within DMM could inform design decision making, with an overall contribution of $69 \%$ against the $13 \%$ from the architects and $19 \%$ from the mixed group. The engineers believed that informing design decision making came from the 
ability to run various iterations quickly and parametrically, through the use of the same model which is essential to the DMM, and checking the design parameters' influence on the end result in a sensitivity test:

"I guess, then you could potentially have the software tell you, that of all the 30 different variables you looked at, these five here, if you changed them even a little bit, they actually throw the whole thing ... they make a really negative outcome, so you should really think about those ones and make sure you design your flexibility into those ones."

The parametric capabilities of DMM, which is a distinguishing trait of DMM compared to the other methods, were perceived to be essential to informing design decisions by the engineers. Their $73 \%$ contribution to the concept surrounded discussion of parametric capabilities of DMM enabling the ability to optimise and identify optimum building designs strategies and compare various design iterations. Where the engineers enjoyed the capability to run hundreds of iteration simulations through the use of DMM, the architects specifically enjoyed the template workflow presented as a concept for further development within this study.

The architects recognised the ability to inform their design decisions by iteration but only saw it as a means to reach an optimised concept, and provided few discussions other than mentioning its worth in prior information:

"Let's say you design houses all around New Zealand, and in Queenstown the optimized WWR is $30 \%$ or something and you knew that going into the design, so if had that broad information to start with then you know it might help streamline the process."

The participants recognized the capability of parametric design and its means of informing design decisions specific to the DMM. They also recognised the need for user libraries, benchmarking of results and shared template workflows through using the workflow created within this study.

Table 12 tabulates the conclusion that DMM has the potential to address the recommendations made from literature.it is recognised that these wants and wishes can also be met by features from other modelling methods, however, the need for parametric design to inform design was seen by participants to only be available in the DMM at the time of writing this thesis:

"I think it opens up a whole new round of possibilities that to me didn't exist five years ago. I've been a consultant for a bit more than 10 years. When I first started, programs like IES were relatively new and they offered a level of computing power that wasn't there before. I feel like it's stayed about the same, most of the time that l've been working. But the ability to run numerous iterations and parametric simulations like that, is a new thing I think that wasn't available and I can't see it going away." 
"I mean, I could have run 50 simulations in EnergyPlus 10 years ago but it would have taken me you know, a month and this is not realistic in how buildings get built but with this ability, potentially you can bring all of that information and churn it out really that quickly."

To conclude: The DMM has potential to meet the recommendations from literature for IIKB, along with providing the capabilities of parametric simulation for informating design. However, architects have expressed beyond the engineers, with an overall contribution of $67 \%$ compared to $33 \%$ from the engineers, the need for templates of building types.

This study had created a conceptual workflow to explore the concept of a building performance sketch, providing a well-received taster for having such a suggested template for the commercial office building type. Having reacted positively to such an example, participants requested further efforts to provide the New Zealand building industry with templates for the other building types. These templates, which include building industry and building type specific data, are hypothesised to further address the problem of the risk of quality assurance an inexperienced user can pose (Donn et al., 2012). In accepting that many users treat the BPS tool as a 'black box', and that they do not often consider checking predetermined assumptions, providing building industry and building type templates and modules can help mitigate risks in quality assurance. These will also compliment the criteria and need for future development in adaptive GUls of different 'modes' discussed earlier in Secion 5.1.1. 


\subsubsection{Accuracy of tools and Ability to simulate Detailed and Complex building Components (AADCC)}

Table 13 Literature recommendations for Accuracy of tools AND Ability to SimUlate DETAILED AND COMPLEX BUILDING COMPONENTS (AADCC) AND WHETHER OR NOT THE PARTICIPANTS OF THIS STUDY BELIEVED THE DMM HAS ADDRESSED THESE RECOMMENDATIONS, OR REQUIRE FURTHER DEVELOPMENT.

\begin{tabular}{|c|c|c|}
\hline $\begin{array}{l}\text { Recommendations from } \\
\text { Literature }\end{array}$ & $\begin{array}{l}\text { The DMM example } \\
\text { addresses this } \\
\text { recommendation }\end{array}$ & $\begin{array}{l}\text { Desirable, not yet } \\
\text { answered and could } \\
\text { readily be as the } \\
\text { DMM process } \\
\text { facilitates this }\end{array}$ \\
\hline $\begin{array}{l}\text { Features which indicate the } \\
\text { degree of error that should be } \\
\text { tolerated in the results to inform } \\
\text { an uneducated user }\end{array}$ & - & $X$ \\
\hline $\begin{array}{l}\text { Features which enable the } \\
\text { description of the uncertainty of } \\
\text { the model, algorithms used and } \\
\text { their limitations }\end{array}$ & - & $x$ \\
\hline $\begin{array}{l}\text { The ability to conduct sensitivity } \\
\text { and uncertainty tests and } \\
\text { represent the data in a format all } \\
\text { users can understand }\end{array}$ & $x$ & $x$ \\
\hline
\end{tabular}

Accuracy of tools and Ability to simulate Detailed and Complex building Components (AADCC)

(33)

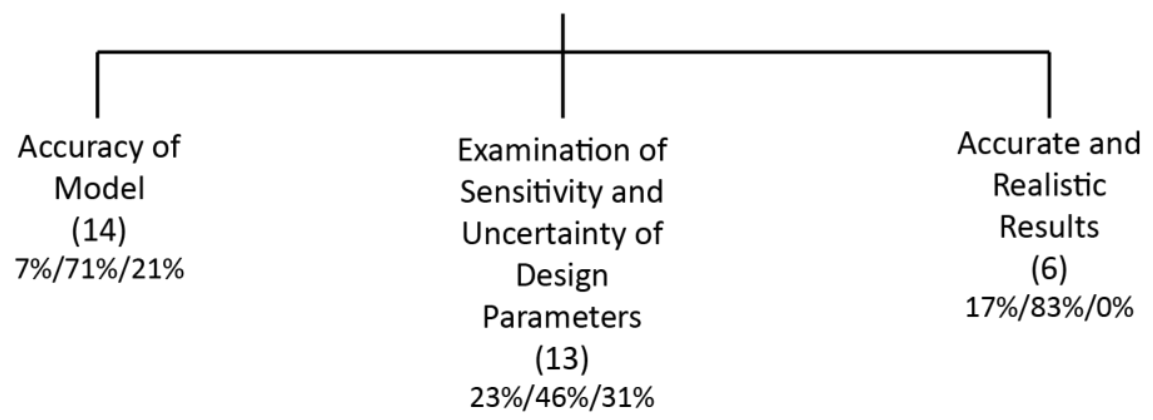

FigURE 21 CONCEPTS UNDER THE AADCC CATEGORY, ALONG WITH INDICATED TOTAL NUMBER OF CODED DATA IN BRACKETS AND THE PERCENTAGE OF CONTRIBUTION TO THE TOTAL FROM EACH GROUP: ARCHITECTS/EngINEERS/MIXED GROUP 
Recommendations by Attia et al (2012) for the AADCC category can potentially be addressed by the DMM. In theory, such features can easily be coded into a workflow as demonstrated by the conceptual workflow created within this study. Furthermore, the ability to conduct sensitivity and uncertainty tests by DMM was perceived by engineers to be a new capability which was not present before. This is heavily linked to the parametric capabilities of DMM using Grasshopper as a parametric tool.

The accuracy in modelling, and producing accurate results, was a heavy topic within the engineering group, with the other groups reflecting only upon the need for quality assurance procedures indicated in the building performance sketch workflow. Figure 21 illustrates that of all topics relating to AADCC, the engineer group contributed a significant amount of data - with $71 \%$ compared to a mere $6 \%$ from the architects in 'Accuracy of Model', 46\% compared to 23\% from architects in 'Examination of Sensitivity and Uncertainty of Design Parameters, and 83\% compared to no comments from the mixed and $17 \%$ from the architects in 'Accurate and Realistic Results'. Their comments largely focused on expertise, and held true to the findings in current literature. The participants agreed with Hensen (2004) and Morbitzer (2003) that to ensure quality of modelling, the user must have "sufficient domain knowledge" and understanding of the processes involved. Their recommendations are similar to those from Donn (2009), calling for building designers to become more educated within a field which is increasingly becoming more engineering-orientated.

Furthermore, engineers suggest the need for quality assurance standards and procedures to ensure model validity and emphasise the use of simulation, as indicated by Hensen (2004) - "Simulation is much more effective when used for comparing the predicted performance of design alternatives, rather than when used to predict the performance of a single design solution in absolute sense". This statement by Hensen (2004) was almost entirely mimicked by the engineers:

"Simulation should always be used as a comparative and assessment of different design ideas, rather than actually telling you how reality will eventuation."

To conclude: participants expressed the need for more documentation, and the availability of resources which could help architects and engineers alike to model New Zealand specific buildings accurately, rather than relying upon international default data derived from buildings in other countries and continents. These can be readily programmed into the VPL of the DMM, along with the coding required to report design parameter uncertainties and the degree of error tabulated in Table 13 as a desirable feature. 


\subsubsection{Interoperability of Building Modelling (IBM)}

TABLE 14 LITERATURE RECOMMENDATIONS FOR INTEROPERABILITY OF BUILDING MODELLING (IBM) AND WHETHER OR NOT THE PARTICIPANTS OF THIS STUDY BELIEVED THE DMM HAS ADDRESSED THESE RECOMMENDATIONS, OR REQUIRE FURTHER DEVELOPMENT.

\begin{tabular}{lll|} 
Recommendations from Literature & $\begin{array}{l}\text { The DMM } \\
\text { example } \\
\text { addresses this } \\
\text { recommendation }\end{array}$ & $\begin{array}{l}\text { Desirable, not yet } \\
\text { answered and could } \\
\text { readily be as the } \\
\text { DMM process } \\
\text { facilitates this }\end{array}$ \\
\hline $\begin{array}{l}\text { One common language to become an } \\
\text { open standard and full IFC (BIM) } \\
\text { compliance }\end{array}$ & $\mathrm{X}$ & $\mathrm{X}$ \\
\hline $\begin{array}{l}\text { The ability to use the same model for } \\
\text { all programs }\end{array}$ & $\mathrm{X}$ & \\
\hline
\end{tabular}

Interoperability of Building Modelling (IBM)

(31)

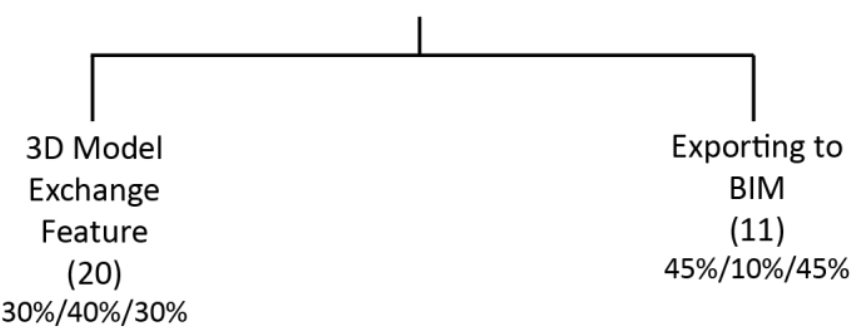

FIGURE 22 CONCEPTS UNDER THE IBM CATEGORY, ALONG WITH INDICATED TOTAL NUMBER OF CODED DATA IN BRACKETS AND THE PERCENTAGE OF CONTRIBUTION TO THE TOTAL FROM EACH GROUP: ArChitects/EngineERs/Mixed Group

The greatest challenge documented by literature is that of interoperability: the interoperability between BPS tools (such as EnergyPlus and DAYSIM) and design tools; and the interoperability between design tools for Building Information Modelling (BIM). Morbitzer (2003) may have been able to implement building performance simulation for the designer if not for the difficulties faced with interoperability within his study. Other authors who attempt to address the issues surrounding BPS tool adoption discuss the challenges of past tool interoperability (Augenbroe, 2002; Donn et al., 2012; Jacobs \& Henderson, 2002; Rezaee et al., 2015).

The engineers praised the interoperability of the DMM in its ability to couple design tools and BPS tools and linked this feature to the two main wishes to implementing building performance sketching described in Chapter Two: Quality assurance and design team communication. With high interoperability, issues with lost information previously faced disappear with the DMM. The ability to use the same model, and 
exchange this model from program to program, allows the process to be stream-lined through the creation of workflows. With the DMM, the VPL or middleware program also allows the same model to be created and simulated by different BPS tools. This benefit can be demonstrated in the example of Honeybee/Grasshopper, where EnergyPlus and DAYSIM are able to use the same model to create lighting schedules for all 8760 hours of the year for every zone, based upon Daylight Autonomy results from the daylight simulation which calculated 8760 hours of daylight availability across 1000 s of test points to be used for energy and thermal simulation - with a QA process involved to increase reliability. Furthermore, users are able to apply their expertise within environments they are comfortable with, and are not limited by the environment of the other tool. With high convergence between tools, the data is able to be transferred and presented in a format the users can understand, thereby addressing design team communication.

As illustrated in Figure 22, the groups where architects were present commented more on the need for interoperability with Building Information modelling (BIM) design tools than the engineers. Their comments surrounded the concern in exchanging data from the design tool to the design tool used in BIM:

"Sometimes you can set up things in a certain way in Revit and then you have to export it out, and different programs read differently so there are certain setups you need to do and that takes time to set up."

However, this study did not focus on the integration with BIM processes. The participants of the study agreed that the interoperability within the DMM between design tools and BPS tools is desirable, but requested further work to be done to demonstrate the interoperability between modelling methods, particularly from the distributed model method to the central model method for BIM. 


\subsubsection{Integration with Building Design Process (IBDP)}

TABLE 15 LiteratuRe RECOMmENDATIONS FOR INTEgRATION WITH BUILDING DESIGN PROCESS (IBDP) AND WHETHER OR NOT THE PARTICIPANTS OF THIS STUDY BELIEVED THE DMM HAS ADDRESSED THESE RECOMMENDATIONS, OR REQUIRE FURTHER DEVELOPMENT.

\begin{tabular}{lll|}
\hline Recommendations from Literature & $\begin{array}{l}\text { The DMM } \\
\text { example } \\
\text { addresses this } \\
\text { recommendation }\end{array}$ & $\begin{array}{l}\text { Desirable, not yet } \\
\text { answered and could } \\
\text { readily be as the } \\
\text { DMM process } \\
\text { facilitates this }\end{array}$ \\
$\begin{array}{l}\text { The ability of the tool to be used } \\
\text { during the design, commissioning and } \\
\text { occupancy phases by different users } \\
\text { for model calibration }\end{array}$ & $\mathrm{X}$ \\
\hline $\begin{array}{l}\text { The ability to create simplified and } \\
\text { detailed models within the same } \\
\text { program }\end{array}$ & $\mathrm{X}$ & \\
\hline $\begin{array}{l}\text { The ability for different user } \\
\text { interfaces to communicate to } \\
\text { different users using their familiar } \\
\text { language }\end{array}$ & $\mathrm{X}$ & \\
\hline
\end{tabular}

Integrated Building Design Process (IBDP)

(14)

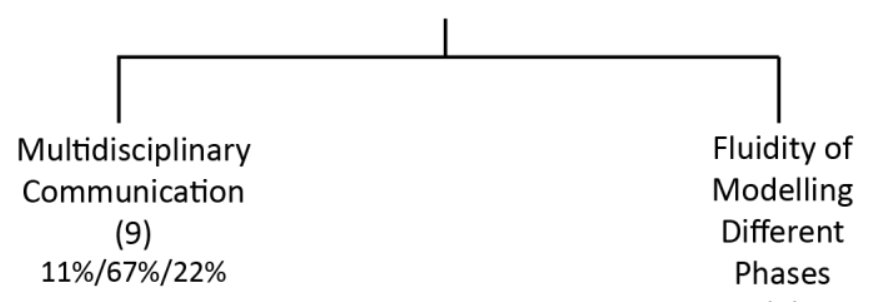

(5)

$0 \% / 80 \% / 20 \%$

FigURE 23 CONCEPTS UNDER THE IBDP CATEGORY, ALONG WITH INDICATED TOTAL NUMBER OF CODED DATA IN BRACKETS AND THE PERCENTAGE OF CONTRIBUTION TO THE TOTAL FROM EACH GROUP: ARCHitects/EngineERs/Mixed Group

This category aims specifically to address issues facing the integrated design process (IDP) approach. In literature, design teams are noted to face difficulties surrounding communication due to the language used for different programs and their functions. Pilgrim et al (2003) specifically note that a barrier towards effective IDP is visualisation. Furthermore, the participants across all three groups have indicated the particular lack 
of knowledge from all members to the processes taken by their members. Architects for example have little understanding of the significance the consultant's expertise can provide their designs, and engineers have little knowledge of the 'non-quantitative' processes the designers take to design.

"There's a lack of an understanding about how things impact on our design"[engineer response in relation to design team communication]

Figure 23 illustrates that the engineers much more than the architects, with a contribution of $67 \%$ compared to the $11 \%$ of the architects and $22 \%$ of the mixed, believe that DMM can provide for effective multidisciplinary communication through visualisation. The architects noted that the specific means of visualisation through the use of real-time is an attractive feature, as they are provided instant feedback from the program within their own program environment to a change in design. For example, when the designer or engineer changes the WWR of the design, they can see the visual result of the window change in the design tool. For Honeybee as the example used within this study, real-time visualisation in Rhino also works where a change in the design can cause a re-simulation of the design. Given the example in Figure 24, the designer may try to change the WWR of the windows to fix the problem of poor Daylight Autonomy at the back of the rooms. In changing the WWR, the model would update and a new daylight simulation would run. If this were connected to EnergyPlus for thermal and energy simulation, the daylight simulation would run first, then update the lighting schedule for the thermal and energy simulation. Given the speed and computer power of the computer used, this whole process can produce updated visualisation in the example model within minutes.

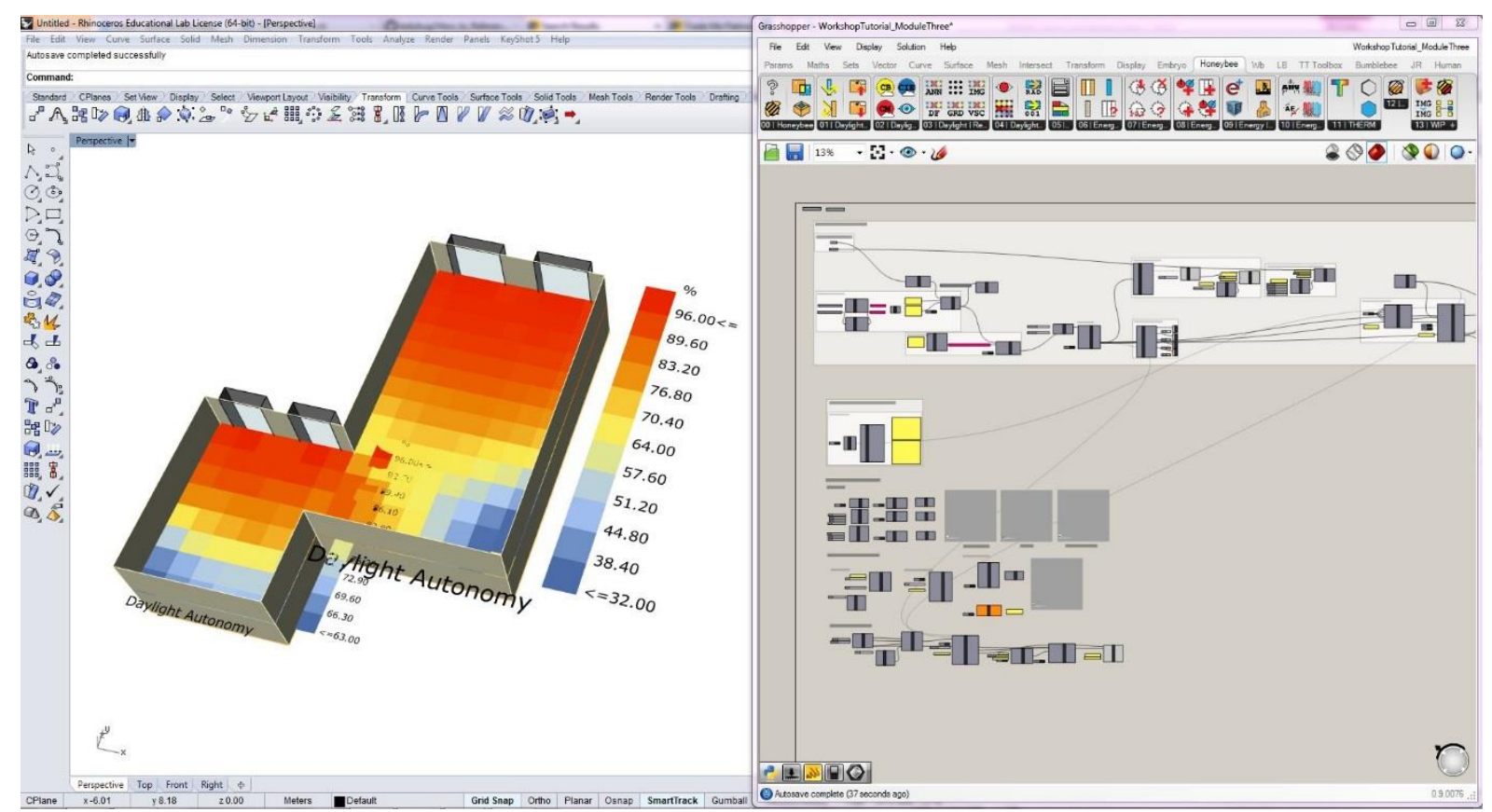

Figure 24 Example of Real-time Visualisation in RHino fRom Honeybee/Grasshopper INTERFACE 
The engineers expressed their attraction to this feature because they stated that it provides a better means to present their data, rather than producing reports which cannot be understood:

"I think the most powerful thing is, it's improving communication between the numbers, the physics you know, and the data side and it's translating it into the visual language that clients and architects can understand."

"We're moving away from the time where, we do this analysis, we write a report and we say, 'Here you go.'”

Engineers also commented that the ability for DMM to enable detailed simulation programs to be used at early stages of design can allow for the possibility of simplified and detailed models to be created within the same program. This capability to draw upon the detailed simulation programs of EnergyPlus, DAYSIM, Radiance and OpenStudio within the example DMM were found by the participants to be an essential feature as it would allow them to move through the design process, from simplified model to detailed, without needing to move to another program. This feature added to the benefits of the interoperability provided by the DMM. The most crucial benefit of this feature found by the engineers is that the ability to introduce detailed simulation engines to the early stages of design can allow the engineer to stop issues which may only have been identified later on in the design process where these engines are conventially used:

"One of the great things I think about what [author] showed us, is the whole mix of the EnergyPlus engine, the Radiance engine, the Daysim engine, all from that one model because, I've optimized many buildings for energy and then gone, "Oh, they're a bit fucking dark." You know, which is normally later on."

As indicated within Table 15, the only recommendation which this study is unable to conclude could be met by DMM is the ability for the tool to be used during commissioning and occupancy phases, as this was not part of the scope of the study.

To conclude: DMM has high potential to improve IDP amongst the design team. However, the method has only been tested in its possible application within the early stages of design and requires further research to determine its applicability past the design process, into commissioning and occupancy phases to aid in creating calibration models for existing buildings. 


\subsubsection{External Influences on the Design Process}

TABle 16 Literature recommendations for External Influences on the Design Process AND WHETHER OR NOT THE PARTICIPANTS OF THIS STUDY BELIEVED THE DMM HAS ADDRESSED THESE RECOMMENDATIONS, OR REQUIRE FURTHER DEVELOPMENT.

\begin{tabular}{|lll|}
$\begin{array}{l}\text { Recommendations from } \\
\text { Literature }\end{array}$ & $\begin{array}{l}\text { The DMM example } \\
\text { address this } \\
\text { recommendation }\end{array}$ & $\begin{array}{l}\text { Desirable, not yet } \\
\text { answered and could } \\
\text { readily be as the } \\
\text { DMM process } \\
\text { facilitates this }\end{array}$ \\
\hline $\begin{array}{l}\text { The ability to sustain complete, } \\
\text { coherent and expressive } \\
\text { communication through } \\
\text { visualisation of value }\end{array}$ & $\mathrm{X}$ & \\
\hline $\begin{array}{l}\text { Reduce time taken to simulation } \\
\text { design iterations }\end{array}$ & $\mathrm{X}$ & \\
\hline
\end{tabular}

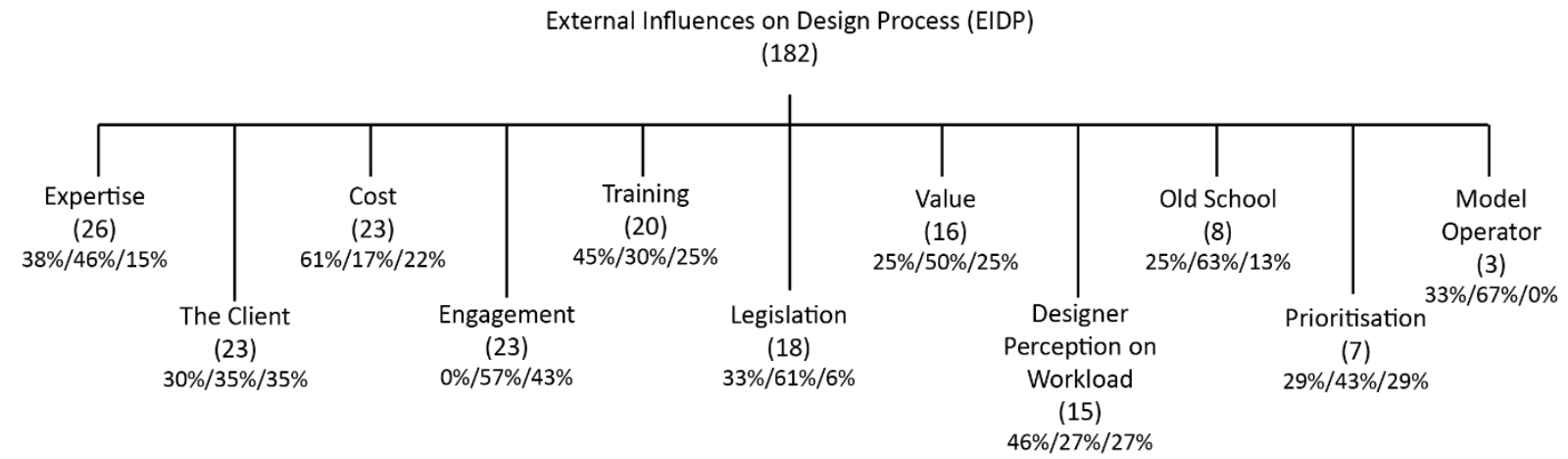

FIGURE 25 CONCEPTS UNDER THE EIDP CATEGORY, ALONG WITH INDICATED TOTAL NUMBER OF CODED DATA IN BRACKETS AND THE PERCENTAGE OF CONTRIBUTION TO THE TOTAL FROM EACH GROUP: ARCHItECTS/EngINEERs/Mixed Group

Participants discussed the greatest barrier to be the client, and the role which the client plays in controlling what they are able to do during early stages of design. In considering the distribution of contributions in Figure 25, the architects discussed mainly external influences such as the client, cost and time taken to do the work. However, when the architects discussed the notion of being 'converted architects' [architect's use of the word], they faced the barrier of knowledge and expertise instead. As the 'model operator' (modeller), the architect requires expertise to create accurate models which he/she can trust to inform their design correctly. However, without experience this process of model validation could be too time consuming (Jacobs \& Henderson, 2002). The architects thus contributed the most to the recommendation of training, as they recognised their own lack of knowledge. 
The engineers focused their discussions on their frustrations with the current processes of design, largely described as 'set in their ways'. They contributed the most to the discussion around the current traditional generation and their views on appropriate time of engagement, their concerns of the architect as the user in terms of quality assurance, the value of what they do as a profession which they believe is largely underestimated and their frustrations at the priorities of the designer. As discussed in Section 4.1.1.1., the engineers stated they cannot approach the client at an appropriate time due to traditional approaches to engagement, the 'Old School' approach to design. Thus resulting in the recommendation from participants of introducing legislation to drive the client to engage them earlier.

It is interesting to note here that the views from the engineers in regards to the 'Old School' approach to design was commented upon by all ages within the engineer and mixed groups. Both the young and the most senior of the engineer group expressed this frustration about the 'set in their ways' attitude of the market, and was confirmed by the most senior engineer in the mixed group. Thus, no age bias was present in these findings.

To conclude: the real challenges to BPS adoption fall outside of what tool development could bring and are instead presented by the level of expertise and traditional attitude of the current building industry. Where the client is viewed by the professions to be their greatest barrier, the real problem is driving the market to change. Furthermore, architects within the industry must be educated to the importance and processes of BPS for informing design if New Zealand wishes to create high performance buildings.

\subsection{Conclusion}

The data of this study from the focus groups is sufficient to conclude that the distributed modelling method (DMM) cannot overcome all barriers preventing the implementation of building performance sketching. This study has shown that architects and engineers within New Zealand's building industry consider some external influences on the design process to be barriers which the DMM cannot overcome on its own. These include barriers such as the client and current 'set in their ways' attitude of the market described in Seciton 4.1.1. However, the architects and engineers of this study believe the DMM has high potential to address all the wants and wishes for future tool development made by current literature, including their own. Their lasting comment is that future development should focus upon furthering the processes in the DMM to implement building performance sketching for the future. 
"I think it opens up a whole new round of possibilities that to me didn't exist five years ago. I've been a consultant for a bit more than 10 years. When I first started, programs like IES were relatively new and they offered a level of computing power that wasn't there before. I feel like it's stayed about the same, most of the time that l've been working. But the ability to run numerous iterations and parametric simulations like that, is a new thing I think that wasn't available and I can't see it going away."

The DMM was seen by the participants as a means to aid in overcoming the barriers against the implementation of building performance sketching by increasing design team communication, reducing time taken during the design process for simulation, and enabling means for quality assurance and effective team collaboration.

\subsubsection{Can the use of the distributed model method address the wants and wishes of users for tool development?}

The simple answer is 'not currently'. The DMM process can facilitate the development to address the wants and wishes of users but requires further development to smooth out the edges. The greatest barriers addressed in literature were that of quality assurance and design team collaboration. The problem addressed in our scenario in Chapter One was that the architect, as an inexperienced simulator, cannot ensure their design will perform as intended. With the help of the engineer, the sensitivity and uncertainty analysis defined within building performance sketching, and tools which promote high interoperability, the participants of this study believe the design team can ensure the quality of the design changes.

Before building performance sketching can become a reality within the future, this study concludes with three main topics which must be addressed by future development and research. This leads onto our next research question.

\subsubsection{What must be improved in order to make the integration of building performance sketching feasible within the design process?}

The participants of this study enjoyed all features of the DMM, however several features noted within the conceptual workflow were indicated to need further development. These features were:

\section{- Standard modelling guidelines and templates specific to New Zealand}

(Section 4.3.3. and 4.3.4.): The participants liked the workflow created within this study, and requested the conceptual workflow to be developed into a standard workflow with templates specific in modelling building types for the New Zealand building industry which contain New Zealand specific building data. Participants also requested the creation of modelling guidelines for their use in DMM for design. These templates should include benchmarks for their 
respective building type and uncertainty reporting to inform the user of the validity and reliability of their results in the building context.

- The development of adaptable graphical user interfaces for different users of these templates to meet their level of modelling expertise and priorities

(Section 4.3.4.) - Architects wished for the number of inputs to be simpler, as the current example is "too overwhelming"; engineers wished for the templates to provide full control and transparency of assumptions, along with the ability to simplify the interface for the architect to ensure the interface is not "too point and press". Thus a template workflow should be created which allows the engineer to quality assure the workflow for the specific building, 'cover the hood' and hand over a template which the architect can trust to provide reliable performance predictions, enabling them to focus upon what they are trained to do.

- The development of the user interface of the workflow structure to be educational for a non-simulation expert to understand the processes of building performance simulation - The interface given to the architect from the engineer mentioned above should be visually appealing in order to communicate the value of building performance simulation and encourage continual use. Furthermore, it would help the architect in remembering the process if they had been disconnected in its use for a long period of time due to the scope of a project.

"When you think it will be useful, if there's a series of comments and tips and helpful hints and things that are in prompts, that are going to come up and disclose other things and say to you, "Hey, what about this?" Or you know, "Your typical ranges would be this." That definitely helps you get to the right answer faster, so I think that's good stuff to have on here. It makes it much easier to use."

Other recommendations from the participants of this study go beyond tool development, focusing on means to address the external barriers on the design process such as: the level of expertise of the architect as designer; and the traditional 'set in their ways' attitude of the current market.

\subsubsection{Education}

A continuous underlining theme of this study has been lack of understanding, knowledge and value awareness by the industry and designers. In refering to the category map diagram of Figure 18 in Section 4.5., the participants believed that an approach to overcoming the issues of expertise in modelling for quality assurance, and the Old School attitude of the market was to educate the 'old' and 'new' architects of the building industry. 
"But these problems that you're dealing with are probably with the current industry, with the current times, with the current architects, but the new generation will come out, if they're taught a different way of design like doing the performance sketch as part of their design right from the beginning. But when we came up with the old school way of designing, so it's just the whole mind set of reversing it and looking at designing as such in a different format..."

Thus, the study concludes the need for:

- Tertiary education of architects to integrate building performance sketching in their design processes: The problem faced in this recommendation is that architects are currently already taught some form of building performance simulation in their education. Thus, designers need to be educated not only in the processes of building performance simulation but in the significance such a design assessment can make to their design decision making process. Students must be rewarded for their use of building performance sketching to inform design decisions in tertiary education, rather than shrugging it off as something which the engineer would only do. Only then would building performance sketching become part of the routine assessment of the architect's design process. Furthermore, the architects within this study indicated the current trend of hiring graduates, stating that where the graduate is trained to have a specific skill required within the industry, they will be hired (refer to Section 4.3.2.). Given the current trend towards building high performance buildings, either for Green Star accreditation, sustainable image, or simply code compliance, future architects would be better equipped to obtaining a job after graduation if they are trained to include building performance sketching. This would encourage the educational and the professional design studio to include building performance sketching in their routine assessment and dialogue in designing. Thus architects can be encouraged to include building performance sketching in their design process, and see it as extra work which would add value. Finally, it is essential for the future of building performance sketching that such a process become the 'norm' within the design process, such that the new generation does not face the same 'set in their ways' old attitude as the current generation of designers.

- The creation and sharing of publicly available resources for upskilling professionals within the field: As indicated by the self-proclaimed 'converted' architect, the barrier of expertise and knowledge of performance simulation prevents a willing architect from building performance sketching within their design studio (refer to Section 4.1.1.7.). Thus, tutorial workshops, and online documentation should become more readily available to the industry to encourage designers to continue their professional development within the industry and implement better ways to inform their design decisions to designing high performance buildings. 


\subsubsection{Legislation and Standards}

The participants in this study believe that the greatest driver to change is legislation. In refering to the category map diagram of Figure 18 in Section 4.5., the participants believed that legislation could demand the education of architects and more engineers. Furthermore, engineers believed that the priorities of the architects, and the time allocated to them by the client and/or project manager, would be changed if it were made mandatory to implement building performance sketching within the design process. Thus we conclude with the following recommendations if legislation were to be used as a driver as suggested by the participants (refer to Section 4.3.1.):

- Legislation made through expertise: Given the need for legislation as a driver, careful consideration of this legislation should be made in regards to quality assurance. Where it is made mandatory to performance sketch a building design, the quality assurance process of building performance sketching should be followed carefully and preferably by an expert within the field. It would defeat the purpose if building performance sketching were done incorrectly, thereby resulting in a poorly performing building in operation.

- Building Performance Simulation Union or Institute: With the growing level of expertise and use of building performance simulation within the design process, New Zealand requires an institute or union where members can collaborate and help each other in modelling:

"I think mine [established barriers] are all about the skill level barrier, which would be address by somehow coming out with a bunch of standardized and repeatable workflows of some nature. Some level of industry/peer collaboration to standardize those workflows, so amongst the people using them. Eventually once the market builds up a bit of momentum, it becomes an agreement about, this is how we get it done and this is the fastest way to do it."

\subsection{Future Work}

All participants believed that future work should focus upon developing the Distributed Model Method (DMM). The limitations of the scope of this study can be addressed by future academic studies which focus on the use of the DMM. Features which were unable to be tested due to the scope of this study are:

- The comparison between Honeybee/Grasshopper/Rhino vs. Dynamo/Revit At the time of writing this thesis, Dynamo/Revit was not at a state which could provide reliable coupling between the design tool and BPS tools without requiring some difficulty in translating model geometry. Thus, a comparison of the two programs and their use in the DMM was unable to be presented to the participants. However, as Dynamo and Grasshopper/Honeybee contain much the same features and parametric capabilities, it was not expected that the 
comparison would produce any additional results for the use of DMM for building performance sketching. The comparison study may however provide grounds for a new research project investigating the interoperability between the DMM and central model method used in BIM. The participants of the study did ask regarding the interoperability between Rhino and Revit, "Taking just the building out of Revit, what's that sort of step putting that into this, is that very hard?", to which an example plug-in (Grevit, 2016) was briefly described, but this interoperability was not the subject of the research and so was not demonstrated.

- The use of DMM for commissioning and occupancy phases for model calibration - The only feature which was not met directly demonstrated to the participants was the use of the DMM in other stages of design and beyond as a method for model calibration, established in Section 5.1.5. Though the DMM process can facilitate the use of EnergyPlus as an example of a tool commonly used for calibration, its use for calibration purposes as a means to make the user interface or process of calibration quicker or easier has not been tested. Future research in this topic could compliment the findings of this study, in that the DMM can meet all wants and wishes of the users within the building industry.

- Validation testing of the translation of languages between programs in the DMM - e.g. the translation of geometry from Rhino to Grasshopper to Honeybee to the building performance simulation engine is coded and may contain a bug within the code. This issue was briefly raised by the engineers of the study in relation to the open source quality of the example Honeybee for the DMM. Due to the DMM process using VPL as a middleware program to translate from one program to the next, this program must be validated. One engineer raised the following quote, but was argued by another that the open source quality of the program allows for quality assurance because there are more 'eyes' looking at the code to spot the bugs and iteration through parametric simulation can make these bugs obvious to the expert. Nevertheless, this raises pause for concern in general use.

"There's a need for quality assurance of that. I mean, the module is so specific, you'd think it would actually be very obvious if there was some bug in the module, which was not doing what you thought it was going to do but there is potential there. Particularly because of open source, if people start writing their own little modules and adding them in in some way, then yeah, there's a quality control issue there."

- Focus groups exploring the views of the client to such a process of design This study focused upon answering how the users of building performance sketching can see it becoming feasible within the design process, therefore only gained insights from the architects and engineers concerning its 
implementation and the barriers they face in dealing with clients. We note therefore that it would be beneficial to hear the perspective of the 'other side' - the client - to understand their wants and wishes for visual communication and expectations of the use of such a process to design. 


\subsection{References}

Amitrano, L., Isaacs, N., Saville-Smith, K., Donn, M., Camilleri, M., Pollard, A., ... Cory, S. (2014). Building Energy End-Use Study (BEES) Part 1: Final Report (Study Report SR 297/1 (2014) No. SR 297/1). Judgeford, New Zealand: BRANZ.

Arup. (2013). The performance gap: Causes \& solutions, green construction board building working group. Retrieved from http://www.greenconstructionboard.org/images/stories/pdfs/performancegap/2013-03-04\%20Closing\%20the\%20Gap_Final\%20Report_ISSUE.pdf

Asadi, S., Amiri, S. S., \& Mottahedi, M. (2014). On the development of multi-linear regression analysis to assess energy consumption in the early stages of building design. Energy and Buildings, 85, 246-255.

ASHRAE. (2007). ANSI/ASHRAE 140-2007: Standard Method of Test for the Evaluation of Building Energy Analysis Computer Programs. ASHRAE.

Attia, S., Beltrán, L., De Herde, A., \& Hensen, J. (2009). 'Architect Friendly': a comparison of ten different building performance simulation tools. Retrieved from http://orbi.ulg.ac.be/handle/2268/167578

Attia, S., Hensen, J. L. M., Beltrán, L., \& Herde, A. D. (2012). Selection criteria for building performance simulation tools: contrasting architects' and engineers' needs. Journal of Building Performance Simulation, 5(3), 155-169. http://doi.org/10.1080/19401493.2010.549573

Augenbroe, G. (1992). Integrated building performance evaluation in the early design stages. Building and Environment, 27(2), 149-161. http://doi.org/10.1016/0360-1323(92)90019-L

Augenbroe, G. (2002). Trends in building simulation. Building and Environment, 37(89), 891-902. http://doi.org/10.1016/S0360-1323(02)00041-0

Autodesk, Inc. (2015a). Autodesk. Retrieved 10 December 2015, from http://www.autodesk.com/

Autodesk, Inc. (2015b). Dynamo BIM. Retrieved from http://dynamobim.org/

Autodesk, Inc. (2015c). Introducing Autodesk Insight 360. Retrieved 10 December 2015, from http://blogs.autodesk.com/insight360/introducing-autodeskinsight-360-2/

Berkeley, P., Haves, P., \& Kolderup, E. (2014). Impact of modeler decisions on simulation results. Presented at the 2014 ASHRAE/IBPSA-USA Building Simulation Conference, Atlanta, GA.

Bordass, B., Cohen, R., \& Field, J. (2004). Energy Performance of Non-Domestic Buildings - Closing the Credibility Gap. Presented at the International Conference on Improving Energy Efficiency in Commercial Buildings, Frankfurt, Germany. 
Bordass, B., Leaman, A., \& Ruyssevelt, P. (2001). Assessing Building Performance in Use 5: Conclusions and Implication. Building Research and Information, 29(2), 144-157.

Boychuk Duchscher, J. E., \& Morgan, D. (2004). Grounded theory: reflections on the emergence vs. forcing debate. Journal of Advanced Nursing, 48(6), 605-612. http://doi.org/10.1111/j.1365-2648.2004.03249.x

Carey, M. A., \& Smith, M. W. (1994). Capturing the Group Effect in Focus Groups: A Special Concern in Analysis. Qualitative Health Research, 4(1), 123-127. http://doi.org/10.1177/104973239400400108

Cerezo, C., Dogan, T., \& Reinhart, C. (2014). Towards Standardized building properties template files for early design energy model generation. In Proceedings of 2014 ASHRAE/IBPSA-USA Building Simulation Conference. Atlanta, GA.

CIBSE. (2006). Standard Tests for the Assessment of Building Services Design Software. London: Chartered Institution of Building Services Engineers.

CIBSE. (2013). Evaluating operational energy performance of buildings at the design stage. The Chartered Institution of Building Services Engineers London.

Cohen, R., Bordass, B., Standeve, M., \& Leaman, A. (1999). Final Report 1: Review of the PROBE Process. PROBE Strategic Review.

Cory, S. (2016). An exploration of the feasibility of converting the New Zealand commercial building stock to be Net Zero Energy. Retrieved from http://restrictedarchive.vuw.ac.nz//handle/123456789/9092

Cory, S., Gates, A., \& Donn, M. (2011). The creation of generic energy simulation models which represent typical commercial buildings and their calibration against real energy data. In Proceedings of 12th Conference of International Building Performance Simulation Association. Sydney, Australia.

Davidson, S. (2015). Grasshopper. Retrieved 9 December 2015, from http://www.grasshopper3d.com/

Davis, D., \& Peters, B. (2013). Design ecosystems: customising the architectural design environment with software plug-ins. Architecture and Design, 83, 124-131.

DAYSIM. (2016). DAYSIM. Retrieved 10 April 2016, from http://daysim.ning.com/

Donn, M. (1997). A survey of users of thermal simulation programs. In Proceedings of 5th International IBPSA Conference (pp. 8-10). Prague, Czech Republic. Retrieved from http://scholar.google.com/scholar?cluster=16579032091486272057\&hl=en\&oi =scholarr

Donn, M. (2001). Tools for quality control in simulation. Building and Environment, 36(6), 673-680. http://doi.org/10.1016/\$0360-1323(00)00059-7

Donn, M. (2009). Simulation of Building Performance. Saarbrücken: VDM.

Donn, M., Selkowitz, S., \& Bordass, B. (2012). The building performance sketch. Building Research \& Information, 40(2), 186-208. 
Elo, S., \& Kyngäs, H. (2008). The qualitative content analysis process. Journal of Advanced Nursing, 62(1), 107-115. http://doi.org/10.1111/j.13652648.2007.04569.x

EnergyPlus. (2016a). EnergyPlus. Retrieved 10 April 2016, from https://energyplus.net/ EnergyPlus. (2016b). Weather Data. Retrieved 11 April 2016, from https://energyplus.net/weather

Gann, D., Salter, A., \& Whyte, J. (2003). Design Quality Indicator as a tool for thinking. Building Research \& Information, 31(5), 318-333.

Gill, Z. M., Tierney, M. J., Pegg, I. M., \& Allan, N. (2010). Low-energy dwellings: the contribution of behaviours to actual performance. Building Research \& Information, 38(5), 491-508. http://doi.org/10.1080/09613218.2010.505371

Glaser, B. G. (1992). Basics of Grounded Theory Analysis: Emergence vs. forcing. Mill Valley, CA: The Sociology Press.

Glaser, B. G., \& Strauss, A. L. (1967). The Discovery of Grounded Theory: Strategies for Qualitative Research. Aldine Publishing Company.

Goulding, J. E. (1993). Energy in architecture: The Passive Solar Handbook. Dublin: Commission of the European Communities.

Granadeiro, V., Duarte, J. P., Correia, J. R., \& Leal, V. M. S. (2013). Building envelope shape design in early stages of the design process: Integrating architectural design systems and energy simulation. Automation in Construction, 32, 196209. http://doi.org/10.1016/j.autcon.2012.12.003

Grevit. (2016). Grevit. Retrieved 8 April 2016, from http://moethu.github.io/Grevit/ Hatch, J. A. (2002). Doing Qualitative Research in Education Settings. SUNY Press. Hensen, J. L. M. (2004). Towards More Effective Use of Building Performance Simulation in Design. Retrieved 2 April 2016, from http://cumincad.scix.net/cgibin/works/Show?ddss2004_d-291

Hsieh, H.-F., \& Shannon, S. E. (2005). Three Approaches to Qualitative Content Analysis. Qualitative Health Research, 15(9), 1277-1288. http://doi.org/10.1177/1049732305276687

Hygh, J. S., DeCarolis, J. F., Hill, D. B., \& Ranji Ranjithan, S. (2012). Multivariate regression as an energy assessment tool in early building design. Building and Environment, 57, 165-175. http://doi.org/10.1016/j.buildenv.2012.04.021

IESVE. (2015). Integrated Environmental Solutions. Retrieved 14 June 2015, from http://www.iesve.com/

Jacobs, P., \& Henderson, H. (2002). State-of-the-Art Review Whole Building, Building Envelope, and Hvac Component and System Simulation and Design Tools. Architectural Energy Corporation, Boulder, CO (US); CDH Energy Corp., Cazenovia, NY (US). Retrieved from http://www.osti.gov/scitech/biblio/795581 Jakubiec, J. A., \& Reinhart, C. (2011). DIVA 2.0: Intregrating daylight and thermal simulations using Rhinoceros 3D, DAYSIM and EnergyPlus. In Proceedings of Building Simulation. Sydney, Australia. 
Kidd, P. S., \& Parshall, M. B. (2000). Getting the Focus and the Group: Enhancing Analytical Rigor in Focus Group Research. Qualitative Health Research, 10(3), 293-308. http://doi.org/10.1177/104973200129118453

Kitzinger, J., \& Barbour, R. (1999). Developing Focus Group Research: Politics, Theory and Practice. SAGE.

Klitgaard, J., Kirkegaard, P. H., \& Mullins, M. (2006). On the integration of digital design and analysis tools (Vol. 1, pp. 187-196). WIT Press. http://doi.org/10.2495/DARC060191

Leech, N. L., \& Onwuegbuzie, A. J. (2005). Qualitative data analysis: Ways to improve accountability in qualitative research. Presented at the American Educational Research Association, Montreal, Canada.

Leech, N. L., \& Onwuegbuzie, A. J. (2007). An array of qualitative data analysis tools: A call for data analysis triangulation. School Psychology Quarterly, 22(4), 557584. http://doi.org/10.1037/1045-3830.22.4.557

Leech, N. L., \& Onwuegbuzie, A. J. (2011). Beyond constant comparison qualitative data analysis: Using NVivo. School Psychology Quarterly, 26(1), 70-84. http://doi.org/10.1037/a0022711

McNeel Europe. (2015). Food4Rhino. Retrieved 9 December 2015, from http://www.food4rhino.com/?ufh

Menezes, A. C. K. de. (2013). Improving predictions of operational energy performance through better estimates of small power consumption (Thesis). (C) Anna Carolina Kossmann de Menezes. Retrieved from https://dspace.lboro.ac.uk/dspace-jspui/handle/2134/13549

Morbitzer, C. A. (2003). Towards the integration of simulation into the building design process. University of Strathclyde, Glasgow, UK.

Morgan, D. L. (1995). Why Things (Sometimes) Go Wrong in Focus Groups. Qualitative Health Research, 5(4), 516-523. http://doi.org/10.1177/104973239500500411

Negendahl, K. (2015). Building performance simulation in the early design stage: An introduction to integrated dynamic models. Automation in Construction, 54, 39-53. http://doi.org/10.1016/j.autcon.2015.03.002

Newsham, G. R., Mancini, S., \& Birt, B. J. (2009). Do LEED-certified buildings save energy? Yes, but... Energy and Buildings, 41(8), 897-905.

Norford, L. K., Socolow, R. H., Hsieh, E. S., \& Spadaro, G. V. (1994). Two-to-one discrepancy between measured and predicted performance of a 'low-energy' office building: insights from a reconciliation based on the DOE-2 model. Energy and Buildings, 21(2), 121-131. http://doi.org/10.1016/03787788(94)90005-1

Ochoa, C. E., Aries, M. B. C., \& Hensen, J. L. M. (2012). State of the art in lighting simulation for building science: a literature review. Journal of Building Performance Simulation, 5(4), 209-233.

http://doi.org/10.1080/19401493.2011.558211 
Ochoa, C. E., \& Capeluto, I. G. (2008). Strategic decision-making for intelligent buildings: Comparative impact of passive design strategies and active features in a hot climate. Building and Environment, 43(11), 1829-1839. http://doi.org/10.1016/j.buildenv.2007.10.018

Onwuegbuzie, A., Dickinson, W., Leech, N., \& Zoran, A. (2009). A qualitative framework for collecting and analyzing data in focus group research. International Journal of Qualitative Methods, 8(3).

OpenStudio. (2016). OpenStudio. Retrieved 10 April 2016, from https://www.openstudio.net/

Patton, M. Q. (2002). Qualitative Research \& Evaluation Methods. SAGE Publications.

Pegg, I. M. (2007). Assessing the Role of Post-occupancy Evaluation in the Design Environment - A Case Study Approach (EngD Environmental Technology Dissertation). Brunel University.

Picco, M., Lollini, R., \& Marengo, M. (2014). Towards energy performance evaluation in early stage building design: A simplification methodology for commercial building models. Energy and Buildings, 76, 497-505. http://doi.org/10.1016/j.enbuild.2014.03.016

Pilgrim, M., Bouchlaghem, N., Loveday, D., \& Holmes, M. (2003). Towards the efficient use of simulation in building performance analysis: a user survey. Building Services Engineering Research and Technology, 24(3), 149-162. http://doi.org/10.1191/0143624403bt068oa

Plume, J., \& Mitchell, J. (2007). Collaborative design using a shared IFC building model-Learning from experience. Automation in Construction, 16(1), 28-36. http://doi.org/10.1016/j.autcon.2005.10.003

Pollock, M., Roderick, Y., McEwan, D., \& Wheatley, C. (2009). Building simulations as an assisting tool in designing an energy efficient building: a case study. Glasgow: Integrated Environmental Solutions Limited. Retrieved from http://www.iesve.com/content/mediaassets/pdf/p135final-long.pdf

Potter, W. J., \& Levine-Donnerstein, D. (1999). Rethinking validity and reliability in content analysis. Journal of Applied Communication Research, 27(3), 258-284. http://doi.org/10.1080/00909889909365539

Punjabi, S., \& Miranda, V. (2005). Development of an integrated building design information interface. Presented at the IBPSA, Montreal, Canada.

Rezaee, R., Brown, J., Augenbroe, G., \& Haymaker, J. (2015). The application of inverse approach to the early stage of performance-based building design. Presented at the IBPSA Conference, Hyderabad, India.

Robert McNeel \& Associates. (2015). Rhinoceros. Retrieved 9 December 2015, from https://www.rhino3d.com/

Sadeghipour Roudsari, M. (2015). Honeybee. Retrieved 11 December 2015, from https://github.com/mostaphaRoudsari/Honeybee 
Sadeghipour Roudsari, M. (2016a). Hydra: Honeybee Example Files. Retrieved 11 April 2016, from

https://hydrashare.github.io/hydra/index.html?keywords=HBExampleFiles

Sadeghipour Roudsari, M. (2016b). Ladybug + Honeybee. Retrieved 12 April 2016, from http://www.grasshopper3d.com/groups/group/show?groupUrl=ladybug

Sadeghipour Roudsari, M. (2016c). Pollination. Retrieved 10 April 2016, from http://mostapharoudsari.github.io/Honeybee/Pollination

Sadeghipour Roudsari, M., \& Pak, M. (2013). Ladybug: a parametric environmental plugin for grasshopper to help designers create an environmentally-conscious design. In Proceedings of the 13th International IBPSA Conference. Lyon, France.

Saldana, J. (2012). The Coding Manual for Qualitative Researchers. SAGE.

Sefaira. (2016). Sefaira Architecture. Retrieved 3 April 2016, from http://sefaira.com/sefaira-architecture/

Selkowitz, S. (2014). COMFEN - Early Design Tool for Commercial Facades and Fenestration Systems.

Solemma, LLC. (2015). Solemma. Retrieved 9 December 2015, from http://www.solemma.net/

Spradley, J. P. (1979). The Ethnographic Interview. Holt, Rinehart and Winston.

Strauss, A. L., \& Corbin, J. (1990). Basics of qualitative research: Grounded theory procedures and processes. Newbury Park, CA: SAGE.

Tianzhen, H., Jinqian, Z., \& Yi, J. (1997). IISABRE: An Integrated Building Simulation Environment. Building \& Environment, 32(3), 291-224.

Todd, Z., Nerlich, B., McKeown, S., \& Clarke, D. D. (2004). Mixing Methods in Psychology: The Integration of Qualitative and Quantitative Methods in Theory and Practice. Psychology Press.

Urquhart, C. (2012). Grounded Theory for Qualitative Research: A Practical Guide. SAGE. 


\subsection{Appendix One: Focus Group Questions}

1. In your practice, what would be the greatest barrier(s) within the design process to overcome in order to make performance sketching in the early stage of design feasible? Please write down your answer on the blank cards provided. If you have more than one answer, please write each answer on its own card.

2. From your experience within the industry, as a group, order the barrier(s) created by Q1 within the design process for the New Zealand industry from greatest to least.

3. Which features of performance sketching with detailed simulation tools should be improved to overcome these barriers?

4. What should be changed in performance sketching to encourage you to use detailed simulation tools to sketch the design's passive performance?

5. Rank the following answers to the question based upon the feature which would increase the value of performance sketching with detailed simulation tools at early stages of design.

The ability to know:

a) Which design changes are the most influential to meeting performance criteria

b) What information for simulation can be kept default in considering impact to performance

c) Which design elements (Glazing, shading, construction material) should be adaptable if the tenants of the building changed

d) Which design changes create the optimised concept

6. Do you believe that developments which couple design tools and building simulation tools together, such as Rhino/Honeybee, are heading in the right direction to encouraging the use of performance sketching at early stages of design? 


\subsection{Appendix Two: Digital Appendix}

Refer to the digital appendix submitted along with this thesis paper for the digital files of:

- Ethics information regarding consent forms and participant provided information

- Tutorial workshop files introducing participants to Honeybee as an example of a tool for DMM

- Workshop preparation files to install and setup Honeybee and Ladybug within Rhino/Grasshopper

- The Building Performance Sketch workflow created for this thesis 